Utah State University

DigitalCommons@USU

$12-2020$

\title{
The Moderating Role of Psychological Inflexibility in the Relationship Between Minority Stress, Substance Misuse, and Suicidality in LGB+ Adolescents
}

Sean N. Weeks

Utah State University

Follow this and additional works at: https://digitalcommons.usu.edu/etd

Part of the Psychiatry and Psychology Commons

\section{Recommended Citation}

Weeks, Sean N., "The Moderating Role of Psychological Inflexibility in the Relationship Between Minority Stress, Substance Misuse, and Suicidality in LGB+ Adolescents" (2020). All Graduate Theses and Dissertations. 7942.

https://digitalcommons.usu.edu/etd/7942

This Thesis is brought to you for free and open access by the Graduate Studies at DigitalCommons@USU. It has been accepted for inclusion in All Graduate Theses and Dissertations by an authorized administrator of DigitalCommons@USU. For more information, please contact digitalcommons@usu.edu.

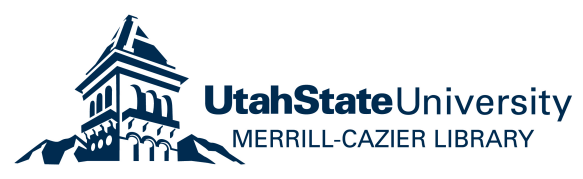


THE MODERATING ROLE OF PSYCHOLOGICAL INFLEXIBILITY IN THE RELATIONSHIP BETWEEN MINORITY STRESS, SUBSTANCE MISUSE, AND SUICIDALITY IN LGB+ ADOLESCENTS

by

Sean N. Weeks

A thesis submitted in partial fulfillment

of the requirements for the degree

of

MASTERS OF SCIENCE

in

Psychology

Approved:

Tyler Renshaw, Ph.D. Committee Chair

Renee Galliher, Ph.D.

Committee Member
Melissa Tehee, Ph.D.

Committee Member

D. Richard Cutler, Ph.D. Interim Vice Provost of Graduate Studies

UTAH STATE UNIVESITY

Logan, UT 
Copyright (C) Sean Weeks 2020

All rights reserved 


\begin{abstract}
The Moderating Role of Psychological Inflexibility in the Relationship Between Minority Stress, Substance Misuse, and Suicidality in LGB+ Adolescents

by

Sean Weeks, Master of Science

Utah State University, 2020

Major Professor: Tyler Renshaw, Ph.D.

Department: Psychology

Adolescence is a difficult time, especially for those who identify as LGB+. Increased rates of substance abuse and suicidality tend to be worse in the LGB+ adolescent community than in mainstream groups. Minority stress has been accepted within the research community as a mechanism to explain the health disparities seen in this group. This study proposed a possible further explanation, in addition to minority stress, that accounts for a portion of the disparity seen, and that is changeable through ACT. Psychological inflexibility was posited as a moderator in the relationship between minority stress and substance misuse or suicidality.

Interactions with both global psychological inflexibility and its sub-processes were examined in quadratic and linear regression models in order to clarify associations between minority stress and both suicidality and substance misuse in the LGB+ adolescent community. A sample of 152 adolescent LGB+ participants responded to
\end{abstract}


measures assessing the constructs of psychological inflexibility. Quadratic regression analysis of Model 1, examining global psychological inflexibility and minority stress' interaction on substance misuse showed a positive significant curvilinear interaction with a small effect. Model 2, examining the moderating effect of global psychological inflexibility on minority stress and suicidality, did not identify significant interactions, but brought to light a positive medium sized direct effect of global psychological inflexibility on suicidality. Exploratory Models looking at the moderating effects of psychological inflexibility's sub-processes found that cognitive fusion and obstruction of valued living both significantly interacted with minority stress in relation to substance misuse in a positive direction. Within sub-process suicidality models, positive direct effects between cognitive fusion and suicidality, and obstruction of valued living and suicidality were observed. Additionally, a negative direct effect between experiential avoidance and suicidality emerged.

Implications based on results suggest that psychological inflexibility as mechanism of change in LGB+ adolescents is worth further study. Preliminary analyses imply psychological inflexibility explains a small significant portion of minority stress' effect on the harmful outcome of substance misuse. Further study into the effectiveness of ACT in LGB+ populations struggling with minority stress' effects and/or substance misuse should be conducted to further understand the implication of these results. 


\section{PUBLIC ABSTRACT}

The Moderating Role of Psychological Inflexibility in the Relationship Between Minority Stress, Substance Misuse, and Suicidality in LGB+ Adolescents

Sean Weeks

Adolescence is a difficult time, especially for those who do not identify as heterosexual (e.g., gay, lesbian, bisexual, asexual, pansexual; LGB+). Increased rates of substance abuse and suicidality are well documented outcomes that tend to be worse in the LGB+ adolescent community than in mainstream groups. Minority stress, the effect of unique stressors experienced by those in the LGB+ community explained by external and societal influences, has been accepted within the research community as a theory used to explain the health disparities seen in this group. This study proposed a possible further explanation, in addition to minority stress, that helps clarify the relationship between minority stress and negative outcomes, and that is changeable through Acceptance and Commitment Therapy (ACT). Psychological inflexibility, a rigid reaction to life events that is inconsistent with values and often promotes avoidant behavior, and five of its six key sub-processes (experiential avoidance, cognitive fusion, lack of values, preoccupation with the past or future, and inaction) was posited as influencing the strength of the relationship between minority stress and substance misuse or suicidality. 
Interactions with both global psychological inflexibility and its sub-processes were examined using statistical models to explore relationships between minority stress and both suicidality and substance misuse in the LGB+ adolescent community. A sample of 152 LGB+ adolescents participated. Significant interactions were found in models of substance misuse but not suicidality, with global psychological inflexibility, cognitive fusion, and obstruction of valued living as moderators that strengthened the relationship between minority stress and substance misuse.

Implications based on results suggest that psychological inflexibility as a mechanism of change in LGB+ adolescents is worth further study. Additional examination into the effectiveness of ACT in LGB+ populations struggling with minority stress' effects and/or substance misuse should be conducted to advance the understanding of these results. 


\section{ACKNOWLEGMENTS}

I would like to thank my major professor, mentor, and advisor, Dr. Tyler Renshaw, for his continued support, guidance, advice, and friendship. His unwavering commitment to me and to the School Mental Health Lab has been invaluable, not only for my growth in research endeavors, but in clinical practice, academics, and life as a professional as well. His kind-hearted nature, openness to collaboration, and passion for free and accessible mental health resources for all is both endearing and contagious. Most of my professional growth, successes and achievements are thanks to him.

I would also like to thank each of my committee members, Dr. Melissa Tehee and Dr. Renee Galliher, for their guidance and support through this project, and throughout my graduate experience. Thank you, Dr. Tehee, for inspiring a multicultural focus in my academic career in my first semester, back when I was bright eyed and bushy tailed, by allowing me to work alongside you to plan inclusive multicultural events for USU's College of Education and Human Services. Thank you, Dr. Galliher, for constructively guiding my research practices in LGB+ topics to further my ability to practice with compassion, understanding, inclusivity, and knowledge of best-practice research. I also want to thank you for extending this mentorship beyond the project at hand, and your expected responsibilities, to help me create and deliver culturally sensitive trainings to USU's faculty, staff, and students.

Furthermore, I would like to thank Dr. Sarah Schwartz and the USU Statistical Consulting Studio for teaching me everything I know about statistical analyses, RStudio, 
and coding. Thank you for spending hours teaching me how to answer my research questions quantitatively, with fidelity and integrity.

I cannot express enough gratitude to my fellow lab mates in the School Mental Health Lab; Siri, Steph, John, Kris, and Caleb. Their friendship, encouragement, ideas, and shared suffering has made this experience a doable one. Thank you to my friends outside of the university who helped me maintain some semblance of normalcy throughout this process. I am lucky to have a community of loving, encouraging, and adventurous people who care about my wellbeing. Lastly, thank you to my family who has supported me beyond words and who made an education possible, especially to my mom who will likely be the only one who reads this (and helps edit it). 


\section{CONTENTS}

Page

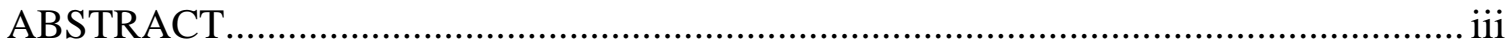

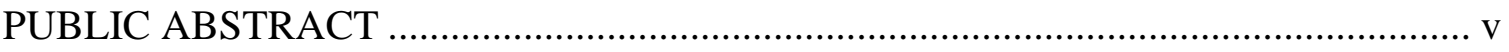

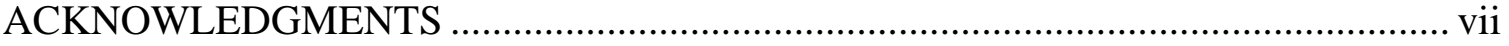

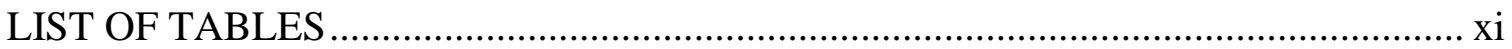

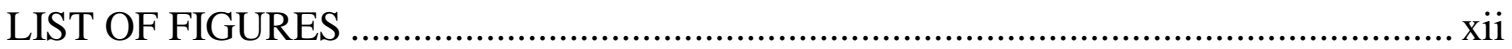

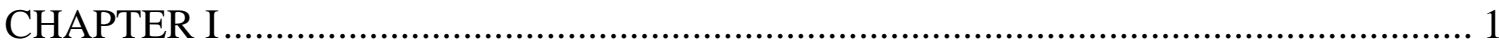

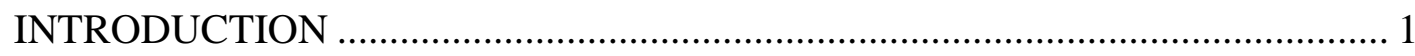

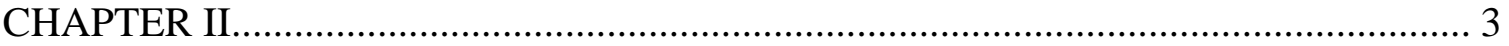

REVIEW OF THE LITERATURE .......................................................... 3

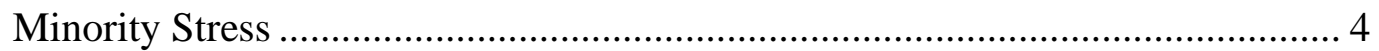

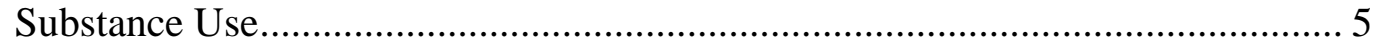

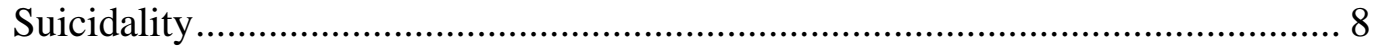

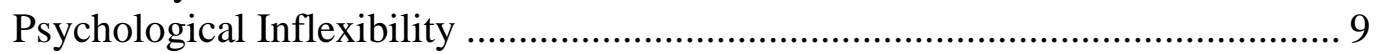

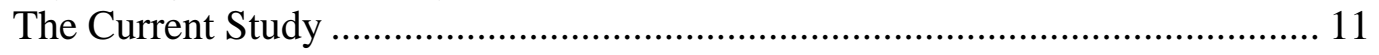

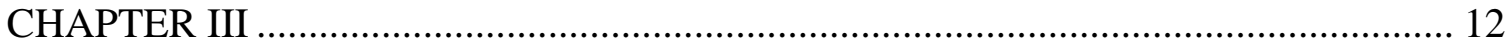

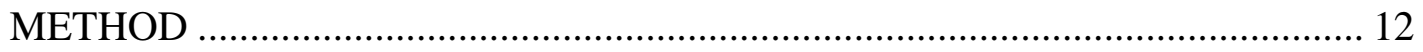

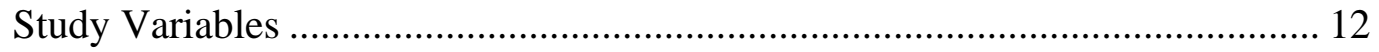

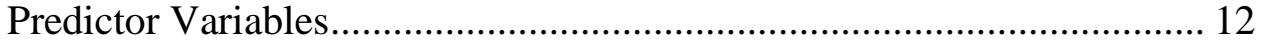

Criterion Variables ............................................................................ 12

Moderating Variables....................................................................... 12

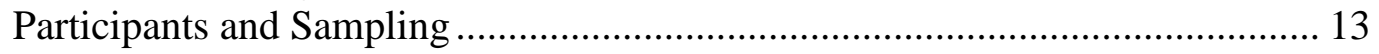

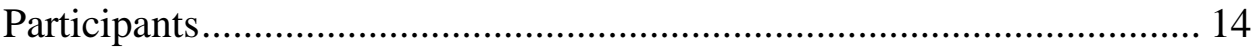

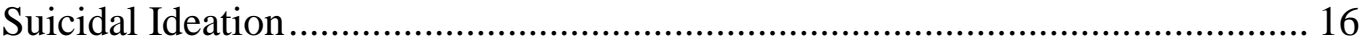

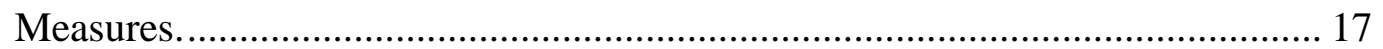

Demographic Questionnaire ............................................................. 17

The Sexual Minority Adolescent Stress Inventory (SMASI) .................. 18

Avoidance and Fusion Questionnaire for Youth (AFQ-Y8)................... 18 
Brief Experiential Avoidance Questionnaire (BEAQ). ......................... 19

Cognitive Fusions Questionnaire (CFQ) . ........................................... 19

Valuing Questionnaire (VQ)........................................................ 20

Mindful Attentive Awareness Scale-Adolescent (MAAS-A)................. 21

Suicidal Behaviors Questionnaire-Revised (SBQ-R) ........................... 21

Suicidal Ideation Questionnaire (SIQ) ................................................ 22

Alcohol Use Disorders Identification Test (AUDIT) ............................ 22

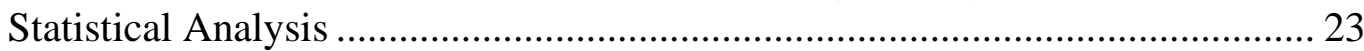

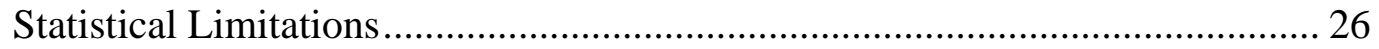

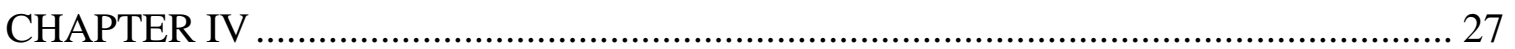

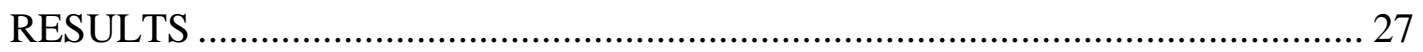

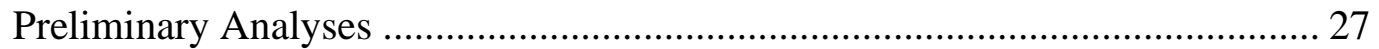

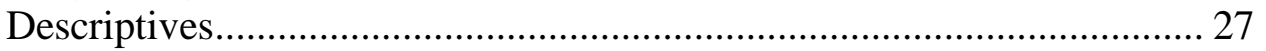

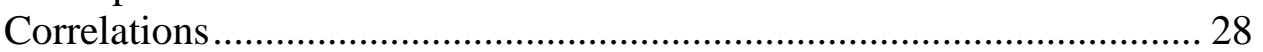

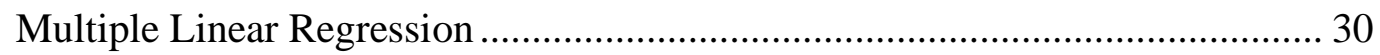

Demographic Covariates.................................................................... 30

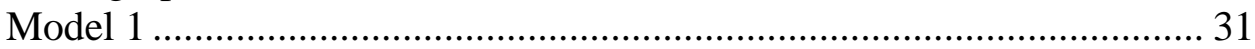

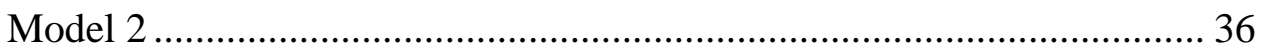

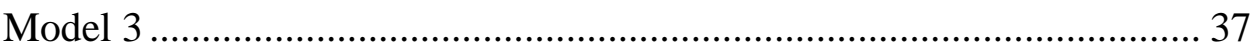

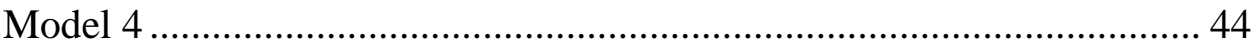

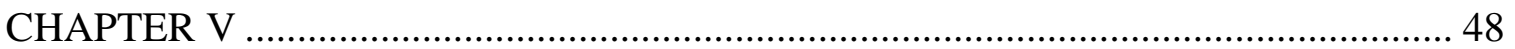

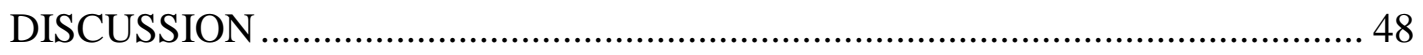

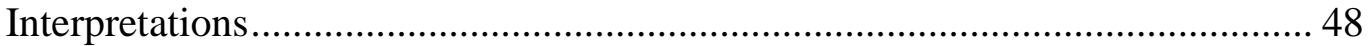

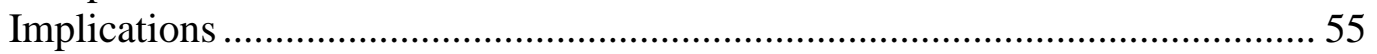

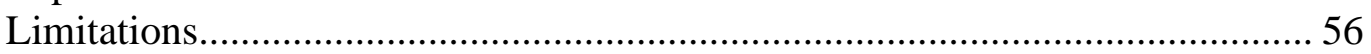

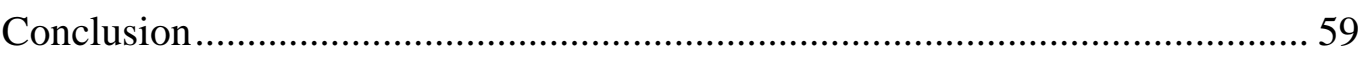

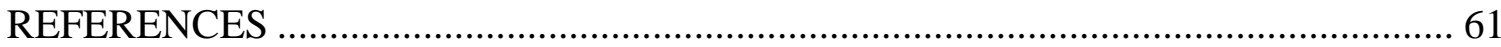

APPENDIX A Informed Consent ...................................................................... 75

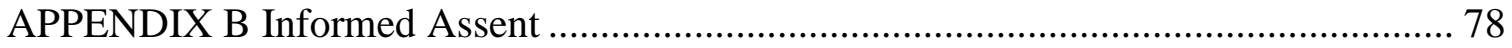

APPENDIX C Sexual Minority Adolescent Inventory ............................................ 79

APPENDIX D Acceptance and Fusion Questionnaire - Youth..................................... 84

APPENDIX E Breif Experiential Avoidance Questionnaire ......................................... 86 


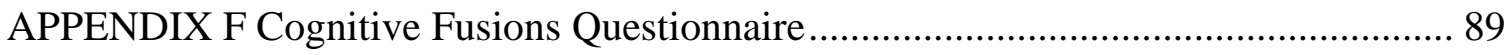

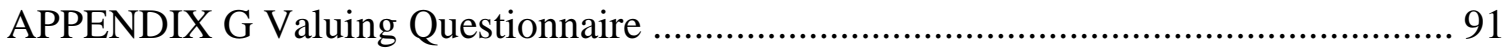

APPENDIX H Mindful Attentive Awareness Scale-Adolescent .................................. 92

APPENDIX I Suicidal Beahviors Questionnaire - Revised ........................................ 95

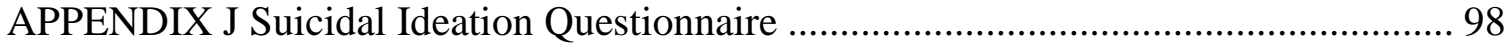

APPENDIX K Alcohol Use Disorders Identification Test........................................... 99

APPENDIX L Sean Weeks Curriculum Vitae ......................................................... 102 


\section{LIST OF TABLES}

Table

1. Demographic Fequencies and Percentage

2. Descriptive Statistics for Central Tendency, Distribution, and Internal Consistency for All Study Measures

3. Pearson's Bivariate Correlation Matrix for All Study Measures

4. Multiple Linear Regression Parameter Estimates ofr Quadratic Effect of Minority Stress (SMASI) Moderated by Psychological Inflexibility AFQ-Y8) Regressed on Substance Misuse (AUDIT) - "Model 1".

5. Multiple Linear Regression Parameter Estimates for Linear Effect of Minority Stress (SMASI) Moderated by Psychological Inflexibility (AFQ-Y8) Regressed on Suicidality (SIQ) - "Model 2"

6. Multiple Linear Regression Parameter Estimates (b) Investigating Potnetial Moderation of Minority Stress (SMASI) by Each of Four Psychological Inflexibility Sub-Processes Regressed on Substance Misuse (AUDIT) with Sub-Process Covariates - "Models 3A-3E"

7. Multiple Linear Regression Parameter Estimates $(b)$ Investigating Potential Moderation of Minority Stress (SMASI) by Each of Four Pscyhological Inflexibility Sub-Processes Regress on Substance Misuse (AUDIT) without Sub-Process Covariates - "Models 3F-3I"

8. Multiple Linear Regression Parameter Estimates $(b)$ Investigating Potnetial Moderation of Minority Stress (SMASI) by Each of Four Psychological Inflexibility Sub-Processes Regressed on Suicidality (SIQ) with Sub-Process Covariates - "Models 4A-4E"

9. Multiple Linear Regression Parameter Estimates (b) Investigating Potential Moderation of Minority Stress (SMASI) by Each of Four Pscyhological Inflexibility Sub-Processes Regress on Suicidality (SIQ) without Sub-Process Covariates - "Models 4F-4I" 


\section{LIST OF FIGURES}

Figure

Page

1. Linear Regression Model for Minority Stress, Global Psychological

Inflexibility, and Substance Misuse

2. Linear Regression Model for Minority Stress, Global Psychological

Inflexibility, and Suicidality ...................................................................... 24

3. Linear Regression Model for Minority Stress, Psychological

Inflexibility Sub-Processes, and Substance Misuse

4. Linear Regression Model for Minority Stress, Psychological

Inflexibility Sub-Processes, and Suicidality....

5. Scatterplot of Minority Stress (SMASI) and Substance Misuse

(AUDIT), Colored by Global Psychological Inflexibility

6. Interaction Plot Illustrating the Moderating Effect of Global

Psychological Inflexibiltiy (AFQ-Y8) on Minority Stress

(SMASI) when Predicting the Estimated Marginal Mean of

Substance Misuse (AUDIT; "fit") -"Model 1"

7. Scatterplot of Minority Stress (SMASI) and Substance Misuse

(AUDIT), Colored by Cognitive Fusion (CFQ).

8. Interaction Plot Illustrating the Moderating Effect of Cognitive

Fusion (CFQ) on Minority Stress (SMASI) when Predicting the Estimated Marginal Mean of Substance Misuse (AUDIT; "fit) -

"Model 1"

9. Scatterplot of Minority Stress (SMASI) and Substance Misuse

(AUDIT), Colored by Obstruction of Valued Living (VQ-O).

10. Interaction Plot Illustrating the Moderating Effect of Obstruction of Valued Living (VQ-O) on Minority Stress (SMASI) when Predicting the Estimated Marginal Mean of Substance Misuse (AUDIT; "fit) - "Model 3D" 


\section{CHAPTER I}

\section{INRODUCTION}

Minority stress is a constant elevated level of stress experienced by members of stigmatized groups (Meyer, 2003) and can be associated with many factors that affect overall functioning and distress both in the short and long term. Lesbian, gay, and bisexual (LGB+) individuals deal with minority stress in unique ways due to a number of features, such as social marginalization and family rejection (Meyer, 2003: Toomey et al., 2018). Minority stress puts LGB+ individuals at higher risk for several physical and psychological problems (Gonzales \& Henning-Smith, 2017). Among these problems, substance misuse and suicidality are two well-studied variables shown to be associated with an LGB+ status (Caputi et al., 2018; King et al., 2008).

Though the association between minority stress and increased risk of suicidality and substance misuse has been recognized in LGB+ populations many times in the literature, little research has focused on variables that potentially moderate this finding. The current study proposes one such variable; psychological inflexibility. Psychological inflexibility is the inability to flexibly and fluidly interact with the present in a manner that allows for change or persistence that is consistent with valued living (Hayes et al., 2006). Psychological inflexibility is a key construct of Acceptance and Commitment Therapy (ACT; Hayes et al., 2006). Researchers have reported associations among minority stress, substance misuse, suicidality, and sexual orientation. Though bidirectional relationships among the variables of this study have been considered, no literature exists looking at all variables in the same model, with psychological 
inflexibility as a moderator. By identifying whether psychological inflexibility's interaction with minority stress are associated with harmful outcomes, this study could contribute to the literature regarding how to identify at-risk individuals and inform intervention through ACT. This research is particularly valuable because of the known consequences of substance misuse, suicidality, and how the two influence each other in LGB+ populations. In this study, the following research questions will be addressed:

1. Will the strength of global psychological inflexibility moderate the relationship between minority stress and substance use/suicidality in LGB+ adolescents?

2. How do the sub-processes of psychological inflexibility deferentially moderate the relationship between substance use/suicidality in LGB+ adolescents? 


\section{CHAPTER II}

\section{REVIEW OF THE LITERATURE}

Sexual minority adolescents and young adults face increased risk factors and health disparities in various aspects of their physical and mental health. In this study, sexual minorities are defined as asexual, bisexual, fluid, gay, lesbian, pansexual, queer, questioning, or other personally meaningful sexual orientation label (LGB+). Within the LGB + communities, increased rates of psychological distress, substance misuse, suicidality, poor physical health, activity limitations, chronic conditions, obesity, and smoking are all examples of the problems for which LGB+ individuals are at higher risk (Caputi et al., 2018; Gonzales \& Henning-Smith, 2017; King et al., 2008; Livingston et al., 2016; McCabe et al., 2003; Silenzio et al., 2007; Smith et al., 2016) . While sexual minorities are faced with a myriad of challenges, substance misuse and suicidality are two of the most frequently studied risk variables within this population. Although these outcomes have been identified as higher risk in LGB+ populations, there is a gap in the current literature when it comes to the relationship between the minority stress experienced by adolescents and young adults who comprise these groups and the mechanisms that moderate harmful outcomes. The current study will focus on global psychological inflexibility and its sub-processes in adolescents as potential moderators in the relationship between LGB+ minority stress and the risk variables of substance misuse and suicidality. 


\section{Minority Stress}

As stated, LGB+ individuals face higher rates of negative health outcomes when compared to heterosexual individuals. Meyer (2003) offered a theory and framework for why these discrepancies exist between majority and minority groups. Minority stress theory posits that stressors associated with marginalization impact harmful outcomes in LGB+ communities, including, but not limited to; experiences of prejudice events, expectation of rejection or discrimination, concealment of one's sexual orientation, and internalized homonegativity (Meyer, 2003; Toomey et al., 2018). The stressors LGB+ individuals frequently confront are often unique to the community and less likely to occur in heterosexual groups. Meyer (2003) labeled this experience minority stress and the theory has since been accepted by scholars and researchers alike. Currently, a strong focus within the literature has turned toward minority stress as a leading cause of health disparities among diverse sexual identity groups.

Minority stress has been linked to many outcome variables within the LGB+ community. As it relates to substance use, minority stress has been found to positively correlate with rates of misuse (Boyle et al., 2017), with researchers theorizing the association is best explained as a coping mechanism. Increased minority stress, specifically internalized homophobia and fear of rejection, has been linked to negative affect and lower life satisfaction in groups of LGB adults (Conlin et al., 2019; Michaels, 2018). Life satisfaction and affect mediate risk for suicide (Haas et al., 2011), with trends showing increased risk for LGB+ individuals (King et al., 2008). Cochran et al. (2003) 
reported similar results, stating experiences of minority stressors negatively influence wellbeing, and went on to state that these stressors were positively correlated with depression and suicidal ideation. From an etiological standpoint, minority stress is understood; however, the literature is sparse when looking at the mechanisms that connect minority stress to harmful outcomes. Although the mechanisms of change have not been duly researched in the current literature, research indicates some processes, like burdensomeness during the coming-out process, as mediating the relationship between minority stress and suicidal ideation (Baams et al., 2015). This gap illustrates a clear need for additional research focusing on the processes that influence the connection between minority stress and harmful outcomes in LGB+ adolescents.

Transdiagnostic approaches, through the use of cognitive behavioral therapy, have been used to successfully address minority stress in gay and bisexual men, though the literature is sparse when it comes to other transdiagnostic methods (Pachankis et al., 2015). ACT and the process of psychological inflexibility are yet to be tested as treatment approaches for coping with LGB+ minority stress. Based on the utility of other transdiagnostic methods, and the overlap of the identity component of minority stress and ACT core processes, psychological inflexibility is a meaningful construct for further study.

\section{Substance Use}

Identifying as LGB+ is known to correlate with higher substance (drugs and alcohol) misuse and harm when compared to heterosexual cohorts (Caputi et al., 2018). These results have been observed in varying degrees across the lifespan (Marshal et al., 
2009), gender identity (Ward et al., 2014), and sexual identity (Green \& Feinstein, 2012; Marshal et al., 2008; Marshal et al., 2009). LGB+ adolescents have been identified by researchers as being at greater risk for drinking alcohol, smoking cigarettes, using cocaine, ecstasy, inhalants, heroin, methamphetamine, prescription drugs, steroids, and synthetic marijuana (Caputi et al., 2018; Dai, 2017; Marshal et al., 2009; Talley et al., 2014). Though similar studies should be conducted across substances, this study will focus strictly on alcohol use, as it is arguably the most common substance that is misused among adolescents (Mericle et al., 2015).

In LGB+ samples, adults reported higher percentages of binge drinking (five or more drinks in one day) within the last year (35.1\%) than those who identified as heterosexual (26.0\%) in a survey by the U.S. Census Bureau (Ward et al., 2014). Among youth LGB+ populations, a meta-analysis of 18 studies by Marshal et al. (2008) showed that LGB+ adolescents are two to four times more likely to use alcohol and drugs compared to heterosexual adolescents. In a review of the consequences of alcohol misuse in college students, Perkins (2002) identified three main categories of harm: damage to self, damage to other people, and institutional costs. Damage to self included consequences such as

academic impairment, personal injuries or death, short- and longer-term physical illnesses, unintended and unprotected sexual activity, suicide, rape victimization, impaired driving, legal repercussions (Perkins, 2002, p. 92).

Damage to other people included "property damage and vandalism, fights and interpersonal violence, sexual violence, hate-related incidents, and noise disturbances" (Perkins, 2002, p. 92). Lastly, Perkins (2002) identified institutional costs as "Property 
damage, student attrition, ... added time demands and emotional strain on staff, and legal costs" (p. 92). The increased risk, use, and abuse of alcohol in the LBG+ population, along with known consequences, make this issue one of great importance. The costs associated with greater rates of substance misuse not only provides an argument for studying markers in LGB+ youth, but also presents a societal motive for focusing on these issues. Identifying transdiagnostic factors that might moderate this relationship is imperative for improving practices to help this at-risk population of youth.

Many studies have identified the increased rate and harm of substance use in LGB+ populations. The results of these studies have led some researchers to begin looking at the etiology and moderators of this risk. In the literature, external factors, such as minority stress, are often cited as the source of higher prevalence rates. Stressors, including stigma, bullying, social rejection, and homophobic culture, have all been identified as risk factors that influence the increased rate of alcohol misuse in LGB+ populations (McCabe et al., 2010; Meyer, 2003; Pachankis et al., 2014). Less research has considered the internal or psychological factors caused by minority stress and possibly moderate LGB+ substance misuse. Internal traits that have been studied thus far include resiliency and psychological distress (Livingston et al., 2016). Due to the lack of research reviewing internal or psychological risk factors affected by minority stress, this study proposes to investigate variables that have not yet been explored as moderators: global psychological inflexibility and its underlying processes of experiential avoidance, cognitive fusion, present moment awareness, and valued living. 


\section{Suicidality}

Along with increased rates of substance misuse, stress associated with identifying as LGB+ increases the risk for suicidality. Suicidality, for the purpose of this study, is defined as suicidal ideation (thoughts of death or suicide), suicidal behavior (preparation for an attempt), and suicide attempt (non-fatal self-injury with the intent to die). Suicide is not only a serious risk for LGB+ minorities, but youth as a whole. Wyman et al. (2010) determined those between the ages of 10 to 24 years are more likely to die by suicide than all natural causes combined. Suicide has also been identified as the second leading cause of death in youth aged 15 to 24 (Centers for Disease Control and Prevention; CDC, 2016b). The CDC (2016a) found that suicide rates are increasing at a national average of $25 \%$, with increases in 49 states. As previously stated, LGB+ status increases one's risk for suicide (King et al., 2008; Silenzio et al., 2007; Smith, et al., 2016). LGB+ youth are almost three times as likely to engage in suicidal thinking and five times as likely to attempt suicide, compared to their heterosexual peers (CDC, 2016a). However, the exact number of suicide deaths in the LGB+ population is unknown (Haas et al., 2011). It is assumed that rates of suicide are higher in LGB+ populations due to findings that show more frequent attempts and for those attempts to be more life-threatening (causing serious injury or requiring medical attention; CDC, 2016a). Though exact rates of suicidality have not been identified, higher rates of suicidal ideation and suicide attempts, along with suicidality statistics from the general population, give cause for alarm.

Many studies have looked at variables that moderate the rates of suicide in LGB+ youth and found that certain demographic groups within the LGB+ community have been 
identified as being at higher risk. LGB + youth who identify as a racial or ethnic minority are at increased risk (Cochran et al., 2007; Meyer et al., 2008; Remafedi, 2002), along with those in a lower socioeconomic class (Paul et al., 2002), and those who identify as gay males (King et al., 2008). Stressors such as interpersonal problems with peers and family, weaker interpersonal supports, and bullying all led to increased risk for suicidality (Russell \& Joyner, 2001; Ryan et al., 2009). Mental distress, which was found to be elevated in LGB+ populations (King et al., 2008), was identified as the leading risk factor for suicidality (Haas et al., 2011). Mental distress also mediated substance misuse (Livingston et al., 2016), which, in turn, mediated suicidality in LGB+ populations (Silenzio et al., 2007; Smith et al., 2016). The effects of the above risk factors have been well-studied on suicidality in LGB+ youth and throughout the lifespan. Many environmental factors that affect stress levels have been addressed, but stress-based internal or psychological transdiagnostic variables that could potentially influence mental distress have not. This supports the need for further research on the potential moderating variables of global psychological inflexibility and its sub-processes.

\section{Psychological Inflexibility}

Psychological inflexibility is defined as rigidly interacting with one's experiences (thoughts and feelings) in the present moment in a way that does not allow for change or persistence that is consistent with valued living (Hayes et al., 2006). Valued living is conceptualized as the engagement in actions consistent with one's personal values. Though psychological inflexibility is a newer concept in the literature, it is garnering attention through its functional role in Acceptance and Commitment Therapy (ACT). 
Global psychological inflexibility can be targeted using six psychological sub-processes of change addressed through the use of ACT (Hayes et al, 2006). In this study, five of the sub-processes will be measured to look for differential effects; experiential avoidance, cognitive fusion, present moment awareness, and obstruction of valued living and committed action. There is a lack of existing empirically sound measurement tools for self-as-context, therefore it was omitted from this study due to its complexity and abstract nature.

A number of studies have been conducted looking at the influence of psychological inflexibility in LGB+ populations. Two studies investigated psychological inflexibility within the context of stages of "coming out" (Masuda et al., 2011; LeleuxLabarge et al., 2015). Both studies found that psychological inflexibility positively correlated with self-concealment. In a study involving bisexual individuals, no significant difference in ratings of psychological flexibility, the desirable opposite of psychological inflexibility, compared to heterosexual cohorts was found; though, similar to the findings of Rosario et al. (2004), Masuda et al. (2011), and Leleux-Labarge et al. (2015), "outness" was positively correlated with psychological flexibility (Hrehorciuc-Caragea \& White, 2017).

Psychological inflexibility was also found to predict suicidality in college students (Chou et al., 2018; Krafft et al., 2018) and serve as a transdiagnostic process across psychological disorders (Levin et al., 2014). Though Levin et al. (2014) found mixed results for psychological inflexibility's role in substance use disorders, nonclinical substance use and dependence was found to be affected by psychological inflexibility in 
college populations (Levin et al., 2012). Despite these relevant connections, studies have yet to consider the process of psychological inflexibility and its influence on suicidality and substance use in LGB+ populations.

\section{The Current Study}

As stated above, global psychological inflexibility is comprised of six underlying processes - experiential avoidance, cognitive fusion, self-as-content, lack of values, preoccupation with the past or future, and inaction.

The six elements that comprise psychological inflexibility are targeted components of ACT (Hayes et al., 2006). ACT interventions have been found to reduce psychological inflexibility in LGB+ populations and reduce self-stigma (Yadavaia \& Hayes, 2012). By identifying whether global psychological inflexibility and its subprocesses moderate the relationship between LGB+ minority stress and harmful outcomes, this study could contribute to the literature regarding how to identify at-risk individuals and inform intervention through ACT. This research is especially valuable because of the known consequences of substance misuse, suicidality, and how these variables influence each other in LGB+ populations. This study will address the following research questions:

1. Will the strength of global psychological inflexibility moderate the relationship between minority stress and substance use/suicidality in LGB+ adolescents?

2. How do the sub-processes of psychological inflexibility deferentially moderate the relationship between substance use/suicidality in LGB+ adolescents? 


\section{CHAPTER III}

\section{METHODS}

\section{Study Variables}

\section{Predictor variable}

The predictor variable of interest in this study was participant levels of LGB+ minority stress. Minority stress was defined by a composite of the following subscales: identity management, negative expectancies, negative disclosure experiences, family rejections, internalized homonegativity, homonegative communication, homonegative climate, social marginalization, and intersectionality. Minority stress will be measured through self-report.

\section{Criterion variables}

The criterion variables were alcohol misuse, defined by frequency and intensity of alcohol use and alcohol related problems, and suicidality. Harmful alcohol use was marked by the number of drinks one consumes and the maladaptive behaviors preceding or following the behavior. Suicidality was defined as a composite of suicidal ideation, suicidal behavior, and suicide attempt. Participant self-reports were used to measure both variables.

\section{Moderating variables}

This study examined the moderating role of global psychological flexibility and five of its core underlying processes (experiential avoidance, cognitive fusion, preoccupation with the past or future, lack of values, and obstruction of committed action) in the relationship between minority stress and the criterion variables of 
suicidality and alcohol misuse. All moderating variables were measured via participant self-reports.

\section{Procedures}

Participants for this study were recruited using purposive sampling procedures through Qualtrics online survey panels. Sample size was estimated using G*Power's F tests' Linear multiple regression: Fixed model, $\mathrm{R}^{2}$ increase, $\mathrm{A}$ priori. Power $=.95$, alpha $=.05$, and a medium effect size yielded a sample size of 119 for three predictors (Figure 1 and 2), and 166 for nine predictors (Figure 3 and 4). Sample size was chosen based on predicted effects among the experimental model pathways and best practice in linear regression modeling (Darlington \& Hayes, 2017). Inclusion criteria included age between 13 and 18 and self-identification as LGB+. Before completing the surveys, participants' parents received and endorsed informed consent. Participants also endorsed their personal assent prior to taking the survey. Information in the consent and assent forms included the purpose and procedures of the study, the length of the study, any risks of harm or discomfort, potential benefits, confidentiality requirements, and PI contact information. In the consent, parents were requested to allow their child to complete the questionnaires in private, so the participant felt comfortable answering honestly. Parents were provided a brief summary of the questions their children were answering, suggestions on how to start difficult dialogues, and national suicide prevention resources. This allowed the option for parents to start a conversation with their children after the survey was completed. The consent and assent forms also confirmed that participation was voluntary, that the participant could withdraw from the study at any point, and had the option to "skip a 
question" if they were uncomfortable answering (e.g., if parents are standing over their shoulder). All participants were required to identify their sexual orientation as a prerequisite for study participation, and therefore must be open and out to their parents. Participants completed a demographic questionnaire (see below) and the following measures: The Sexual Minority Adolescent Stress Inventory, Avoidance and Fusion Questionnaire for Youth, Brief Experiential Avoidance Questionnaire, Cognitive Fusion Questionnaire, Valuing Questionnaire, Mindful Attentive Awareness Scale-Adolescent, The Suicidal Behaviors Questionnaire - Revised, The Suicidal Ideation Questionnaire, and The Alcohol Use Disorders Identification Test.

\section{Participants}

A total sample of $152 \mathrm{LGB}+$ adolescents participated in the study. Sample demographic information regarding age, gender, race/ethnicity, and sexual orientation is provided in Table 1. 
Table 1

Demographic Frequencies and Percentages $(n=152)$

\begin{tabular}{cccc}
\hline & Variable & Count & $\%$ \\
\hline Age & & & \\
13 & 10 & 6.6 \\
14 & 23 & 15.1 \\
15 & 36 & 23.7 \\
16 & 26 & 17.1 \\
17 & 21 & 13.8 \\
18 & 36 & 23.7
\end{tabular}

Gender

$\begin{array}{lll}\text { Woman } & 76 & 50\end{array}$

$\begin{array}{lll}\text { Man } & 61 & 40.1\end{array}$

Transgender Woman $\quad 2 \quad 1.3$

Transgender Man $\quad 2 \quad 1.3$

Gender Fluid $\quad 10 \quad 6.6$

$\begin{array}{lll}\text { I identify differently } & 1 & 0.7\end{array}$

Sexual Orientation

$\begin{array}{lrl}\text { Asexual } & 4 & 2.6\end{array}$

Bisexual $\quad 59 \quad 38.8$

$\begin{array}{lll}\text { Fluid } & 4 & 2.6\end{array}$

Gay $\quad 31 \quad 20.4$

Lesbian $\quad 21 \quad 13.8$

Pansexual $\quad 10 \quad 6.6$

$\begin{array}{lll}\text { Queer } & 1 & 0.7\end{array}$

Questioning $\quad 21 \quad 13.8$

$\begin{array}{lll}\text { I identify differently } & 1 & 0.7\end{array}$

Race/Ethnicity

Asian $\quad 3 \quad 2$

$\begin{array}{lll}\text { Multiracial } & 23 & 15.1\end{array}$

Black or African American $\quad 16 \quad 10.5$

Hispanic or Latinx $12 \quad 1.9$

Middle Eastern $\quad 4 \quad 2.6$

American Indian or Native American $\quad 4 \quad 2.6$

$\begin{array}{lll}\text { White or European } & 88 & 57.9\end{array}$ 
Ages ranged from 13 to 18 , with a mean age of 15.88 and standard deviation of 1.59. Male and female gendered participants were sampled to represent the United States population proportions, according to the most recent national census. Thus, caps were placed on male and female participant sample sizes so groups did not exceed census norms. No caps were placed on genderqueer participants, with $9.9 \%$ of the total sample representing gender identities other than man or woman. Additionally, no limits were placed for number of participants within racial/ethnic nor sexual orientation groups. The majority of participants identified as European or White $(n=88,57.9 \%)$, followed by Multiracial $(n=23,15.1 \%)$, Black or African American $(n=16,10.5 \%)$, and Hispanic or Latinx $(n=12,7.9 \%)$. Much smaller proportions of participants $(<3 \%)$ identified as Asian, Middle Eastern, and American Indian or Alaskan Native (see Table 1). The modal category for participant sexual identity label was bisexual $(n=59,38.8 \%)$, followed by gay $(n=31,20.3 \%)$, lesbian $(n=21,13.8 \%)$, and questioning $(13.8 \%)$, with smaller proportions of participants $(<7 \%)$ self-identifying as asexual, fluid, queer, pansexual, or other (see Table 1).

\section{Suicidal Ideation}

Participants were asked to answer highly sensitive questions regarding their past and current suicidal ideation and behaviors. National suicide prevention resources were provided to parents on the consent form, to all participants at the end of the study, and as an immediate pop-up with clickable links through Qualtrics if a participant indorsed a certain answer or reached a predetermined threshold. The statement read: 
"The National Suicide Prevention Lifeline is 800-273-8255. Other international suicide helplines can be found at befrienders.org. You can also text TALK to 741741 for free, anonymous $24 / 7$ crisis support in the US from the Crisis Text Line"

\section{Measures}

\section{Demographic Questionnaire}

Participants completed a demographic questionnaire to indicate their sexual orientation. Participants had the option to choose between "heterosexual or straight (in which they were exited out of the survey), gay or lesbian, bisexual, fluid, pansexual, queer, questioning, asexual, I identify differently, or I prefer not to answer.” Participants also identified their age (by birth year), gender identity (“man, male, or masculine," "transgender man, male, or masculine," "woman, female, or feminine," "transgender woman, female, or feminine," "gender nonconforming, genderqueer, or gender questioning," "intersex, disorders of sex development, two-spirit, or other related terms," “other," or "prefer not to answer"), and their ethnicity/race ("American Indian or Alaska Native," "Asian or Asian American," "Black or African American," "Hispanic, Latinx, or Spanish Origin," "Middle Eastern or North African," "Native Hawaiian or Other Pacific Islander," "European or White American," "some other race, ethnicity, or origin," and/or "I prefer not to answer"). These questions were designed based on best practice when asking questions to identify minority respondents on population-based surveys (The GenIUSS Group, 2014). 


\section{The Sexual Minority Adolescent Stress Inventory (SMASI)}

Schrager et at. (2018) designed the SMASI to assess minority stress across several subscales in LGB+ adolescents. The SMASI is a 64-item measure that looks at minority stress both across the lifespan and within the past thirty days and consists of the following subscales: Identity management, Negative expectancies, Negative disclosure experiences, Family rejection, Internalized homonegativity, Homonegative communication, Homonegative climate, Social marginalization, Intersectionality, Religion, and Work. The present study removed Religion and Work subscales in the case that participants were not working or were not religious, as the wording was not appropriate for those who do not have these experiences. This study also focused on global minority stress across the lifespan and remove items from the past thirty days. Adaptations to the measure reduced the total items to 49. Responses on the SMASI were given in a binary fashion through a response of either "Yes", coded as 1, or "No", coded as 0 . Higher scores were associated with higher levels of overall global minority stress. The SMASI was found to have good divergent and criterion validity (Goldbach et al., 2017) and high reliability when looking measuring the overall composite score $(\alpha=.98$;

Schrager et al., 2018). In the present study, internal consistency was high at $\alpha=.95$.

\section{Avoidance and Fusion Questionnaire for Youth (AFQ-Y8)}

The AFQ-Y8 (Greco et al., 2008) measures global psychological inflexibility, with a high score on the measure indicating greater levels of global psychological inflexibility. The questionnaire consists of eight items, with response sets ranging from $" 1=$ Not true at all" to " $5=$ Very true" on a five-point response scale. Item samples 
include: "My life won't be good until I feel happy," "The bad things I think about myself must be true," and "I am afraid of my feelings." Reliability for the AFQ-Y8 was high in a sample of youth participants, with an alpha value of 0.90 (Livheim, et al., 2016) and 0.90 in the present study. Additionally, in a sample of college students, the AFQ-Y8 was found to have strong reliability, with an alpha value of 0.82 (Renshaw, 2018).

\section{Brief Experiential Avoidance Questionnaire (BEAQ)}

The BEAQ (Gámez et al., 2014) is a 15-item self-report measure assessing participant's levels of experiential avoidance (the avoidance of unpleasant thoughts or feelings). Responses are recorded on a six-point Likert scale, with " 1 = Strongly Disagree" to " 6 = Strongly Agree". Item samples include, "The key to a good life is never feeling any pain," "I would give up a lot not to feel bad," and "I work hard to keep out upsetting feelings." Higher scale scores represent higher levels of experiential avoidance. No large-scale normative data exists for this measure; however, during initial validation, the BEAQ was found to have good internal consistency $(\alpha=0.86)$ and strong convergence with related measures ( $r=0.39$ - 0.80; Gámez et al., 2014). Additionally, reliability was found to be strong in the current study at $\alpha=0.89$. Past research has used the BEAQ with adults, but with items written at a third-grade reading level, it is argued that this measure is appropriate for use with adolescents.

\section{Cognitive Fusions Questionnaire (CFQ)}

The CFQ (Gillanders et al., 2014) measured levels of cognitive fusion, or the level of attachment one has to their thoughts and cognitions. The CFQ consists of seven items and is measured on a scale from one to seven, " $1=$ Never True" to " $7=$ Always True." 
Item examples include, "I struggle with my thoughts," and "I tend to get very entangled in my thoughts." Overall, higher scores on the CFQ represent higher levels of cognitive fusion. The CFQ has been translated and normed with various populations, with findings supporting the validation study of good preliminary evidence of readability (second grade level) and internal reliability ( $\alpha=0.88$ to 0.93 ) in seven samples (Gillanders et al., 2014) and $\alpha=0.95$ in the current sample.

\section{Valuing Questionnaire (VQ)}

The VQ (Smout et al., 2014) is a measure used for assessing valued living. In this study, the VQ assessed the two ACT processes of Values and Committed Action. This is defined as how much a person can identify what is most important to them and how to live a life consistent with those values. The VQ is a short measure comprised of ten items, with a response scale ranging from zero ("Not at all true") to six ("Completely true"). The VQ is broken into two subscales, Progress and Obstruction. Higher scores on Progress (items, 3, 4, 5, 7, 9) relates to higher levels of actions consistent with one's values. Scores on Obstruction (items, 1, 2, 6, 8, 10) are correlated with hindrance of one's valued living. Smout et al. (2014) found internal consistency for both the Progress and Obstruction scales to be high ( $\alpha=0.87$ and $\alpha=0.87$ ). Other studies have found reliability levels around a similar degree (Christie et al, 2017; Fischer et al., 2016; Mosher et al., 2016) and the current study found coefficients of progress and obstruction to be 0.84 and 0.90 , respectively. The Obstruction subscale was used for primary analyses because higher scores represent undesirable effects, similar to other measures, and due to higher reliability coefficients. 


\section{Mindful Attentive Awareness Scale - Adolescent (MAAS-A)}

The MAAS-A (Brown, et al., 2011) is a measure adapted from the widely used MAAS (Brown \& Ryan, 2003) for use with adolescent samples. The MAAS-A is employed to evaluate dispositional awareness with the present moment, with an emphasis on attention. The MAAS-A is a 15-item measure using a Likert scale from one ("Almost Always") to six (“Almost Never”) for participant response. Examples of items on the MAAS-A include, "I find it difficult to stay focused on what's happening in the present," and "I find myself preoccupied with the future or the past". Though questions address mindlessness, score is such that higher scores on the MAAS-A are associated with higher levels of awareness and attention in the present moment. Brown et al. (2011) found the MAAS-A to be psychometrically sound, with internal reliability ranging from $\alpha=0.85$ to $\alpha=0.88$. The present study found corresponding reliability at $\alpha=0.93$.

\section{Suicidal Behaviors Questionnaire - Revised (SBQ-R)}

The SBQ-R (Osman, 2002) is a four-item self-report measure determining past suicidal ideation or attempts, frequency of suicidal ideation over the past 12 months, threat of suicide attempt, and likelihood of future suicidal behavior. Response types and scoring on the SBQ-R vary by question. Total scores are summative and can range from 3-18, with a score of seven or higher falling in the "at risk" category. In a high school sample, the SBQ-R was determined to have high reliability $(\alpha=0.87)$ and validity (Area Under the ROC Curve $=1.00)$ as a screener of suicidality (Osman et al., 2001). It should be noted that item one, "Have you ever thought about or attempted to commit suicide?" was changed to "Have you ever thoughts about or attempted to kill yourself?" The SBQ- 
$\mathrm{R}$ was later removed from any statistical analyses due to redundancy with the SIQ, absence of questions regarding suicidal thoughts, and lower reliability.

\section{Suicidal Ideation Questionnaire (SIQ)}

The SIQ measures the frequency and severity of suicidal ideation in high school students through a 15-item questionnaire (Reynolds, 1987). Responses are given on a seven-point-scale ranging from zero $=$ "I never had this thought" to six $=$ "Almost every day." A summative score greater than 41 suggests risk and higher overall scores are associated with greater levels of suicidal ideation. Reliability of the scale ranges from $\alpha=$ 0.74 (school sample) to $\alpha=0.97$ (clinical sample; Pinto et al., 1997; Winters, Myers, \& Proud, 2002), and $\alpha=0.96$ in the current sample. Any participants who received scores above the cutoff for either suicide related measure were provided with suicide prevention resources while taking the survey. Furthermore, the SIQ was used as the construct measure for suicidality in statistical analyses.

\section{Alcohol Use Disorders Identification Test (AUDIT)}

The final scale used in this study is the AUDIT (Saunders et al., 1993). This scale measures alcohol consumption, drinking behaviors, and alcohol related problems. The AUDIT is a 10-item measure using a five-point response scale (0-4). Responses vary based on question type and include questions such as "How often do you have a drink containing alcohol," "Has a relative, friend, doctor, or other health care worker been concerned about your drinking or suggested you cut down?" and "How often during the last year have you failed to do what was normally expected of you because of drinking?" An overall score of eight or more indicates hazardous or harmful alcohol use. This scale 
has high reliability $(\alpha=0.86)$ and strong diagnostic accuracy (sensitivity $=0.90$ and specificity $=0.80$ ) for various indices of problematic drinking in adult samples (Barbor et al., 2001). Similarly, high sensitivities (sensitivity $=0.88$ ) were reported in a sample of adolescents ages 14-18 (Knight et al., 2006) and good reliability was found in the current study, $\alpha=0.95$.

\section{Statistical Analysis}

Preliminary univariate analyses assessed central tendency, internal consistency, and distribution of all scales that contain multiple items. Prior to putting observed variables into the regression analyses models, bivariate correlations between total scores of all measures were conducted and organized into a correlation matrix. Four linear regression models tested main effects and interactions of the predictor variables. Model 1 (Figure 1) tested the main effects of minority stress and psychological inflexibility and the interaction of the two on the outcome of substance misuse.

\section{Figure 1.}

Linear regression model for Minority Stress, Global Psychological Inflexibility, and Substance Misuse.

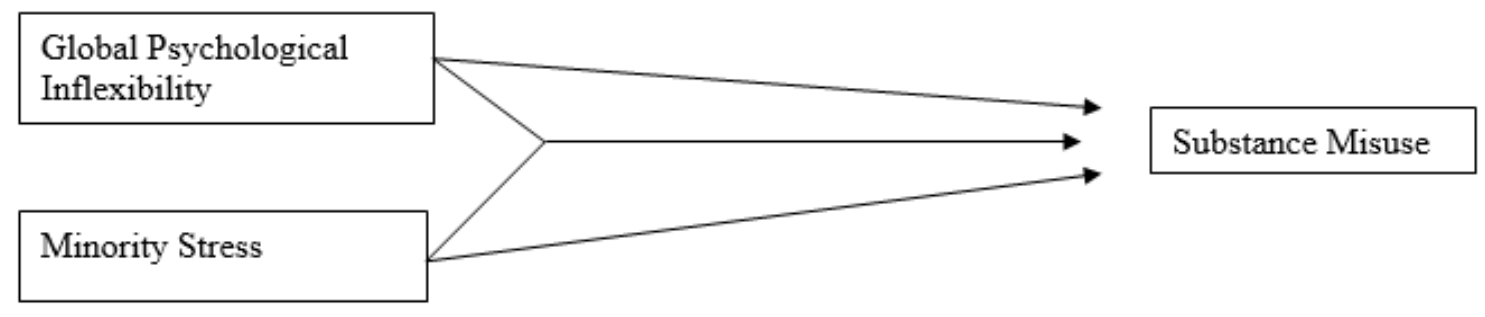


Model 2 (Figure 2) tested the main effects of minority stress and psychological inflexibility and the interaction of the two on the outcome of suicidality.

Figure 2.

Linear regression model for Minority Stress, Global Psychological Inflexibility, and Suicidality.

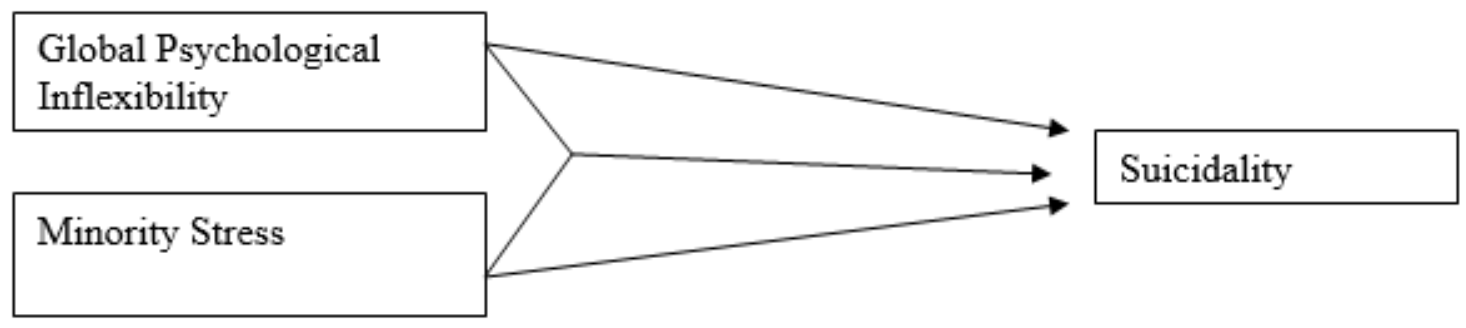

Model 3 (Figure 3) tested the main effects and interactions of minority stress, cognitive fusion, experiential avoidance, valued living, and present moment awareness on the outcome of substance misuse.

Figure 3. 
Linear regression model for Minority Stress, Global Psychological Inflexibility SubProcesses, and Substance Misuse.

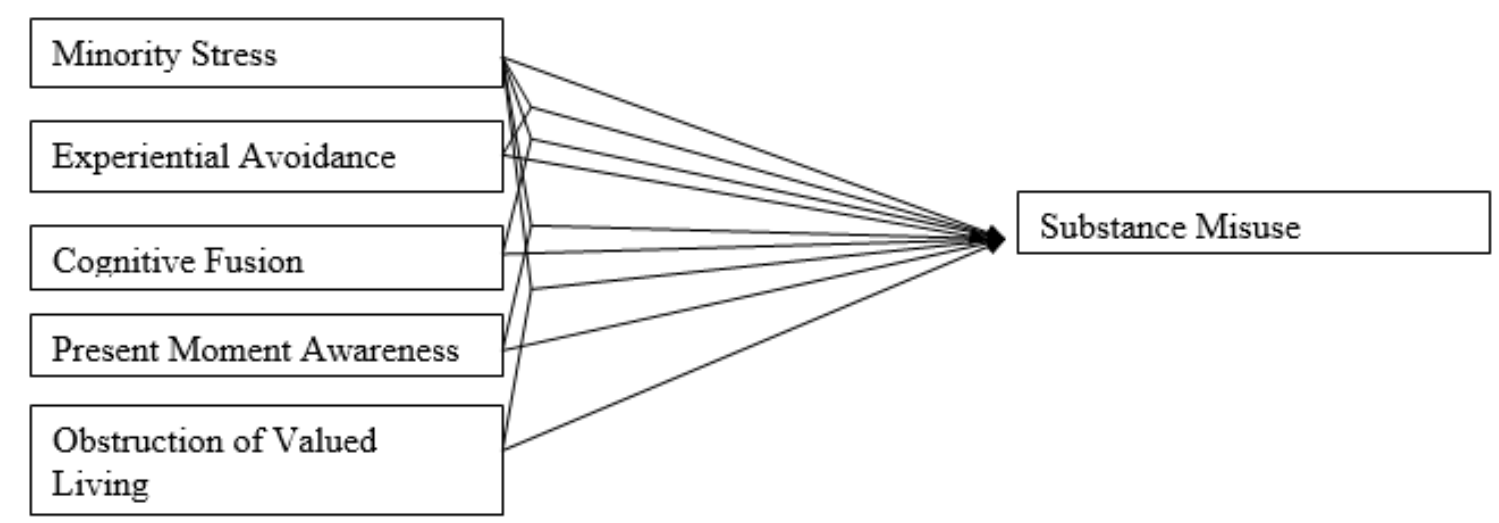

Model 4 (Figure 4) tested the main effects and interactions of minority stress, cognitive fusion, experiential avoidance, valued living, and present moment awareness on the outcome of suicidality.

\section{Figure 4.}

Linear regression model for Minority Stress, Global Psychological Inflexibility SubProcesses, and Suicidality.

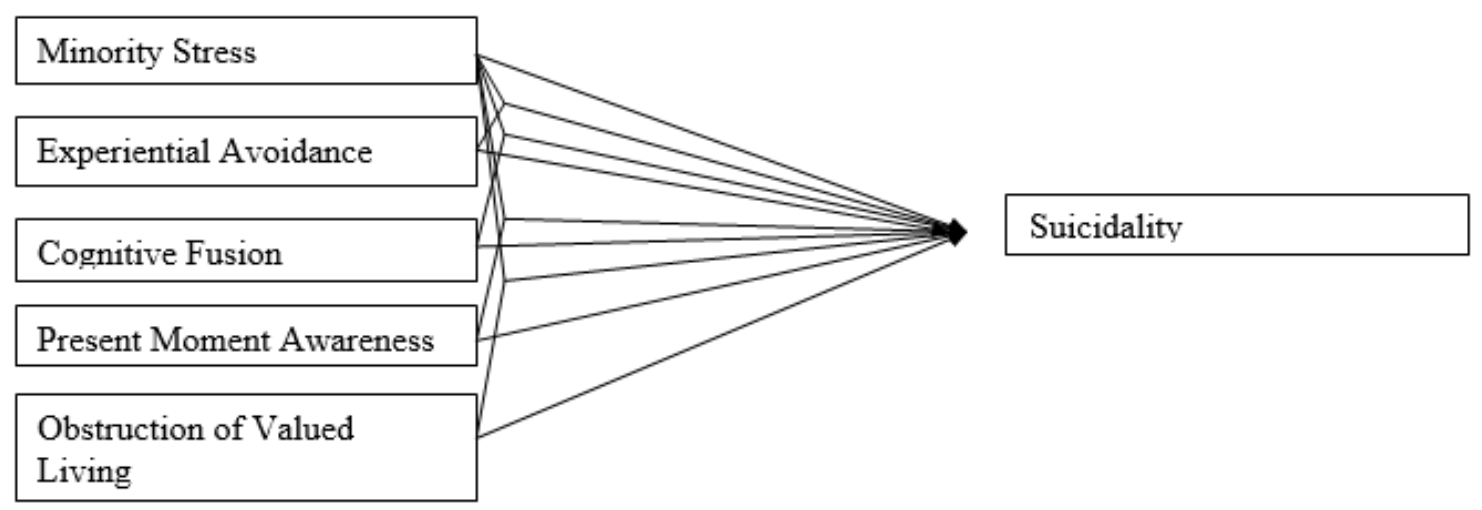


Residual diagnostics were calculated using variance inflation factors to show if multicollinearity was a concern. Summary statistics, bivariate correlations, linear regression models, and the variance inflation factor were calculated through the $\mathrm{R}$ statistical environment.

\section{Statistical Limitations}

Limitations to the statistical analysis originate in the exploratory nature of the proposed pathways in this study. While effects between minority stress/global psychological inflexibility/psychological inflexibility sub-processes and the outcome variables is predictable, no literature exists connecting minority stress with global psychological inflexibility/psychological inflexibility sub-processes. Though best practice was used while selecting sample size (Darlington \& Hayes, 2017), guessing at effect sizes among pathways made sample size selection no more than semi-informed (Hayes, 2017). Additionally, regression models work under the assumption of independence among predictors. Though there is no current literature on the correlation among the proposed measures, conceptually, there is a likelihood that some of the predictors will be correlated. 


\section{CHAPTER IV}

\section{RESULTS}

\section{Preliminary Analyses}

\section{Descriptive Statistics}

Descriptive statistics for all study variables are presented in Table 2. Each variable was examined to look at participants' pattern of response through central tendencies and distribution, including mean, range, standard deviation, skewness, and kurtosis. Additionally, normality was tested for each variable using Q-Q plots, histograms, and Shapiro Wilk's tests. Finally, reliability analyses were conducted to assess internal consistencies using Cronbach's alpha.

Histograms showed distribution of item responses to have greater clusters toward the mean and fewer responses at the tails for most variables, excluding the measures of suicidality and substance misuse. All variables measuring suicidality and substance use showed floor effects, demonstrating a pattern in which the majority of participants presented neither suicidal tendencies nor excessive alcohol use, as seen in previous studies (Esser et al., 2017; Nock et al., 2013). Furthermore, Q-Q plots demonstrated slight deviations at the tails, except in the instances of the criterion variables (i.e., suicidality and substance use), which showed considerable deviations. Shapiro Wilk's tests were violated $(p<.05)$ in all measures except for the measurement of mindful attention (MAAS-A, $p=.057$ ), indicating rejection of the null hypothesis that sample responses were normally distributed. In this study, violating the assumption of normal distribution indicated limitations of measurement scales due to floor effects; though in 
large samples, Shapiro Wilk's is known to be overly sensitive (Ghasemi \& Zahediasl, 2012) and less often relied upon. Reliability analyses showed strong internal consistencies for all variables, with Cronbach's alphas ranging from 0.84 to 0.96 (see Table 2). Strong reliabilities indicated that all measures were precise and consistent in measuring the construct. These data provide encouraging information in regard to the use of the current measures in primary analyses by reducing measurement error.

\section{Table 2}

Descriptive Statistics for Central Tendency, Distribution, and Internal Consistency for All Study Measures

\begin{tabular}{lcrccccc}
\hline \multicolumn{1}{c}{ Measure } & $M$ & SD & min & max & skewness & kurtosis & $\begin{array}{c}\text { Cronbach's } \\
\alpha\end{array}$ \\
\hline SMASI & 20.43 & 12.93 & 0 & 49 & 0.17 & -0.97 & .95 \\
AFQ-Y8 & 23.12 & 8.60 & 8 & 40 & -0.01 & -0.91 & .90 \\
BEAQ & 59.03 & 14.55 & 15 & 86 & -0.50 & 0.04 & .89 \\
CFQ & 30.89 & 10.99 & 7 & 49 & -0.38 & -0.64 & .95 \\
VQ-O & 15.38 & 8.29 & 0 & 30 & -0.21 & -0.80 & .90 \\
MAAS-A & 3.70 & 1.11 & 1 & 6 & 0.05 & -0.36 & .93 \\
SIQ & 20.06 & 22.18 & 0 & 83 & 1.16 & 0.18 & .96 \\
AUDIT & 5.20 & 8.54 & 0 & 37 & 1.88 & 2.77 & .95 \\
\hline
\end{tabular}

Note: SMASI = The Sexual Minority Adolescent Stress Inventory; AFQ-Y8 = Avoidance and Fusion Questionnaire for Youth; BEAQ = Brief Experiential Avoidance Questionnaire; CFQ = Cognitive Fusions Questionnaire; VQ-O = Valuing Questionnaire - Obstruction; MAAS-A = Mindful Attentive Awareness Scale - Adolescent SIQ = Suicidal Ideation Questionnaire; AUDIT = Alcohol Use Disorders Identification Test.

\section{Correlations}

Bivariate correlations among all study variables are presented in Table 3. Correlation coefficients were examined in order to confirm or deny assumptions of 
independence and direction and strength of relationships between variables. Results showed moderate associations between minority stress and psychological inflexibility ( $r$ $=.54, p<.001)$, along with its sub-processes of experiential avoidance $(r=.40, p<.001)$, cognitive fusion $(r=.43, p<.001)$, obstruction of valued living $(r=.43, p<.001)$, and mindful attention $(r=-.38, p<.001)$.

Associations between predictor variables and suicidality showed correlations ranging from weak (experiential avoidance, $r=.21$ ) to moderate (psychological inflexibility, $r=.44$; see Table 3 ). Associations between the predictor variables and substance misuse also ranged from weak (cognitive fusion, $r=.25, p=.002$ ) to moderate (minority stress, $r=.44, p<.001$; see Table 3 ). There were strong associations between psychological inflexibility and its sub-processes of experimental avoidance $(r=.67, p<$ $.001)$, cognitive fusion $(r=.78, p<.001)$, and obstruction of valued living $(r=.62, p<$ .001). Additionally, psychological inflexibility and the sub-process of mindful attention showed a moderate negative relationship $(r=-.46, p<.001)$. Overall, associations amongst variables indicated weak to moderate relationships between predictors, moderators, and criterion variables. For the moderator variables, coefficients were moderate to high with relationships showing expected directionality. These results suggested measures were appropriate for use in primary analyses as they meet theoretical expectations regarding the strength and directionality of relationships among variables. 
Table 3

Pearson's Bivariate Correlation Matrix for All Study Measures

\begin{tabular}{|c|c|c|c|c|c|c|c|c|}
\hline Measures & SMASI & AFQ-Y8 & BEAQ & CFQ & VQ-O & MAAS-A & SIQ & AUDIT \\
\hline SMASI & & & & & & & & \\
\hline AFQ-Y8 & $.54 * *$ & & & & & & & \\
\hline BEAQ & $.40 * *$ & $.67 * *$ & & & & & & \\
\hline CFQ & $.43 * *$ & $.78 * *$ & $.73 * *$ & & & & & \\
\hline VQ-O & $.43 * *$ & $.62 * *$ & $.70 * *$ & $.69 * *$ & & & & \\
\hline MAAS-A & $-.38 * *$ & $-.46 * *$ & $-.42 * *$ & $-.47 * *$ & $-.51 * *$ & & & \\
\hline SIQ & $.27 * *$ & $.44 * *$ & $.21 *$ & $.38 * *$ & $.34 * *$ & $-.31 * *$ & & \\
\hline AUDIT & $.44 * *$ & $.34 * *$ & $.31 * *$ & $.25^{*}$ & $.35^{* *}$ & $-.26 * *$ & $.32 * *$ & \\
\hline
\end{tabular}

Note: SMASI $=$ The Sexual Minority Adolescent Stress Inventory; AFQ-Y8 = Avoidance and Fusion Questionnaire for Youth; BEAQ = Brief Experiential Avoidance Questionnaire; CFQ = Cognitive Fusions Questionnaire; VQ-O = Valuing Questionnaire - Obstruction; MAAS-A = Mindful Attentive Awareness Scale - Adolescent; SIQ = Suicidal Ideation Questionnaire; AUDIT = Alcohol Use Disorders Identification Test.

\section{Multiple Linear Regression}

\section{Demographic covariates}

Demographic variables of age, gender, sexual orientation, and race/ethnicity were included in Model 1 and Model 2 analyses as covariates to control for potential confounding effects. This allowed for more precise interpretation of effects and interactions among predictor, moderator, and criterion variables. Additionally, by controlling for demographic variables, residual errors were reduced in both models. Due to the exploratory nature and complexity of Model 3 and Model 4, demographic variables were not included in the analyses as covariates. 
Demographic sub-groups with samples less than 30 were combined into larger categorical aggregations. Due to the large quantity of demographic sub-groups, small demographic samples included as controls in the regression analyses would have produced meaningless results. Gender was coded to include three groups, female (reference group; included female and transgender female participants), male (included male and transgender male participants), and gender nonbinary (included gender nonbinary and participants who selected "other"). Gender groupings of transgender participants was based on current best practice, indicating gender identity is more meaningful than biological sex when norming samples (De Vries et al., 2011). Racial and ethnic consolidation of groups was conducted in a binary fashion. Due to the high percentage of White participants, race and ethnicity was divided into White (reference group) and Person of Color. Lastly, sexual orientation was parsed into four sub-groups due to a more even distribution of participants among identifiers: Bisexual (reference group), Gay, Lesbian, and Queer (consisting of asexual, pansexual, queer, questioning, fluid, and "I identify differently").

\section{Model 1}

Based on observed curvilinear patterns in scatterplots (see Figure 5) of the raw data and improvements in residual variance, a quadratic regression analysis was conducted to assess global psychological inflexibility as moderating the relationship between minority stress and substance misuse, while controlling for age, gender, sexual orientation, and race/ethnicity. Results from Model 1 are presented in Table 4. 


\section{Figure 5}

Scatterplot of Minority Stress (SMASI)and Substance Misuse (AUDIT), Shaded by Psychological Inflexibility (AFQ-Y8)

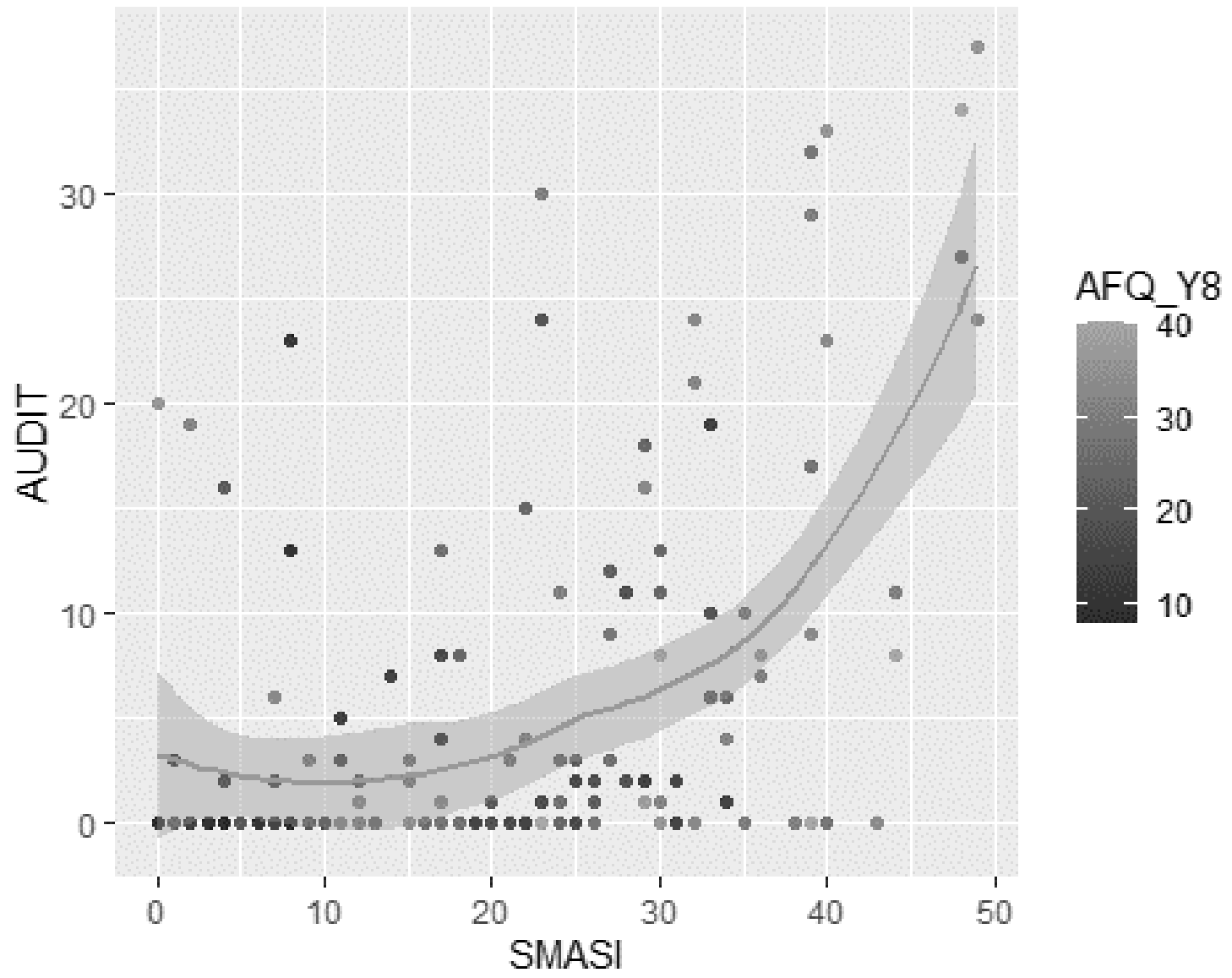

Note $:$ SMASI $=$ The Sexual Minority Adolescent Stress Inventory, AFQ-Y8 $=$ Avoidance and Fusion

Questionnaire for Youth, AUDIT = Alcohol Use Disorders Identification Test 
Table 4

Multiple Linear Regression Parameter Estimates for Quadratic Effect of Minority Stress (SMASI) Moderated by Psychological Inflexibility (AFQ-Y8) Regressed on Substance Misuse (AUDIT) - "Model 1"

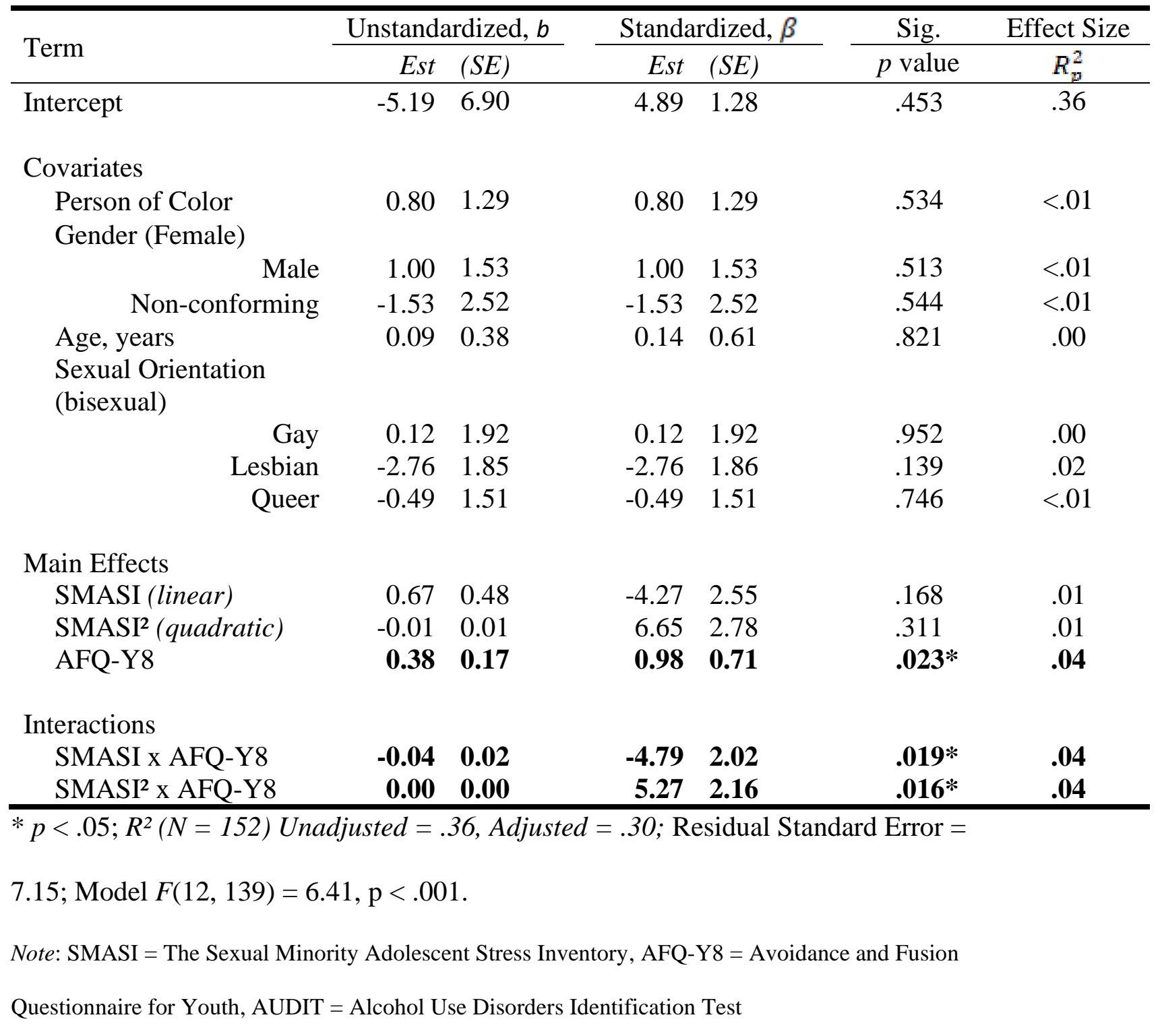

Psychological inflexibility was found to have a significant main effect on substance misuse, $p=.023$, in Model 1. Additionally, there was evidence that 
psychological inflexibility moderated the relationship between minority stress and substance misuse, $p=.016$, thus rejecting the null hypothesis that there were no significant interactions (see Figure 6). When taken together, the combined effects of Model 1 account for $30 \%$ of the variance in substance misuse in this sample of LGB+ adolescents, which is a very large effect size. Specifically, the quadratic interaction between minority stress and psychological inflexibility accounted for $4 \%$ of the variance within this model, which is a small effect size. This interaction indicates that the relationship between minority stress and substance misuse is stronger when under conditions of high psychological inflexibility. Residual tests indicated greater instances of residual deviations as participants neared higher ends of measures, implying more variability in extreme participant reports. 


\section{Figure 6}

Interaction Plot Illustrating the Moderating Effect of Psychological Inflexibility (AFQY8) on Minority Stress (SMASI) when Predicting the Estimated Marginal Mean of Substance Misuse (AUDIT; "fit") - "Model 1"

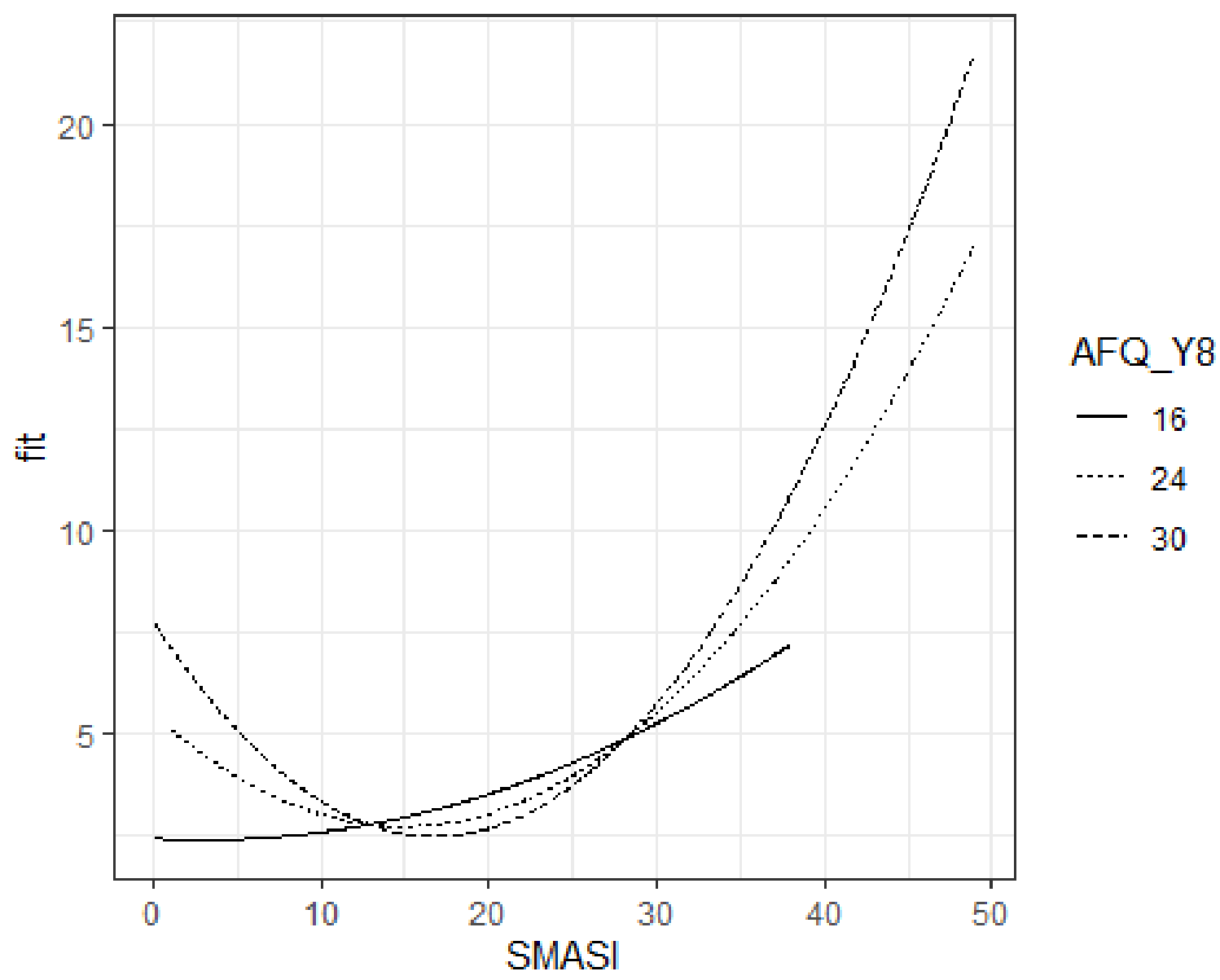

Note $:$ SMASI $=$ The Sexual Minority Adolescent Stress Inventory, AFQ-Y8 = Avoidance and Fusion

Questionnaire for Youth, AUDIT $=$ Alcohol Use Disorders Identification Test 


\section{Model 2}

Global psychological inflexibility was tested as moderating the relationship between minority stress and suicidality while controlling for age, gender, sexual orientation, and race/ethnicity. Results from Model 2 are presented in Table 5.

\section{Table 5}

Multiple Linear Regression Parameter Estimates for Linear Effect of Minority Stress (SMASI) Moderated by Psychological Inflexibility (AFQ-Y8) Regressed on Suicidality (SIQ) - "Model 2"

\begin{tabular}{|c|c|c|c|c|c|c|}
\hline \multirow{2}{*}{ Term } & \multicolumn{2}{|c|}{ Unstandardized, $b$} & \multicolumn{2}{|c|}{ Standardized, $\beta$} & \multirow{2}{*}{$\begin{array}{c}\text { Sig. } \\
p \text { value }\end{array}$} & \multirow[t]{2}{*}{ Effect Size } \\
\hline & Est & $(S E)$ & Est & $(S E)$ & & \\
\hline Intercept & 7.10 & 19.00 & 22.66 & 3.50 & .709 & .23 \\
\hline \multicolumn{7}{|l|}{ Covariates } \\
\hline Person of Color & -5.27 & 3.56 & -5.27 & 3.56 & .142 & .02 \\
\hline \multicolumn{7}{|l|}{ Gender (Female) } \\
\hline Male & -3.09 & 4.30 & -3.09 & 4.30 & 474 & $<.01$ \\
\hline Non-conforming & -3.14 & 6.97 & -3.14 & 6.97 & .653 & $<.01$ \\
\hline Age, years & -1.10 & 1.07 & -1.75 & 1.70 & .305 & .01 \\
\hline Gay & 4.83 & 5.40 & 4.84 & 5.40 & .372 & .01 \\
\hline Lesbian & 2.22 & 5.24 & 2.22 & 5.24 & .673 & $<.01$ \\
\hline Queer & 2.45 & 4.26 & 2.45 & 4.26 & .566 & $<.01$ \\
\hline \multicolumn{7}{|l|}{ Main Effects } \\
\hline SMASI & 0.43 & 0.38 & 1.35 & 2.03 & .266 & .01 \\
\hline AFQ-Y8 & 1.34 & 0.35 & 9.05 & 2.00 & $<.001 * * *$ & 10 \\
\hline \multicolumn{7}{|l|}{ Interactions } \\
\hline SMASI x AFQ-Y8 & -0.01 & 0.01 & -1.55 & 1.58 & .327 & .01 \\
\hline
\end{tabular}


Note $:$ SMASI $=$ The Sexual Minority Adolescent Stress Inventory, AFQ-Y8 = Avoidance and Fusion Questionnaire for Youth, SIQ = Suicidal Ideation Questionnaire.

While higher scores on minority stress did not directly affect suicidality, $b=0.43$, $\beta=1.35, p=.266$, psychological inflexibility did have a direct effect on suicidality, $b=$ 1.34, $\beta=9.05, p<.001$, explaining $10 \%$ of the variance within the model. For every additional point of psychological inflexibility indicated by a participant on the AFQ-Y8, their suicidality ratings increased by 1.34 points on the SIQ. There was no evidence of a significant interaction between minority stress and psychological inflexibility in their relationship with suicidality, $p=.327$, thus the null hypothesis of no significant interactions cannot be rejected. Residual tests indicated appropriate variation and deviation, showing an expected distribution of residuals.

\section{Model 3}

A series of exploratory multiple linear regression analyses were run for each individual psychological inflexibility sub-process — cognitive fusion, experiential avoidance, mindful attention, and valued living — so all sub-processes could be controlled for in the relationship between minority stress and substance misuse. Multiple regression models were run looking at one construct at a time due to multicollinearity concerns of running an analysis with all sub-processes as potential moderators. Additionally, five main effect regression models were conducted to pinpoint direct effects without interactions. Key results from this series of exploratory models are presented in Table 6. 


\section{Table 6}

Multiple Linear Regression Parameter Estimates (b) investigating potential moderation of Minority Stress (SMASI) by Each of Four Psychological Inflexibility Sub-processes Regressed on Substance Misuse (AUDIT) with sub-process covariates - "Model's $3 A-$ $3 E ”$

\begin{tabular}{|c|c|c|c|c|c|}
\hline & \multicolumn{5}{|c|}{ Psychological Inflexibility Sub-processes Moderating Minority Stress } \\
\hline & Model 3-A & Model 3-B & Model 3-C & Model 3-D & Model 3-E \\
\hline & None & CFQ & MAAS-A & VQ-O & BEAQ \\
\hline Intercept & -2.27 & 2.92 & -7.19 & 1.15 & 3.24 \\
\hline SMASI & $0.24 * * *$ & -0.06 & $0.46 * *$ & $<0.01$ & -0.11 \\
\hline \multicolumn{6}{|l|}{ Sub-process } \\
\hline BEAQ & 0.07 & 0.06 & 0.06 & 0.08 & -0.03 \\
\hline CFQ & -0.11 & $-0.24 *$ & -0.08 & -0.09 & -0.10 \\
\hline MAAS-A & -0.30 & -0.44 & 0.92 & -0.40 & -0.32 \\
\hline VQ-O & 0.19 & 0.19 & 0.20 & -0.06 & 0.20 \\
\hline SMASI x Sub-process & & 0.01* & -0.06 & 0.01* & 0.01 \\
\hline \multicolumn{6}{|l|}{ Model Fit } \\
\hline$R^{2}$ & .23 & 0.26 & 0.25 & 0.26 & 0.25 \\
\hline $\operatorname{Adj} R^{2}$ & .21 & 0.23 & 0.22 & 0.23 & 0.22 \\
\hline Residual Std. Error & 7.60 & 7.52 & 7.56 & 7.49 & 7.55 \\
\hline
\end{tabular}

Note $:$ SMASI $=$ The Sexual Minority Adolescent Stress Inventory; BEAQ = Brief Experiential Avoidance Questionnaire; $\mathrm{CFQ}=$ Cognitive Fusions Questionnaire; VQ-O = Valuing Questionnaire - Obstruction; MAAS-A $=$ Mindful Attentive Awareness Scale - Adolescent; AUDIT $=$ Alcohol Use Disorders Identification Test.

Additionally, a series of exploratory models assessed direct effects of each subprocess on substance misuse without accounting for other sub-processes, due to their highly correlated nature and the assumption of independence. Key results from this series of analyses are presented in Table 7. 
Table 7

Multiple Linear Regression Parameter Estimates (b) Investigating Potential Moderation of Minority Stress (SMASI) by Each of Four Psychological Inflexibility Sub-Processes Regressed on Substance Misuse (AUDIT)without Sub-Process Covariates - "Model's $3 F$ $-3 I ”$

\begin{tabular}{lcccc}
\hline & \multicolumn{3}{c}{ Psychological Inflexibility Sub-processes Moderating Minority } \\
& \multicolumn{4}{c}{ Stress } \\
\cline { 2 - 5 } & Model 3-F & Model 3-G & Model 3-H & Model 3-I \\
& CFQ & MAAS-A & VQ-O & BEAQ \\
\hline Intercept & 2.13 & -1.95 & 0.71 & -0.22 \\
SMASI & -0.03 & $\mathbf{0 . 5 0 * * *}$ & 0.01 & -0.08 \\
Sub-process Direct Effects & -0.08 & 0.39 & -0.02 & 0.01 \\
& & & & 0.01 \\
SMASI x Sub-process & $\mathbf{0 . 0 1 *}$ & -0.06 & $\mathbf{0 . 0 1 *}$ & \\
& & & & \\
\hline Model Fit & & & 0.25 & 0.23 \\
$\quad R^{2}$ & 0.22 & 0.22 & 0.24 \\
$\quad$ Adj $R^{2}$ & 0.21 & 0.20 & 7.46 & 7.58 \\
$\quad$ Residual Std. Error & 7.62 & 7.63 & \\
\hline
\end{tabular}

$* p<.05 . * * p<.01 . * * * p<.001$

Note: SMASI $=$ The Sexual Minority Adolescent Stress Inventory; AFQ-Y8 = Avoidance and Fusion Questionnaire for Youth; AUDIT = Alcohol Use Disorders Identification Test.

Direct effects were identified in a few models, though no specific sub-process was found to significantly affect substance misuse across all analyses when covariate subprocesses were controlled for. Significant interactions with cognitive fusion and obstruction of valued living emerged. Cognitive fusion moderated the relationship between minority stress and substance misuse, $p=.040$, thus rejecting the null hypothesis of no significant interactions (see Figure $7 \& 8$ ). This finding suggests that the relationship between minority stress and substance misuse is significantly stronger when individuals are cognitively fused with their thoughts or are not living in line with their 
values. The combined effects of the terms in this model accounted for $23 \%$ of the variance in substance misuse, representing a large effect, but the specific moderating effect was relatively small. 
Figure 7

Scatterplot of Minority Stress (SMASI) and Substance Misuse (AUDIT), Shaded by Cognitive Fusion (CFQ)

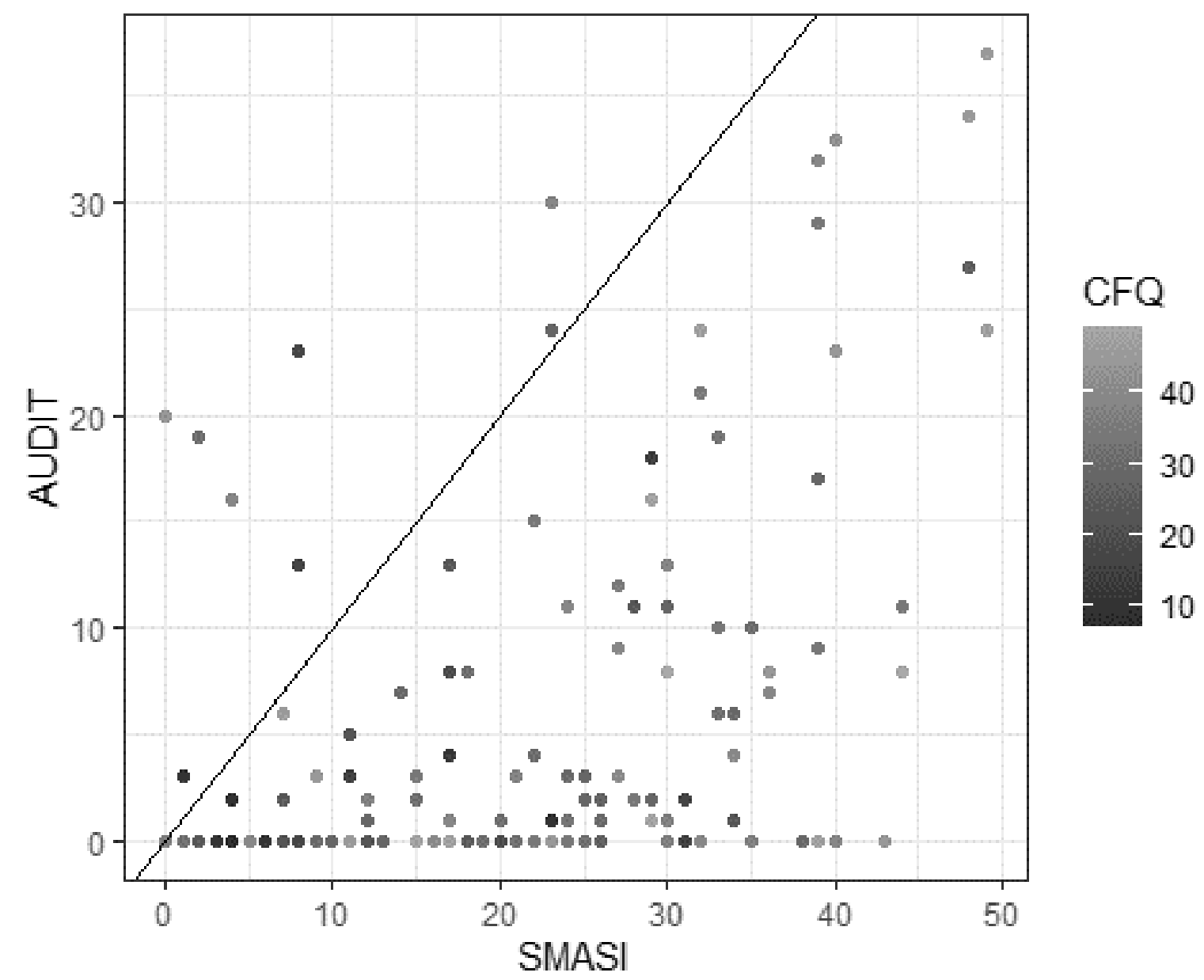

Note: SMASI = The Sexual Minority Adolescent Stress Inventory; CFQ = Cognitive Fusion Questionnaire; AUDIT $=$ Alcohol Use Disorders Identification Test. 


\section{Figure 8}

Interaction Plot Illustrating the Moderating Effect of Cognitive Fusion (CFQ) on Minority Stress (SMASI) when Predicting the Estimated Marginal Mean of Substance Misuse (AUDIT; "fit") - "Model's 3B"

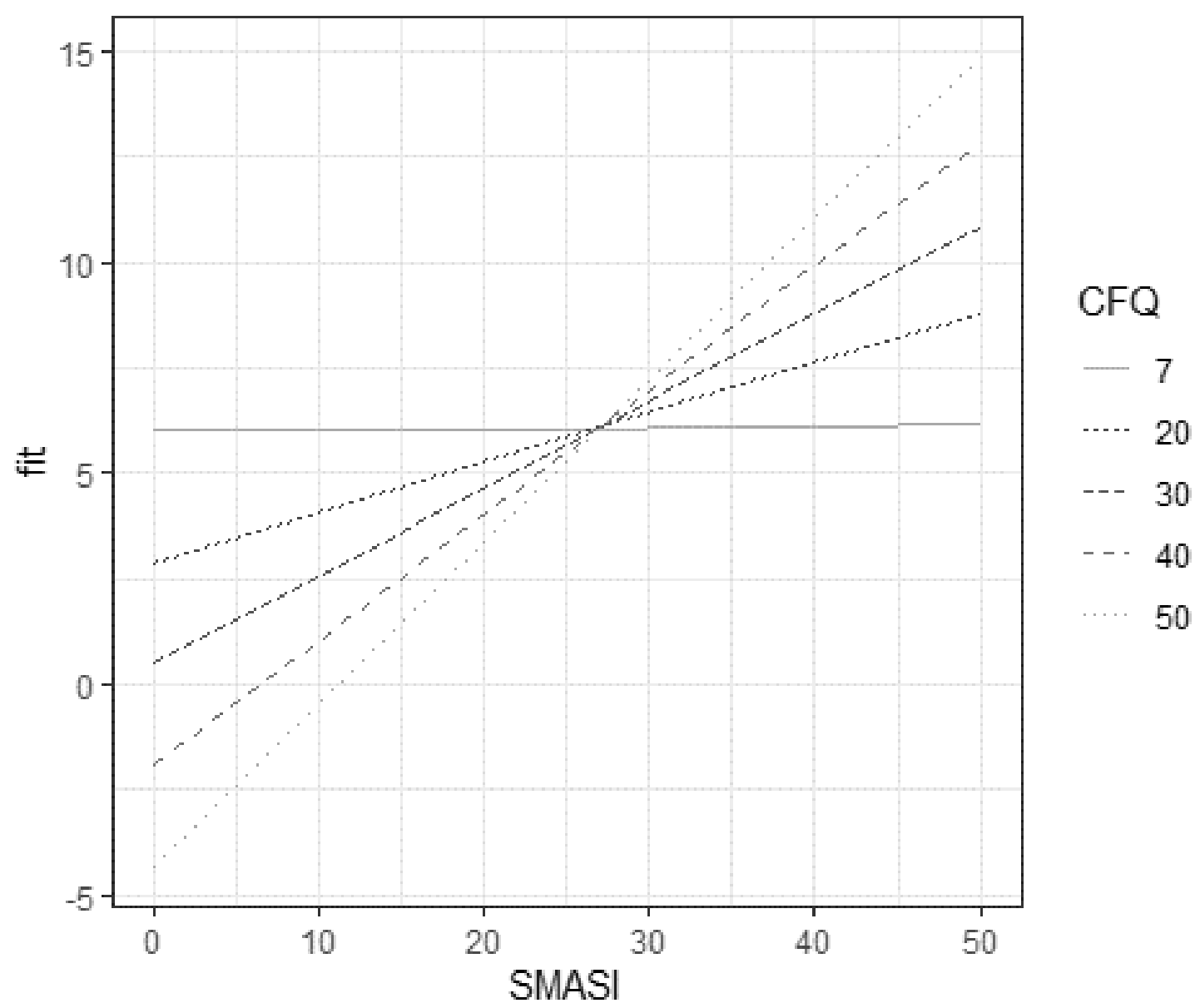

Note: SMASI $=$ The Sexual Minority Adolescent Stress Inventory, $\mathrm{CFQ}=$ Cognitive Fusion Questionnaire, AUDIT $=$ Alcohol Use Disorders Identification Test

Obstruction of valued living was also found to significantly moderate the relationship between minority stress and substance misuse, $p=.022$, thus rejecting the null (see Figure $9 \& 10$ ). This model accounted for $23 \%$ of the variance in substance misuse, which is a large effect, but the interaction effect was again relatively small. 
Residual tests for both interactions showed fanning and deviations of residuals that stress the assumptions of normality. Though this signifies potentially problematic variance in participant responses, the exploratory nature of these analyses are still thought to be informative.

\section{Figure 9}

Scatterplot of Minority Stress (SMASI) and Substance Misuse (AUDIT), Colored by Obstruction of Valued Living (VQ-O)

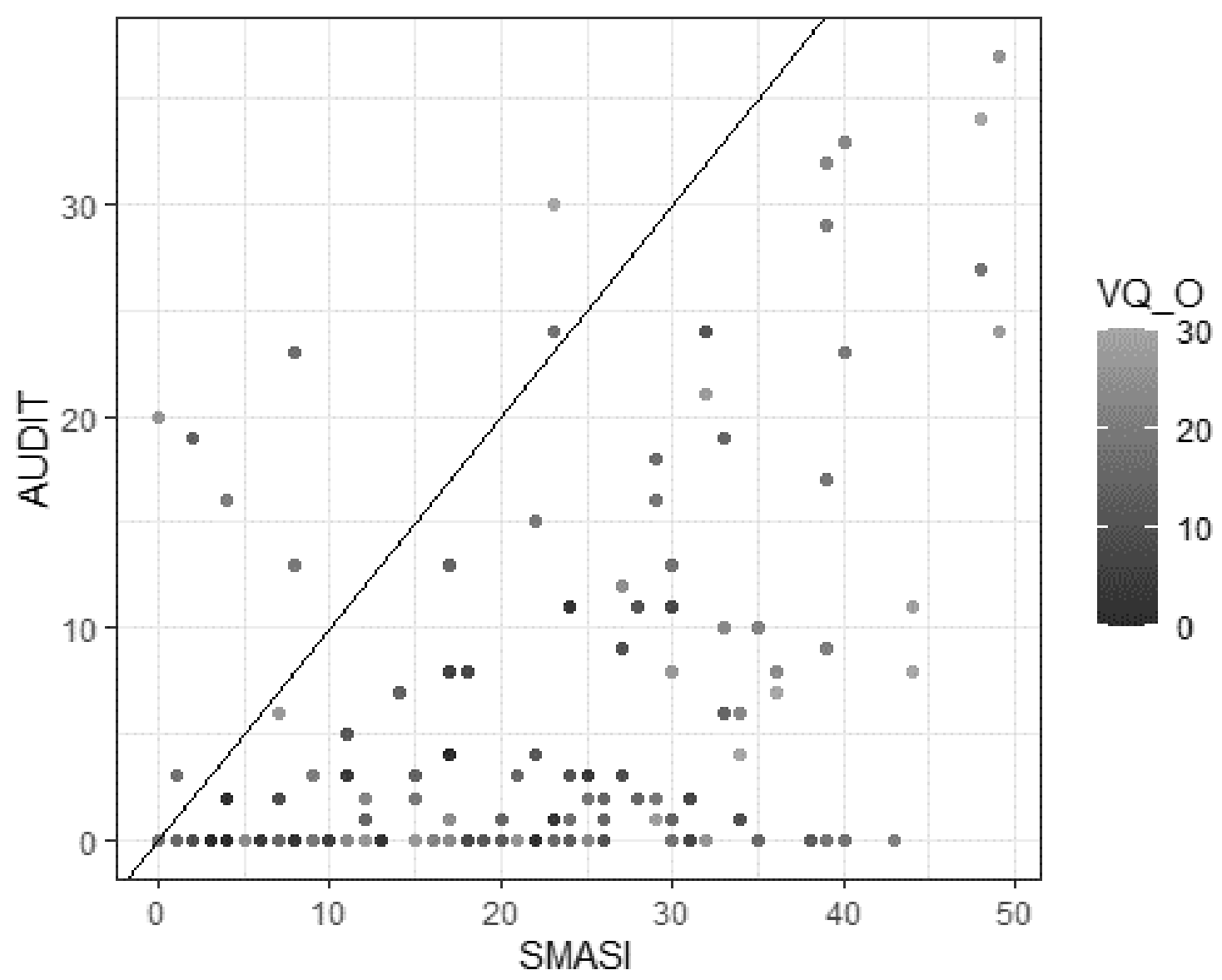

Note: SMASI = The Sexual Minority Adolescent Stress Inventory, VQ-O = Valuing Questionnaire -

Obstruction, AUDIT $=$ Alcohol Use Disorders Identification Test 


\section{Figure 10}

Interaction Plot Illustrating the Moderating Effect of Valued Living Obstruction (VQ-O) on Minority Stress (SMASI) when Predicting the Estimated Marginal Mean of Substance Misuse (AUDIT; "fit") - "Model's 3D”

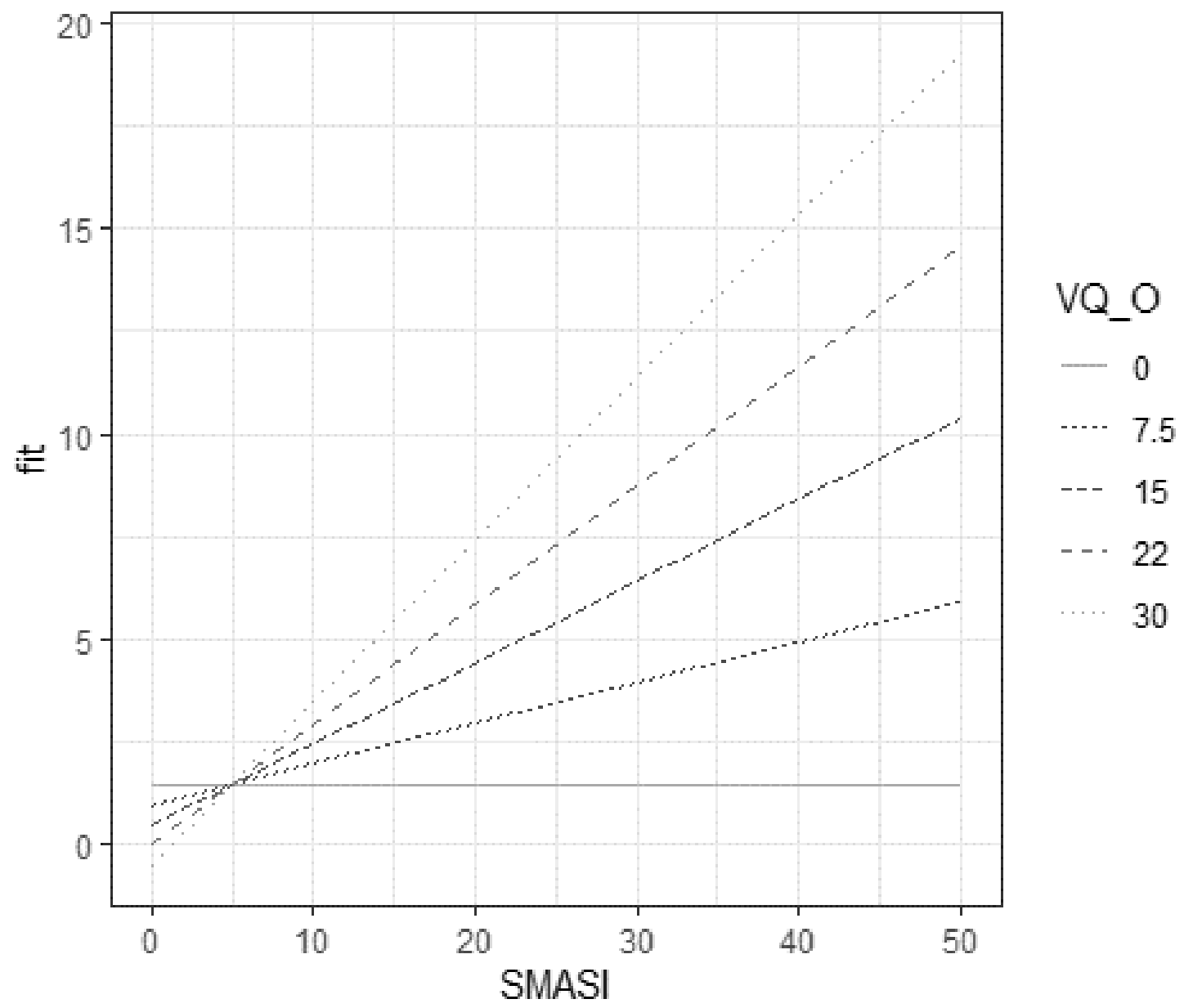

Note: SMASI = The Sexual Minority Adolescent Stress Inventory, VQ-O = Valuing Questionnaire -

Obstruction, AUDIT $=$ Alcohol Use Disorders Identification Test

\section{Model 4}

A series of exploratory multiple linear regression analyses were run to test the direct effects and interactions of psychological inflexibility's core sub-processes in the 
relationship between minority stress and suicidality while controlling for all other subprocesses as well as in the absence of these controls. Key results from these series of analyses are presented in Table 9 and Table 10. Both cognitive fusion and experiential avoidance were found to have significant direct effects on suicidality when accounting for the covariate of other psychological inflexibility sub-processes (controlled analyses). Cognitive fusion significantly was associated with suicidality in all models (controlled and non-controlled analyses), with effects ranging from $b=0.72, p<.001$ to $b=0.69, p=$ .023. In all instances of analyses, as scores of cognitive fusion increased, so did suicidality scores. Experiential avoidance was related to suicidality in the opposite direction, with significant effects in all models excluding the one examining experiential avoidance as the moderator. In all other controlled models, effects of experiential avoidance on suicidality ranged from $b=-0.38, p=.039$, to $b=-0.39, p=.034$. Interestingly, in controlled analyses, increased ratings of experiential avoidance decreased suicidality, though associations between the variables in Pearson's $r$ correlation table (Table 3) suggested effects in the opposite direction. However, when experiential avoidance was examined in the non-controlled model, an opposite, nonsignificant, effect was discovered in line with theoretical expectations and the correlation matrix. Given associations with other sub-processes, it is likely this result is suppression effect that occurred due to multicollinearity. Overall, no evidence of a significant interaction among any of the sub-process variables and minority stress were found in their relationship with suicidality, therefore the null hypothesis of no significant interactions cannot be rejected. 


\section{Table 8}

Multiple Linear Regression Parameter Estimates (b) investigating potential moderation of Minority Stress (SMASI) by Each of Four Psychological Inflexibility Sub-processes Regressed on Suicidality (SIQ) with sub-process covariates - "Model's 4A-4E”

\begin{tabular}{|c|c|c|c|c|c|}
\hline & \multicolumn{5}{|c|}{ Psychological Inflexibility Sub-processes Moderating Minority Stress } \\
\hline & Model 4-A & Model 4-B & Model 4-C & Model 4-D & Model 4-E \\
\hline & None & BEAQ & CFQ & MAAS-A & VQ-O \\
\hline Intercept & 19.97 & 13.11 & 20.21 & 15.02 & 20.16 \\
\hline SMASI & 0.17 & 0.61 & 0.16 & 0.40 & 0.16 \\
\hline \multicolumn{6}{|l|}{ Sub-process } \\
\hline BEAQ & $-0.38 *$ & -0.26 & $-0.38 *$ & $-0.39 *$ & $-0.38 *$ \\
\hline CFQ & $0.69 *$ & $0.69 * *$ & $0.69 *$ & $0.72 * *$ & $0.69 * *$ \\
\hline MAAS-A & -2.52 & -2.49 & -2.53 & -1.30 & -2.53 \\
\hline VQ-O & 0.45 & 0.45 & 0.45 & 0.45 & 0.44 \\
\hline SMASI x Sub-process & & -0.01 & $<0.01$ & -0.06 & $<0.01$ \\
\hline \multicolumn{6}{|l|}{ Model Fit } \\
\hline$R^{2}$ & .20 & .20 & .20 & .20 & .20 \\
\hline $\operatorname{Adj} R^{2}$ & .17 & .17 & .17 & .17 & .17 \\
\hline Residual Std. Error & 20.17 & 20.20 & 20.24 & 20.21 & 20.24 \\
\hline
\end{tabular}

$* p<.05 . * * p<.01$.

Note $:$ SMASI $=$ The Sexual Minority Adolescent Stress Inventory; BEAQ = Brief Experiential Avoidance

Questionnaire; CFQ = Cognitive Fusions Questionnaire; VQ-O = Valuing Questionnaire - Obstruction;

MAAS-A = Mindful Attentive Awareness Scale - Adolescent; SIQ = Suicidal Ideation Questionnaire 
Table 9

Multiple Linear Regression Parameter Estimates (b) Investigating Potential Moderation of Minority Stress (SMASI) by Each of Four Psychological Inflexibility Sub-Processes Regressed on Suicidality (SIQ) without Sub-Process Covariates - "Model's 4F-4I"

\begin{tabular}{|c|c|c|c|c|}
\hline & \multicolumn{4}{|c|}{$\begin{array}{c}\text { Psychological Inflexibility Sub-processes Moderating Minority } \\
\text { Stress }\end{array}$} \\
\hline & Model 4-F & Model 4-G & Model 4-H & Model 4-I \\
\hline & BEAQ & CFQ & MAAS-A & VQ-O \\
\hline Intercept & -7.52 & -5.90 & 31.01 & 2.34 \\
\hline SMASI & 0.93 & 0.32 & 0.32 & 0.34 \\
\hline Sub-process Direct Effects & 0.33 & $0.69 * *$ & -4.67 & $0.80 *$ \\
\hline SMASI x Sub-process & -0.01 & $<-0.01$ & $<-0.01$ & $<-0.01$ \\
\hline \multicolumn{5}{|l|}{ Model Fit } \\
\hline$R^{2}$ & .09 & .16 & .12 & .13 \\
\hline $\operatorname{Adj} R^{2}$ & .07 & .14 & .10 & .12 \\
\hline Residual Std. Error & 21.34 & 20.56 & 20.99 & 20.84 \\
\hline
\end{tabular}

Note SMASI $=$ The Sexual Minority Adolescent Stress Inventory; BEAQ = Brief Experiential Avoidance Questionnaire; CFQ = Cognitive Fusions Questionnaire; VQ-O = Valuing Questionnaire - Obstruction; MAAS-A = Mindful Attentive Awareness Scale - Adolescent; SIQ = Suicidal Ideation Questionnaire 


\section{CHAPTER V}

\section{DISCUSSION}

Minority stress in the LGB+ community has been considered in many studies and is associated with several harmful outcomes (Boyle et al., 2017; Conlin et al., 2019; Haas et al., 2011; Meyer, 2003). This study proposed to further explain how minority stress influences outcomes in LGB+ adolescents. Psychological inflexibility was investigated as a moderating psychological process that could help advance the understanding of minority stress's relationship with harmful outcomes. It was discovered that global psychological inflexibility may moderate the relationship minority stress has with harmful behaviors. However, global psychological inflexibility was shown to interact with the outcome variables conditionally, meaning it does not influence the strength of the relationship between minority stress and harmful behaviors ubiquitously. Specifically, this study found that global psychological inflexibility has a significant moderating effect on the relationship between minority stress and substance misuse (see Table 4) but not on the relationship between minority stress and suicidality (see Table 5). This general moderating effect was small and positive, suggesting that greater levels of global psychological inflexibility modestly strengthens the relationship between minority stress and substance misuse.

When looking at the sub-processes of global psychological inflexibility, a more comprehensive understanding of the mechanisms that drive the global moderating effect can be explored. Assessing the degree to which each sub-process of psychological inflexibility differentially relates to minority stress and harmful outcomes may offer clues 
for researchers and practitioners about what processes to target when providing ACT with LGB+ adolescents. Again, significant interactions between sub-processes and minority stress were only found in the models predicting substance misuse as the outcome (see Table $6 \&$ Table 7) and did not evidence any meaningful moderation when predicting suicidality (see Table $8 \&$ Table 9). Within the variables of the substance misuse models (both with and without covariates), only cognitive fusion and obstruction of valued living were identified as having significant interactions with minority stress. Both of these moderating effects were small and positive (see Figure $8 \& 10$ ), suggesting that higher levels of cognitive fusion and obstruction of valued living may modestly influence the relationship between minority stress and substance misuse. Overall, it appears that global psychological inflexibility, and two of its sub-processes, play a small role in moderating the relationship between minority stress and substance misuse, but not suicidality.

In terms of the suicidality models, a number of significant direct effects were found for psychological inflexibility. Model 2 showed that global psychological inflexibility had a medium positive effect on suicidality, suggesting higher levels of psychological inflexibility may moderately predict more suicidal ideation (see Table 5). The relationship between cognitive fusion and suicidality and experiential avoidance and suicidality in Models 4-A through 4-E also demonstrated significant direct effects (see Table 8). Additionally, obstruction of valued living was found to directly affect suicidality in Model 4-I (see Table 9). While interactions in substance misuse models supported the research hypotheses, those in the suicidality models did not. However, significant direct effects, which were not included in the research hypotheses, were 
discovered and will be discussed below, following further interpretation of the interactions.

By first examining these interactions from a broader perspective of global psychological inflexibility, a look into the effects prejudice, discrimination, and societal pressures has on one's behaviors when they do not subscribe to the majority group is presented. Though no direct effect of minority stress on substance misuse in the model looking at interactions of global psychology inflexibility was found (Model 1; see Table 4), psychological inflexibility did significantly affect substance misuse in the model looking solely at direct effects without any interaction analysis (Model 3-A; see Table 6). That said, the interaction between psychological inflexibility and minority stress was shown to be significant in their relationship with substance misuse, and main effects alongside significant interactions should be further scrutinized. Further examination of interaction plots supports the hypothesis that rates of substance misuse increase as minority stress increases, with growth differentials positively associated with higher levels of inflexibility (see Figure 6). These findings suggest that adolescents who have higher scores of global psychological inflexibility have no higher risk for substance misuse until their experiences of minority stress rise. While we know LGB+ populations have higher rates of substance misuse (King et al., 2008), this study contributes to the literature by showing that this phenomenon may be partially explained by variable interactions, like minority stress and psychological inflexibility. Thus, an understanding of LGB+ adolescent's higher rates of substance misuse may benefit from considering the interplay of societally driven factors, such as stigma, prejudice, heteronormativity, 
rejection, and internalized homophobia, along with more global processes, such as psychological inflexibility.

When looking at the sub-processes that comprise global psychological inflexibility, cognitive fusion and obstruction of valued living were identified as the only two that significantly moderated the relationship between minority stress and substance misuse. Both variables interacted with minority stress in a positive manner (Figure $8 \&$ 10), meaning that as minority stress increased, so did rates of substance misuse, at a degree partially determined by obstruction of valued living and cognitive fusion. These findings partially support the study's hypotheses in both instances, demonstrating higher ratings of obstructed valued living and cognitive fusion moderated the relationship between minority stress and substance misuse. However, moderating effects were not demonstrated for the other key sub-processes of psychological inflexibility: mindful attention and experiential avoidance.

As mentioned in the introduction, the relationships and influences of cognitive fusion and obstruction of valued living along with other common problems seen in this population (e.g., distress, depression, anxiety) is often cyclical, with each influencing the other. In Model 3-B and 3-D, the finding that cognitive fusion and obstruction of valued living were identified as having significant interactions with minority stress may be supported by the current literature. For instance, Hatzenbuehler et al. (2009) found that LGB+ individuals with more implicit homonegative attitudes engaged in significantly more rumination, a behavior commonly associated with cognitive fusion. Toomey et al. (2018) explained substance abuse in LGB+ populations as a coping skill that provides a 
refuge from these preoccupations and reservations regarding internalized feelings about sexuality. In LGB+ populations, there is thus more to worry about, with greater amounts of stress, which can be more difficult to handle appropriately (Meyer, 2003). This explanation may describe the interaction between minority stress and cognitive fusion in terms of substance misuse: the inhibitory effects of alcohol may allow for a reprieve and refuge from overbearing thoughts that might burden someone in the LGB+ community.

The interaction of obstruction of valued living and minority stress in the relationship with substance misuse is also likely understandable through past research. The interaction of obstruction of valued living could be explained by LGB + adolescents' concealment and the inability or unwillingness to be open about their identity. In the context of such concealment, misusing substances may inhibit one's cognitive functions, anxieties, and mental restraints to a degree that allows for engagement in actions consistent with identity and community culture. Thus, substance misuse may increase as minority stress and obstructed valued living do too. For example, a closeted adolescent faced with high levels of minority stress, like family rejection or internalized homonegativity, may only feel comfortable living authentically when they lower their inhibitions through the use of alcohol or other substances. Rosario et al. (2004) described in detail the associations of psychological distress during the "coming out" process in LGB + populations, which consists of stages that are gradual and often overlap with identity development and understanding of oneself. Living consistently with personal values can be complicated through the "coming out" phase, as individuals are beginning to discover themselves and what they value in terms of their sexual orientation. 
Researchers have written about the psychological distress that ensues when there is incongruence in one's personal beliefs and values and their sexual orientation (Meyer, 2003). Rosario et al. (2004) posit that these incongruences continue to exist until LGB+ individuals begin engaging in supportive activities consistent with their sexual identities, which is synonymous with valued living.

This move toward committed action in line with one's values is an important first step in finding harmony between one's personal identity and beliefs. This action often begins in bars and clubs, where alcohol can be used as a coping mechanism to reduce the pressure of interacting with an unfamiliar community (Boyle et al., 2017). Boyle et al. (2017) studied these behaviors in adults. When extended to adolescents, it could manifest as similar community engagement but in age-appropriate settings, such as parties or clubs. The result is creating LGB+ "safe places" that exist in areas of heavy drinking and drug use. While this first step in engaging with the LGB+ community may seem in line with valued living, this stage of the "coming out" process is often associated with concealment, a spike in psychological distress, cutting ties with heterosexual peers, heavy use of alcohol, and engagement in only LGB+ community activities (Rosario et al., 2004). For example, an individual in this stage may begin engaging with their community at parties, clubs, or bars, but at the expense of other values, like cutting ties with heterosexual loved ones because they are not ready to "come out." As LGB+ individuals become more comfortable in their community and with themselves, progress toward valued living generalizes to other aspects of life and represents a pattern of behaviors more consistent with personal values, which also incorporates other members from within 
the LGB+ community. This progression from concealment to disclosure, and potential inhibiting role of alcohol throughout, may offer one explanation for the interaction seen in obstruction of valued living, minority stress, and their relationship with substance misuse.

Although interactions throughout Models 1 and 3 demonstrated positive relationships between global psychological inflexibility, its sub-processes, and minority stress on substance misuse, a different pattern of effects was observed for suicidality. No significant interactions in global psychological inflexibility nor its sub-processes were evidenced in the relationship between minority stress and suicidality, but a few direct effects were discovered. Global psychological inflexibility significantly affected ratings of suicidality, moderately predicting worse suicidal outcomes (see Table 5). This finding is consistent with the literature and past research in non-specific college samples (Krafft et al., 2018). Thus, the lack of interaction effect did not support the hypothesis of this study but was not a surprising result, based on the outcomes of other studies. Additionally, in the regression analysis of psychological inflexibility's sub-processes (Model 4, see Table 8), cognitive fusion and experiential avoidance were both identified as directly related to suicidality. Cognitive fusion is to the tendency to fuse with a thought and subsequently struggle to let it go. Because the SIQ was a measure of suicidal ideation (and not other suicide-related behavior), it is reasonable that cognitive fusion would be positively associated with this. Additionally, rumination and worry, which are behaviors associated with cognitive fusion, are known to be positively associated with suicidal ideation (Morrison \& O’Conner, 2008). It is theorized that suicide is essentially the most 
severe form of experiential avoidance (Chiles \& Strosahl, 2005; Hayes, Pistorello, \& Biglan, 2008) and should therefore be associated with higher ratings of experiential avoidance as measured in this study. Yet in Models 4-A, 4-C, 4-D, and 4E (see Table 8), greater participant ratings of experiential avoidance had negative effects on suicidality, which is contrary to past research (Hayes et al., 2006). However, in Model 4-F (see Table 9), looking at experiential avoidance without psychological inflexibility sub-process covariates, the direction of the effect matched that of the correlation matrix and the theoretic relationship with suicidality. While this finding is curious, it does not require interpretation due to other model findings in the correlation matrices, the uncontrolled analyses, and the theoretical conceptualization of the construct, but is best explained by multicollinearity.

\section{Implications}

Results from this study are exploratory in nature and the majority of implications will best serve future research projects. Overall, these findings suggest variables that might be targeted as therapeutic mechanisms. Global psychological inflexibility is considered the active ingredient of change in ACT. By identifying its moderating effect with minority stress on substance misuse, this study suggests the potential for future applied research looking at the therapeutic effects of ACT in LGB+ adolescents experiencing significant minority stress. However, until further research can be conducted to study the efficaciousness of ACT with LGB+ adolescents experiencing high levels of minority stress, interpretations that this is an actual therapeutic mechanism moderating substance misuse with this population should be taken with caution. 
Additionally, results looking at the differential effects of ACT's sub-processes suggest future research might put further emphasis on cognitive defusion, values, and committed action activities when working in LGB+ populations struggling with alcohol misuse. These foci could potentially create quicker and more engrained goal completion. Again, until applied studies have targeted these findings in controlled therapeutic settings, applications of these findings should be critical and wary. Furthermore, prior to moving to these applied studies, replication and generalization of these basic findings is warranted, especially in light of this study's limitations.

\section{Limitations}

When considering the interpretation and implications of this study, there are several major limitations to keep in mind. First, statistical analyses did not meet residual assumptions, meaning normality of residuals was not met. Due to the exploratory nature of this study, the smallest sample size estimated to acquire significant results was used. However, this sample was not large enough to provide adequate distribution of residuals across all variables or outcomes. Future research would benefit from using larger samples and possibly running polynomial regression models to account for residual deviations. Further limitations include the nature in which data was collected. Purposive sampling procedures were used to access a diverse sample of participants from across the United States through an online paneling company. This method only allowed for individuals with access to internet and computers to participate, and possibly ignored adolescents in lower socio-economic statuses. 
Additional limitations include the way in which variables were conceptualized and the measures chosen to capture these constructs. Psychological inflexibility, the moderating variable of this study, has been broken down into core sub-processes discussed throughout this study. Hayes et al. (2006) have identified six key processes that comprise global psychological inflexibility: experiential avoidance, cognitive fusion, lack of values, preoccupation with past or future, attachment to the conceptualized self, and inaction. The sub-process variables are all intended to work together to inform change in global psychological inflexibility, and for that reason, sub-process interaction models were run to account for covariate effects of sub-processes when considered in the context of each other. However, because of the complicated nature of one of the six subprocesses - attachment to the conceptualized self — and the lack of reliable measurement in adolescent samples, data was not collected on this construct. Additionally, due to the overlap in measurement of lack of values and inaction, it was decided that measurement of obstruction of valued living was sufficient to capture both. Because of these decisions, analyses were unable to account for all of the sub-processes comprising global psychological inflexibility. While it is the hope of this study to inform future practice and research, this study fails to comprehensively represent the breadth of ACT processes targeted during treatment.

Furthermore, this study was approached from a deficits-based model, looking at the mechanism of change in ACT as global psychological inflexibility (undesirable) as opposed to flexibility (desirable). Many ACT-based models in research view the change through a strengths-based lens, with global psychological flexibility as the overarching 
process and acceptance, defusion, values, present moment awareness, self as context, and committed action as the sub-processes. Difference in measurement valence (undesirable vs. desirable) and item phrasing could potentially influence respondent answers and study outcomes. Therefore, future research replicating this model with a strengths-based approach to measurement is suggested. This study chose reliable and valid measures for measuring psychological inflexibility that were mostly normed with adolescent samples. But a strengths-based approach may be more challenging to measure, as not all variables have multiple measures to choose from. Another approach for future research would be to model both deficit-based and strength-based approaches simultaneously, comparing the results found alone and together. For example, the Multidimensional Psychological Flexibility Inventory (MPFI; Rolffs et al., 2016) looks at both psychological inflexibility and flexibility, attempting to measure both sides of the key dimensions of flexibility addressed through ACT using 12 subscales. While this format of measurement could offer new perspectives to the questions addressed in this study, the MPFI has yet to be validated with adolescents. Like the MPFI, several other measures of psychological flexibility have also yet to be validated with youth, leaving the AFQ-Y8 as the prime choice for the present study.

Similarly, the SMASI was chosen to assess minority stress because it has been validated with adolescents and offered a total minority stress score. That said, there are other minority stress measures that should be considered in future research, including the Gay-related Stressful Life Events Scale (Rosario et al., 2002), the Heterosexist Harassment, Rejection and Discrimination Sale (Szymanski, 2009), The Daily 
Heterosexist Experiences Questionnaire (Balsam et al., 2013), and the LGBT People of Color Microaggressions Scale (Balsam et al., 2011) that look at additional aspects of minority stress, including racial and ethnic intersectionality. Ultimately, the measures in this study were chosen due to reliability, accessibility, readability, length, and validity; however, results found in this study would benefit from being tested with other scales measuring the same constructs.

\section{Conclusion}

Adolescence is a difficult time, especially for those who identify as LGB+. Increased rates of substance abuse and suicidality are well documented outcomes that tend to be worse in the LGB+ adolescent community than in mainstream groups. Minority stress has been accepted within the research community as a theory to explain the health disparities seen in this group. Psychological inflexibility and five of its six key sub-processes (experiential avoidance, cognitive fusion, lack of values, preoccupation with the past or future, and inaction) was posited as a moderator in the relationship between minority stress and substance misuse or suicidality.

This study found that global psychological inflexibility, cognitive fusion, and obstruction of valued living did indeed have significant positive interactions with minority stress in the relationship with substance misuse. Though no interactions were found in suicidality, moderate to small direct effects of global psychological inflexibility, cognitive fusion, and experiential avoidance were discovered. Implications suggest that psychological inflexibility as mechanism of change in LGB+ adolescents is worth further study. Preliminary analyses imply psychological inflexibility explains a small significant 
portion of minority stress' effect on the harmful outcome of substance misuse. Further study into the effectiveness of ACT in LGB+ populations struggling with minority stress' effects and/or substance misuse should be conducted to better understand the implication of these results. Sample size, valence, and measure selection are possible limitations to the current study.

While this study is limited, it is hopeful that these exploratory results open a door for future research that can replicate and improve procedures toward a growth-minded, empirically based dialogue toward healing in this vulnerable community. 


\section{REFERENCES}

Baams, L., Grossman, A. H., \& Russell, S. T. (2015). Minority stress and mechanisms of risk for depression and suicidal ideation among lesbian, gay, and bisexual youth. Developmental Psychology, 51(5), 688-696.

Babor, T.F., Higgins-Biddle, J.C., Saunders, J.B. and Monteiro, M.G. (2001) The Alcohol Use Disorders Identification Test (AUDIT) manual: Guidelines for use in primary care. 2nd Edition, Department of Mental Health and Substance Dependence. World Health Organization, Geneva, WHO/MSD/MSB/01.6a, 4-32.

Balsam, K. F., Molina, Y., Beadnell, B., Simoni, J., \& Walters, K. (2011). Measuring multiple minority stress: the LGBT People of Color Microaggressions Scale. Cultural diversity \& ethnic minority psychology, 17(2), 163174. https://doi.org/10.1037/a0023244

Balsam, K. F., Beadnell, B., \& Molina, Y. (2013). The Daily Heterosexist Experiences Questionnaire: Measuring Minority Stress Among Lesbian, Gay, Bisexual, and Transgender Adults. Measurement and evaluation in counseling and development: the official publication of the Association for Measurement and Evaluation in Counseling and Development, 46(1), 3-25. https://doi.org/10.1177/0748175612449743

Berzonsky, M. D., \& Cieciuch, J. (2016). Mediational role of identity commitment in relationships between identity processing style and psychological well-being. Journal of Happiness Studies, 17, 145-162. https://doi.org/10.1007/s10902-0149588-2 
Boyle, S. C., Labrie, J. W., Costine, L. D., \& Witkovic, Y. D. (2017). “It's how we deal”: Perceptions of LGB peers' use of alcohol and other drugs to cope and sexual minority adults' own coping motivated substance use following the Pulse nightclub shooting. Addictive Behaviors, 65, 51-55.

https://doi.org/10.1016/j.addbeh.2016.10.001

Brown, K. W., \& Ryan, R. M. (2003). The benefits of being present: Mindfulness and its role in psychological well-being. Journal of Personality and Social Psychology, 84, 822-848. doi:10.1037/0022- 3514.84.4.822

Brown, K. W., West, A. M., Loverich, T. M., Biegel, G. M., Hospital, K. P., \& Jose, S. (2011). Assessing adolescent mindfulness: Validation of an adapted Mindful Attention Awareness Scale in adolescent normative and psychiatric populations. Psychological Assessment, 23(4), 1023-1033. https://doi.org/10.1037/a0021338

Caputi, T. L., Smith, L. R., Strathdee, S. A., \& Ayers, J. W. (2018). Substance use among lesbian, gay, bisexual, and questioning adolescents in the United States, 2015. American Journal of Public Health, 108(8), 1031-1034. https://doi.org/10.2105/AJPH.2018.304446

Centers for Disease Control and Prevention. (2016a). Sexual identity, sex of sexual contacts, and health-risk behaviors among students in 9-12: Youth risk behavior surveillance. Atlanta, GA: U.S. Department of Health and Human Services

Centers for Disease Control and Prevention. (2016b). WISQARS leading causes of death reports. Atlanta, GA: U.S. Department of Health and Human Services 
Christie, A. M., Atkins, P. W. B., \& Donald, J. N. (2017). The meaning and doing of mindfulness: The role of values in the link between mindfulness and well-being. Mindfulness, 8(2), 368-378. https://doi.org/10.1007/s12671-016-0606-9.

Chiles, J. A., \& Strosahl, K. D. (2005). Clinical manual for assessment and treatment of suicidal patients. Washington, DC: American Psychiatric Pub.

Chou, W., Yen, C., \& Liu, T. (2018). Predicting effects of psychological inflexibility/experiential avoidance and stress coping strategies for internet addiction, significant depression, and suicidality in college students: A prospective study. International Journal of Environmental Research and Public Health, 15(788), 1-11. https://doi.org/10.3390/ijerph15040788

Cochran, S. D., Mays, V. M., \& Sullivan, J. G. (2003). Prevalence of mental disorders, psychological distress, and mental health services use among lesbian, gay, and bisexual adults in the United States. Journal of Consulting and Clinical Psychology, 71(1), 53-61.

Cochran, S. D., Mays, V. M., Alegria, M., Ortega, A. N., \& Takeuchi, D. (2007). Mental health and substance use disorders among Latino and Asian American lesbian, gay, and bisexual adults. Journal of Consulting and Clinical Psychology, 75(5), 785-794. https://doi.org/10.1037/0022-006X.75.5.785

Conlin, S. E., Douglass, R. P., Ouch, S. (2019). Discrimination, subjective wellbeing, and the role of gender : A mediation model of LGB minority stress. Journal of Homosexuality, 66(2), 238-259. https://doi.org/10.1080/00918369.2017.1398023 
Dai, H. (2017). Tobacco product use among lesbian, gay, and bisexual adolescents.

Pediatrics, 139(4), 1-8. https://doi.org/10.1542/peds.2016-3276

Darlington, R.B. \& Hayes, A.F. (2017). Regression Analysis and Linear Models:

Concepts, Applications, and Implementation. New York: The Guilford Press.

De Vries, A. L. C., Kreukels, B. P. C., Steensma, T. D., Doreleijers, T. A. H., \& CohenKettenis, P. T. (2011). Comparing adult and adolescent transsexuals: An MMPI-2 and MMPI-A study. Psychiatry Research, 186(2-3), 414-

418. https://doi.org/10.1016/j.psychres.2010.07.033

Esser, M. B., Clayton, H., Demissie, Z., Kanny, D., \& Brewer, R. D. (2017). Current and Binge Drinking Among High School Students - United States, 19912015. MMWR: Morbidity \& Mortality Weekly Report, 66(18), 474478. https://doi-org.dist.lib.usu.edu/10.15585/mmwr.mm6618a4

Fischer, T. D., Smout, M. F., \& Delfabbro, P. H. (2016). The relationship between psychological flexibility, early maladaptive schemas, perceived parenting and psychopathology. Journal of Contextual Behavioral Science, 5, 169-177. https://doi.org/10. 1016/j.jcbs.2016.06.002.

Gámez, W., Chmielewski, M., Kotov, R., Suzuki, N., \& Watson, D. (2014). The Brief Experiential Avoidance Questionnaire: Development and initial validation. Psychological Assessment, 26(1), 35-45. https://doi.org/10.1037/a0034473

Ghasemi, A., \& Zahediasl, S. (2012). Normality tests for statistical analysis: a guide for non-statisticians. International journal of endocrinology and metabolism, 10(2), 486-489. https://doi.org/10.5812/ijem.3505 
Gillanders, D. T., Bolderston, H., Bond, F. W., Dempster, M., Flaxman, P. E., Campbell, L., ... Remington, B. (2014). The development and initial validation of the Cognitive Fusion Questionnaire. Behavior Therapy, 45(1), 83-101. https://doi.org/10.1016/j.beth.2013.09.001

Gonzales, G., \& Henning-Smith, C. (2017). Health disparities by sexual orientation: Results and implications from the behavioral risk factor surveillance system. Journal of Community Health, 42(6), 1163-1172. https://doi.org/10.1007/s10900$\underline{017-0366-\mathrm{Z}}$

Greco, L. A., Lambert, W., \& Baer, R. A. (2008). Psychological inflexibility in childhood and adolescence: Development and evaluation of the Avoidance and Fear Questionnaire for Youth. Psychological Assessment, 20, 93-102. doi:10.1037/1040-3590.20.2.93

Green, K. E., \& Feinstein, B. A. (2012). Substance use in lesbian, gay, and bisexual populations: An update on empirical research and implications for treatment. Psychology of Addictive Behaviors, 26(2), 265-278. https://doi.org/10.1037/a0025424

Goldbach, J. T., Schrager, S. M., Mamey, M. R. (2017). Criterion and divergent validity of the Sexual Minority Adolescent Stress Inventory. Frontiers in psychology, 8, 2057.

Haas, A. P., Eliason, M., Mays, V. M., Mathy, R. M., Cochran, S. D., D’Augelli, A. R., ... Clayton, P. J. (2011). Suicide and suicide risk in lesbian, gay, bisexual, and 
transgender populations: Review and recommendations. Journal of Homosexuality, 58(1), 10-51. https://doi.org/10.1080/00918369.2011.534038

Hayes, A. F. (2017). Methodology in the social sciences. Introduction to mediation, moderation, and conditional process analysis: A regression-based approach, $2^{\text {nd }}$ Edition. New York, NY, US: Guilford Press.

Hayes, S. C., Luoma, J. B., Bond, F. W., Masuda, A., \& Lillis, J. (2006). Acceptance and commitment therapy: Model, processes and outcomes. Behaviour Research and Therapy, 44, 1-25. doi:10.1016/ j.brat.2005.06.006

Hayes, S. C., Pistorello, J., \& Biglan, A. (2008). Acceptance and commitment therapy: Model, data, and extension to the preven- tion of suicide. Revista Brasileira de Terapia Comportamental e Cognitiva, 10. Retrieved from http://usp.br/rbtcc/index.php/ RBTCC/article/download/329/269

Hrehorciuc-Caragea, A., \& White, L. T. (2017). An investigation of the relationship between psychological flexibility and bisexuality. Journal of Bisexuality, 17(4), 473-486. https://doi.org/10.1080/15299716.2017.1377137

King, M., Semlyen, J., Tai, S. S., Killaspy, H., Osborn, D., Popelyuk, D., \& Nazareth, I. (2008). A systematic review of mental disorder, suicide, and deliberate self harm in lesbian, gay and bisexual people. BMC Psychiatry, 8, 1-18. https://doi.org/10.1186/1471-244X-8-70

Knight, J. R., Sherritt, L., Kim Harris, S., Gates, E. C., \& Chang, G. (2006). Validity of brief alcohol screening tests among adolescents: A comparison of the AUDIT, 
POSIT, CAGE, and CRAFFT. Alcoholism: Clinical and Experimental Research, 27(1), 67-73. https://doi.org/10.1111/j.1530-0277.2003.tb02723.x

Krafft, J., Hicks, T., Mack, S., \& Levin, M. (2018). Psychological inflexibility predicts suicidality over time in college students. The American Association of Suicidology, 1-9. https://doi.org/10.1111/sltb.12533

Leleux-labarge, K., Hatton, A. T., Goodnight, B. L., \& Masuda, A. (2015). Psychological distress in sexual minorities: Examining the roles of self-concealment and psychological inflexibility. Journal of Gay \& Lesbian Mental Health, 19(1), 4054. https://doi.org/10.1080/19359705.2014.944738

Levin, M. E., Lillis, J., Seeley, J., Hayes, S. C., Pistorello, J., \& Biglan, A. (2012). Exploring the relationship between experiential avoidance, alcohol use disorders, and alcohol-related problems among first-year college students. Journal of American College Health, 60(6), 443-448.

Levin, M. E., Maclane, C., Daflos, S., Seeley, J. R., Hayes, S. C., Biglan, A., \& Pistorello, J. (2014). Examining psychological inflexibility as a transdiagnostic process across psychological disorders. Journal of Contextual Behavioral Science, 3, 155-163. https://doi.org/10.1016/j.jcbs.2014.06.003

Livheim, F., Tengström, A., Bond, F. W., Andersson, G., Dahl, J., \& Rosendahl, I. (2016). Psychometric properties of the Avoidance and Fusion Questionnaire for Youth: A psychological measure of psychological inflexibility in youth. Journal of Contextual Behavioral Science, 5(2), 103-110.

https://doi.org/10.1016/j.jcbs.2016.04.001 
Livingston, N. A., Christianson, N., \& Cochran, B. N. (2016). Minority stress, psychological distress, and alcohol misuse among sexual minority young adults: A resiliency-based conditional process analysis. Addictive Behaviors, 63, 125131. https://doi.org/10.1016/j.addbeh.2016.07.011

Masuda, A., Anderson, P. L., Wendell, J. W., Chou, Y., Price, M., \& Feinstein, A. B. (2011). Psychological flexibility mediates the relations between self-concealment and negative psychological outcomes. Personality and Individual Differences, 50(2), 243-247. https://doi.org/10.1016/j.paid.2010.09.037

Marshal, M. P., Friedman, M. S., Stall, R., King, K. M., Miles, J., Gold, M. A., ... Morse, J. Q. (2008). Sexual orientation and adolescent substance use: A meta-analysis and methodological review. Addiction, 103(4), 546-556.

https://doi.org/10.1111/j.1360-0443.2008.02149.x

Marshal, M. P., Friedman, M. S., Stall, R., \& Thompson, A. L. (2009). Individual trajectories of substance use in lesbian, gay and bisexual youth and heterosexual youth. Addiction, 104(6), 974-981. https://doi.org/10.1111/j.1360$\underline{0443.2009 .02531 . x}$

McCabe, S. E., Bostwick, W. B., Hughes, T. L., West, B. T., \& Boyd, C. J. (2010). The relationship between discrimination and substance use disorders among lesbian, gay, and bisexual adults in the United States. American Journal of Public Health, 100(10), 1946-1952. https://doi.org/10.2105/AJPH.2009.163147 
McCabe, S. E., Boyd, C., Hughes, T. L., \& D’Arcy, H. (2003). Sexual identity and substance use among undergraduate students. Substance Abuse, 24(2), 77-91. https://doi.org/10.1023/A:1023768215020

Meeus, W. (2011). The study of adolescent identity formation 2000 - 2010: A review of longitudinal research. Journal of Research on Adolescence, 21(1), 75-94. https://doi.org/10.1111/j.1532-7795.2010.00716.x

Mericle, A. A., Arria, A. M., Meyers, K., Cacciola, J., Winters, K. C., \& Kirby, K. (2015). National trends in adolescent substance use disorders and treatment availability: 2003-2010. Journal of child \& adolescent substance abuse, 24(5), 255-263. doi:10.1080/1067828X.2013.829008

Meyer, I. H. (2003). Prejudice, social stress, and mental health in lesbian, gay, and bisexual populations: Conceptual issues and research evidence. Psychological Bulletin, 129(5), 674-697. https://doi.org/10.1037/0033-2909.129.5.674

Meyer, H., Dietrich, J., \& Schwartz, S. (2008). Lifetime prevalence of mental disorders and suicide attempts in diverse lesbian, gay, and bisexual populations. American Journal of Public Health, 98(6), 1004-1007.

https://doi.org/10.2105/AJPH.2006.096826

Michaels, C. (2018). Testing a structural model of LGB minority stress to assess on stress-related growth and life satisfaction (Unpublished doctoral dissertation). New Mexico State University, Las Cruces, NM. 
Morrison R., O'Connor R.C. (2008). A systematic review of the relationship between rumination and suicidality. Suicide Life-Threatening Behavior, 38, 523-538. http://dx.doi.org/10.1521/ suli.2008.38.5.523.

Mosher, C. E., Tometich, D. B., Hirsh, A., Rand, K. L., Johns, S. A., Matthias, M. S., \& Miller, K. (2016). Symptom experiences in metastatic breast cancer patients: Relationships to activity engagement, value-based living, and psychological inflexibility. Psycho-Oncology. https://doi.org/10.1002/pon.4283.

Nock, M. K., Green, J. G., Hwang, I., McLaughlin, K. A., Sampson, N. A., Zaslavsky, A. M., \& Kessler, R. C. (2013). Prevalence, correlates, and treatment of lifetime suicidal behavior among adolescents: Results from the National Comorbidity Survey Replication Adolescent Supplement. JAMA Psychiatry, 70(3), 300310. https://doi-org.dist.lib.usu.edu/10.1001/2013.jamapsychiatry.55

Osman A (2002), Suicide Behavior Questionnaire-Revised (SBQ-R) University of Northern Iowa, Dept. of Psychology. Available from Auguston Osman, PhD, Department of Psychology, University of Northern Iowa, Cedar Falls, IA 50614; augustin.osman@uni.edu

Osman, A., Bagge, C. L., Gutierrez, P. M., Konick, L. C., Kopper, B. A., \& Barrios, F. X. (2001). The Suicidal Behaviors Questionnaire-Revised (SBQ-R): Validation with clinical and nonclinical samples. Assessment, 8(4), 443-454.

Pachankis, J. E., Hatzenbuehler, M. L., \& Starks, T. J. (2014). The influence of structural stigma and rejection sensitivity on young sexual minority men's daily tobacco and 
alcohol use. Social Science and Medicine, 103, 67-75.

https://doi.org/10.1016/j.socscimed.2013.10.005

Pachankis, J. E., Hatzenbuehler, M. L., Rendina, H. J., Safren, S. A., \& Parsons, J. T. (2015). LGB-Affirmative Cognitive-Behavioral Therapy for young adult gay and bisexual men: A randomized controlled trial of a transdiagnostic minority stress approach. Journal of Consulting And Clinical Psychology, 83(5), 875-889.

Paul, J. P., Catania, J., Pollack, L., Moskowitz, J., Canchola, J., Mills, T., \& Binson, D. (2002). Suicide attempts among gay and bisexual men: Lifetime prevalence and antecedents. American Journal of Public Health, 92(8), 1338-1346.

Perkins, H. W. (2002). Surveying the damage: A review of research on consequences of alcohol misuse in college populations. Journal of Studies on Alcohol, 14, 91-100.

Pinto, A., Whisman, M. A., \& McCoy, K. J. M. (1997). Suicidal ideation in adolescents: Psychometric properties of the Suicidal Ideation Questionnaire in a clinical sample. Psychological Assessment, 9(1), 63-66.

Remafedi, G. (2002). Suicidality in a venue-based sample of young men who have sex with men. Journal of Adolescent Health, 31(04), 305-310.

Reynolds W. M. (1987). Suicidal Ideation Questionnaire (SIQ): Professional Manual. Odessa, FL. Psychological Assessment Resources.

Rolffs, J. L., Rogge, R. D., \& Wilson, K. G. (2018). Disentangling Components of Flexibility via the Hexaflex Model: Development and Validation of the Multidimensional Psychological Flexibility Inventory (MPFI). Assessment, 25(4), 458-482. https://doi-org.dist.lib.usu.edu/10.1177/1073191116645905 
Rosario, M., Schrimshaw, E. W., \& Hunter, J. (2004). Predictors of substance use over time among gay, lesbian, and bisexual youths: An examination of three hypotheses. Addictive Behaviors, 29, 1623-1631. https://doi.org/10.1016/j.addbeh.2004.02.032

Rosario, M., Schrimshaw, E. W., Hunter, J., \& Gwadz, M. (2002). Gay-Related Stress and Emotional Distress Among Gay, Lesbian, and Bisexual Youths: A Longitudinal Examination. Journal of Consulting \& Clinical Psychology, 70(4), 967. https://doi-org.dist.lib.usu.edu/10.1037/0022-006X.70.4.967

Russell, I. S. T., \& Joyner, K. (2001). Adolescent sexual orientation and suicide risk: Evidence from a national study. American Journal of Public Health, 91(8), 12761282.

Ryan, C., Huebner, D., Diaz, R. M., \& Sanchez, J. (2009). Family rejection as a predictor of negative health outcomes in White and Latino lesbian, gay, and bisexual young adults. Pediatrics, 123(1), 346-352. https://doi.org/10.1542/peds.2007-3524

Saunders, J. B., Aasland, O. G., Babor, T. F., de la Fuente, J. R., \& Grant, M. (1993). Development of the Alcohol Use Disorders Identification Test (AUDIT): WHO collaborative project on early detection of persons with harmful alcohol consumption-II. Addiction, 88,791-804. http://dx.doi.org/10.1111/j.13600443.1993.tb02093.x.

Schrager, S. M., Goldbach, J. T., Mamey, M. R. (2018). Development of the Sexual Minority Adolescent Stress Inventory. Frontiers in psychology, 9, 319. 
Silenzio, V. M. B., Pena, J. B., Duberstein, P. R., Cerel, J., \& Knox, K. L. (2007). Sexual orientation and risk factors for suicidal ideation and suicide attempts among adolescents and young adults. American Journal of Public Health, 97(11), 20172019. https://doi.org/10.2105/AJPH.2006.095943

Smith, B. C., Armelie, A. P., Boarts, J. M., Brazil, M., \& Delahanty, D. L. (2016). PTSD, depression, and substance use in relation to suicidality risk among traumatized minority lesbian, gay, and bisexual youth. Archives of Suicide Research, 20(1), 80-93. https://doi.org/10.1080/13811118.2015.1004484

Smout, M., Davies, M., Burns, N., \& Christie, A. (2014). Development of the Valuing Questionnaire (VQ). Journal of Contextual Behavioral Science, 3(3), 164-172. https://doi.org/10.1016/j.jcbs.2014.06.001

Szymanski, D. M. (2009). Examining Potential Moderators of the Link Between Heterosexist Events and Gay and Bisexual Men's Psychological Distress. Journal of Counseling Psychology, 56(1), 142-151. https://doiorg.dist.lib.usu.edu/10.1037/0022-0167.56.1.142

Talley, A. E., Hughes, T. L., Aranda, F., Birkett, M., \& Marshal, M. P. (2014). Exploring alcohol-use behaviors among heterosexual and sexual minority adolescents: Intersections with sex, age, and race/ethnicity. American Journal of Public Health, 104(2), 295-303. https://doi.org/10.2105/AJPH.2013.301627

The GenIUSS Group. (2014). Best Practices for Asking Questions to Identify Transgender and Other Gender Minority Respondents on Population-Based Surveys. J.L. Herman (Ed.). Los Angeles, CA: The Williams Institute. 
Toomey, R. B., Ryan, C., Diaz, R. M., Russell, S. T. (2018). Coping with sexual orientation - Related minority stress coping with sexual orientation - Related minority stress. Journal of Homosexuality, 65(4), 484-500. https://doi.org/10.1080/00918369.2017.1321888

Ward, B. W., Dahlhamer, J. M., Galinsky, A. M., \& Joestl, S. S. (2014). Sexual orientation and health among U.S. adults: national health interview survey, 2013. National Health Statistics Reports, (77), 1-10. https://doi.org/10.1016/j.econmod.2011.12.001

Winters, N. C., Myers, K., \& Proud, L. (2002). Ten-year review of rating scales. III: Scales assessing suicidality, cognitive style, and self esteem. Journal of the American Academy of Child \& Adolescent Psychiatry, 41(10), 11501181. https://doi.org/10.1097/00004583-200210000-00006

Wyman, P. A., Brown, C. H., LoMurray, M., Schmeelk-Cone, K., Petrova, M., Yu, Q., ... Wang, W. (2010). An outcome evaluation of the sources of strength suicide prevention program delivered by adolescent peer leaders in high schools. American Journal of Public Health, 100(9), 1653-1661. https://doi.org/10.2105/AJPH.2009.190025

Yadavaia, J. E., \& Hayes, S. C. (2012). Acceptance and commitment therapy for selfstigma around sexual orientation: A multiple baseline evaluation. Cognitive and Behavioral Practice, 19(4), 545-559. https://doi.org/10.1016/j.cbpra.2011.09.002 


\section{APPENDIX A}

\section{Informed Consent}

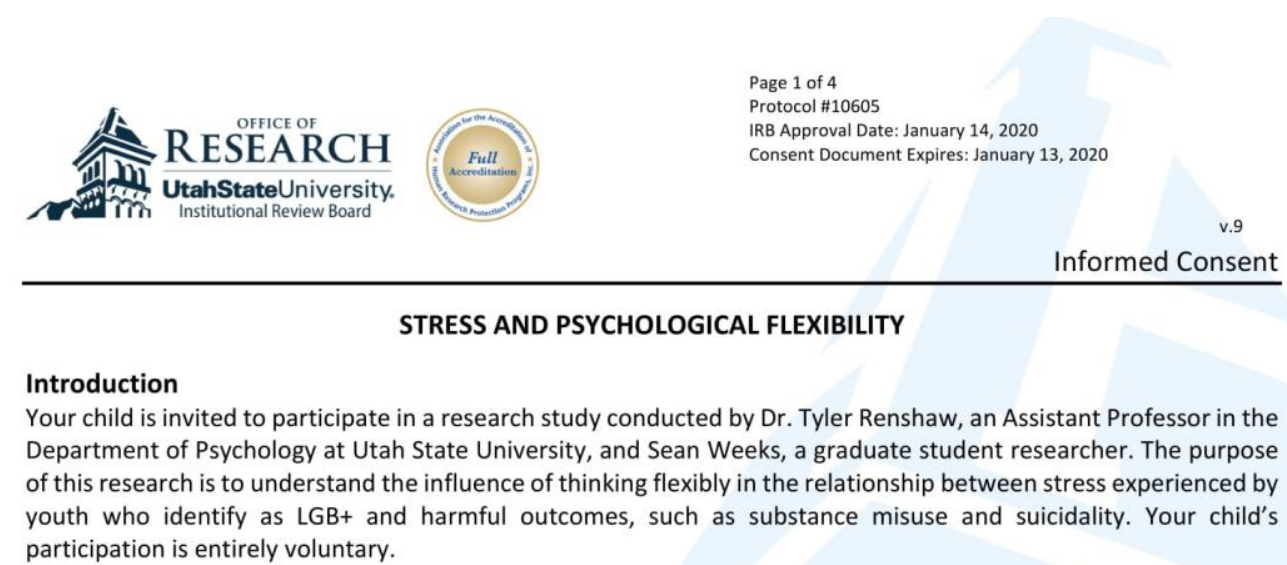
participation is entirely voluntary.

This form includes detailed information on the research to help you decide whether to allow your child to participate. Please read it carefully and ask any questions you have before you agree to participate.

\section{Procedures}

Your child's participation will involve completing nine short surveys asking about thoughts, feelings, and behaviors, and one longer survey about experiences they have had related to their LGB+ identity. If you agree to allow your child to participate, the researchers will also collect information about their age, sexual orientation, race/ethnicity, and gender identity. Your child's total participation in this project will take approximately 20 minutes. We anticipate that 145 people will participate in this research study.

Before you read this form, Qualtrics online survey panels already collected information regarding your child's eligibility for this study, including age and sexual orientation. Researchers will never have personal identifiers regarding your child. Once you have finished signing, please allow your child to complete the rest of the survey by themselves. These questionnaires ask personal questions so please give your child privacy while they fill it out. Feel free to download the "starting a conversation" document (see below) for ideas on how to talk about some of the topics they will be responding to in the survey.

\section{Risks}

This study is greater than minimal risk, meaning that the risks are slightly higher than those you encounter in everyday activities. The foreseeable risks or discomforts include psychological risks (answering deeply personal questions regarding bullying, suicidality, lying, substance use, and sexuality), possible invasion of privacy (if surveys are completed in public places or on public computers), and possible breach of confidentiality. In order to minimize those risks and discomforts, the researchers have provided resources for starting a discussion about tough topics between parents and children, national suicide resources during and after completion of the surveys, and anonymous data collection so answers are never paired with respondent identifying information. We also ask that you allow your child privacy while they complete these surveys. If you have a bad research-related experience, please contact Sean Weeks at snweeks@aggiemail.usu.edu or Dr. Tyler Renshaw at tyler.renshaw@usu.edu. If you are injured in any way, additional compensation is not available. Please see below for resources for suicidality, substance abuse, and assault or harassment.

The National Suicide Prevention Lifeline is 800-273-8255. Other international suicide helplines can be found at befrienders.orq. You can also text TALK to 741741 for free, anonymous $24 / 7$ crisis support in the US from the Crisis $\underline{\text { Text Line }}$

If your child has been the victim of assault, please report the experience to local police as soon as possible by dialing 911. If your child is a student enrolled in a public school and has been a victim of abuse (physical, sexual, or emotional) or harassment at school because of gender, gender expression, or sexual orientation, then your child is protected under Title IX. You can report to the school district's Title IX coordinator to file a complaint and seek accommodations and supports for your child. Local Title IX coordinators can be found at Title IX Locator.

$$
\text { Department of Psychology ｜ psychology.usu.edu ｜ } 2810 \text { Old Main Hill ｜ Logan, UT } 84322
$$



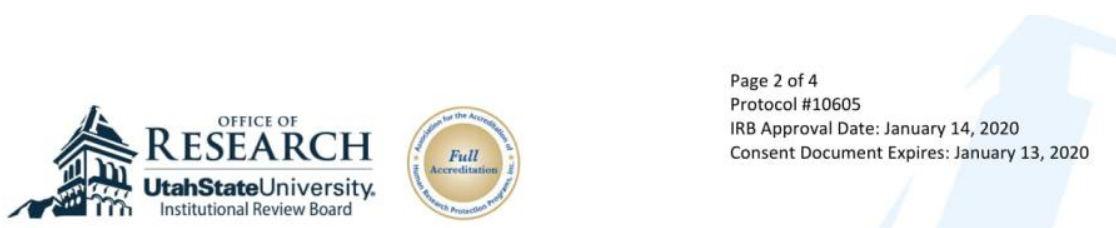

If your child is experiencing mental or behavioral health problems, you can contact the Substance Abuse and Mental Health Services Administration's National Helpline: 1 -800-662-HELP (4357). This hotline is a confidential, free, 24hour-a-day, 365-day-a-year, information service, in English and Spanish, for individuals and family members facing mental and/or substance use disorders. This service provides referrals to local treatment facilities, support groups, and community-based organizations. Callers can also order free publications and other information. You can also locate service providers by visiting online treatment locators.

\section{Benefits}

Although you will not directly benefit from this study, it has been designed to learn more about what inspires change in behaviors related to LGB+ youth who experience minority stress. We intend to use the results of this study to help develop effective supports for LGB+ youth.

\section{Confidentiality}

The researchers will make every effort to ensure that the information your child provides as part of this study remains confidential. The researchers will not collect any personally identifying information and so you and your child's identity will not be revealed in any publications, presentations, or reports resulting from this research study. Additionally, you will not have access to the survey or your child's responses after they complete the survey. You can learn more about the topics your child is asked about in the survey by downloading and reading the "starting a conversation" document (see below).

We will collect your child's information through online survey panels. Online activities always carry a risk of a data breach, but we will use systems and processes that minimize breach opportunities. This data will be securely stored in a restricted-access folder on Box.com, an encrypted, cloud-based storage system. Your digital signature to this form will be kept for three years after the study is complete, and then it will be destroyed.

It is unlikely, but possible, that others (Utah State University or state or federal officials) may require us to share the information your child gives us from the study to ensure that the research was conducted safely and appropriately. We will only share your child's information if law or policy requires us to do so.

\section{Voluntary Participation \& Withdrawal}

Your child's participation in this research is completely voluntary. If you agree to allow your child to participate now and change your mind later, they may withdraw at any time by exiting out of the survey. If your child chooses to withdraw from the study before fully completing the surveys, then any data already collected will be discarded and compensation will not be distributed.

\section{Payment}

For your child's participation in this research study, financial compensation will be received as stated by the online paneling service. Payment is only issued if your child completes the survey fully with quality. After your child answers the survey the entire way through, the researchers will have time to look through the data and decide who is a quality data point (e.g., by conducting time-to-completion checks and looking at variability in response patterns). Most of the time, it is almost all participants that receive compensation if they complete the survey. No other forms of compensation will be provided for participating in this study.

\section{Findings}

Identifiers will never be collected or associated with your child's information. These de-identified data may be used or distributed for future research without additional consent from you. If you do not wish for us to use your child's information in this way, please state so below.

IRB Review 


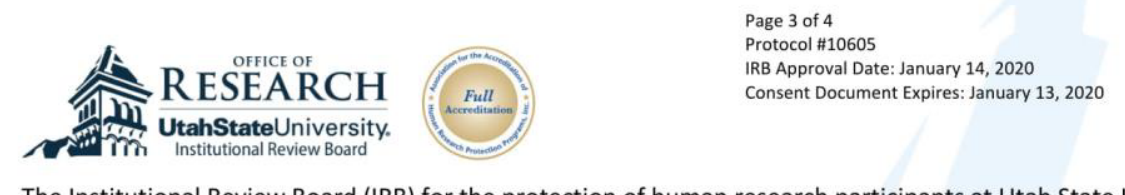

The Institutional Review Board (IRB) for the protection of human research participants at Utah State University has reviewed and approved this study. If you have questions about the research study itself, please contact the Principal Investigator at tyler.renshaw@usu.edu. If you have questions about your rights or would simply like to speak with someone other than the research team about questions or concerns, please contact the IRB Director at (435) 7970567 or irb@usu.edu.

Tyler Renshaw, PhD

Principal Investigator

(435) 757-6324; tyler.renshaw@usu.edu

\section{Sean Weeks}

Lead Graduate Student Researcher

snweeks@aggiemail.usu.edu

\section{Informed Consent}

By typing your name below, you agree to allow your child to participate in this study. You indicate that you understand the risks and benefits of participation, and that you know what they will be asked to do. You also agree that you have asked any questions you might have, and are clear on how to stop your child's participation in the study if you choose to do so. Below is a downloadable copy of the consent form. Please be sure to save and print a copy of this form for your records. 


\section{APPENDIX B}

\section{Informed Assent}
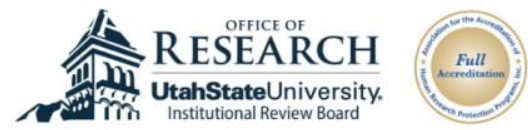

Page 4 of 4

Protocol \#10605

IRB Approval Date: January 14, 202

Consent Document Expires: January 13, 2020

Youth Assent

Dr. Tyler Renshaw and Sean Weeks at Utah State University are doing a research study about how stress leads to harmful behaviors. Research studies help us learn more about people. If you would like to be a part of this research study, you will complete nine surveys on your computer about your thoughts, feelings, and behaviors. This study should take approximately 20 minutes to finish.

When the researchers do things like collecting personal information from people, some other things could happen. For example, answering tough personal questions might bring up unwanted feelings or make you think hurtful thoughts. Also, information collected online can sometimes end up in the wrong hands or a parent might look over your shoulder while you are answering questions and see something you did not want them to. We will do everything we can to prevent those things from happening, but there is still a chance, so we want you to know that first. We recommend going to a private place, like your room or a quiet area, to take the survey. We asked that your parents give you privacy, but you can also ask for privacy while taking these questionnaires. If questions make you feel sad or uncomfortable, please reach out to your parents or an adult who you feel comfortable talking to about your feelings.

Not everyone who is a part of research studies receives something good from it. In this study, nothing directly good will happen to you, but you will help us learn more about people like you. Also, we will tell other people about what we learned from doing this study with you and the 145 other people who are in the study, but we won't tell anyone your name or that you were in the study.

If this sounds like something you would like to do, and you feel like you understand everything in this form, you can participate. You do not have to be in this study if you do not want to be. If you decide to stop after we begin, you just need to exit out of the survey on your computer. No one will be upset if you don't want to do this. Also, nothing will happen if you change your mind later and choose to exit out of the survey before finishing. It's all up to you.

You can ask any questions you have, now or later, by emailing Sean Weeks at snweeks@aggiemail.usu.edu or Dr. Tyler Renshaw at tyler.renshaw@usu.edu. Your parents know about this research study, and they have said you can participate, if you want. Your parents will never see your answers, but you can talk with them about the survey when you're done, if you choose.

By clicking "YES" below, you agree to participate in this study. If you do not want to participate, you can click "NO" and then exit out of the survey on your computer. By clicking "YES," you're showing that you understand the risks and benefits of participation, and that you know what you will be asked to do. You also agree that you have asked any questions you might have, and that you are clear on how to stop your participation in the study if you choose to do so. Below is a downloadable copy of this assent form. Please be sure to save and print a copy of this form for your records. 


\title{
APPENDIX C
}

\section{The Sexual Minority Adolescent Stress Inventory (SMASI)}

\author{
The Sexual Minority Adolescent Stress Inventory (SMASI)
}

We'd Illke to understand more about stress experienced by LGBTQ youth. This survey includes statements that reflect thoughts, feellings and experlences that may be happening to you now or have happened sometime in the past. Some questions and statements have different instructions so please read each of these instructions carefully. There are no right or wrong answers.

Below are statements that reflect different types of stressful thoughts or events that you may have experlenced. Please read each statement and answer "Yes" if it has ever happened to you in the past, or "No" If it hasn't If you sald "Yes" to a statement. please also answer the follow-up question about whether it is currently happening. For the follow-up questions, you should answer "Yes" if it happened to you within the past 30 days, or "No" if It happened to you more than 30 days ago.

You should select the one option that best represents your experience for each statement.

\begin{tabular}{|c|c|c|}
\hline & Ye8 & No \\
\hline \multirow{2}{*}{\multicolumn{3}{|c|}{$\begin{array}{l}\text { 1. I am questioning how to label my sexual orlentation. } \\
\text { IF YES: was it within the past } 30 \text { days? }\end{array}$}} \\
\hline & & \\
\hline \multicolumn{3}{|l|}{ 2. I am having trouble accepting that I am LGBTQ. } \\
\hline$\longrightarrow$ IF YES: was it within the past 30 days? & & \\
\hline \multicolumn{3}{|l|}{ 3. I feel pressured to label myseif as gay or lesblan. } \\
\hline$\longrightarrow$ IF YES: was it within the past 30 days? & & \\
\hline \multicolumn{2}{|l|}{ 4. I am concerned that If I am LGBTQ, I wII have a worse Ife than If I were } & \\
\hline$\longrightarrow$ IF YES: was it within the past 30 days? & 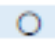 & \\
\hline \multicolumn{3}{|l|}{$\begin{array}{l}\text { 5. A famlly member told other famlly members that I am LGBTQ without my } \\
\text { permission. }\end{array}$} \\
\hline$\rightarrow$ IF YES: was it within the past 30 days? & ) & \\
\hline \multicolumn{3}{|l|}{$\begin{array}{l}\text { 6. A famlly member told me not to tell other famlly members that I am } \\
\text { LGBTQ. }\end{array}$} \\
\hline$\longrightarrow$ IF YES: was it within the past 30 days? & & \\
\hline \multicolumn{3}{|l|}{ 7. I have to le to my famlly about beling LGBTQ. } \\
\hline \multicolumn{3}{|l|}{$\longrightarrow$ IF YES: was it within the past 30 days? } \\
\hline \multicolumn{3}{|l|}{ 8. I think I will lose frlends If I come out as LGBTQ. } \\
\hline \multicolumn{3}{|l|}{$\longrightarrow$ IF YES: was it within the past 30 days? } \\
\hline \multirow{2}{*}{\multicolumn{3}{|c|}{$\begin{array}{l}\text { 9. I expect people to reject me when they find out that I am LGBTQ. } \\
\longrightarrow \text { IF YES: was it within the past } 30 \text { days? }\end{array}$}} \\
\hline & & \\
\hline \multicolumn{3}{|l|}{ 10. If I come out, it wil cause problems within my famlly. } \\
\hline$\longrightarrow$ IF YES: was it within the past 30 days? & & \\
\hline \multicolumn{2}{|l|}{ 11. A famly member asked me if I was gay or lesblan before I wanted to } & \\
\hline$\longrightarrow$ IF YES: was it within the past 30 days? & & \\
\hline \multicolumn{3}{|l|}{ 12. I was forced to come out to someone because I got "caught". } \\
\hline$\longrightarrow$ IF YES: was it within the past 30 days? & & \\
\hline \multicolumn{3}{|l|}{ 13. I was "outed" by someone other than my family without my permission. } \\
\hline \multicolumn{3}{|l|}{$\longrightarrow$ IF YES: was it within the past 30 days? } \\
\hline \multicolumn{3}{|l|}{ 14. There are times when I do not want to be LGBTQ. } \\
\hline \multicolumn{3}{|l|}{$\longrightarrow$ IF YES: was it within the past 30 days? } \\
\hline \multicolumn{3}{|l|}{ 15. If I could, I would become straight. } \\
\hline$\longrightarrow$ IF YES: was it within the past 30 days? & & \\
\hline
\end{tabular}




\begin{tabular}{|c|c|c|}
\hline \multirow{2}{*}{ 16. I hate being LGBTQ. } & \multirow{2}{*}{$\frac{Y e s}{\mathrm{O}}$} & \multirow{2}{*}{$\frac{\text { No }}{\mathrm{O}}$} \\
\hline & & \\
\hline$\longrightarrow$ IF YES: was It within the past 30 days? & & \\
\hline 17. I think it is wrong for me to be LGBTQ. & & \\
\hline$\longrightarrow$ IF YES: was It within the past 30 days? & & \\
\hline 18. I hope that being LGBTQ is just a phase for me. & & \\
\hline$\longrightarrow$ IF YES: was It within the past 30 days? & & \\
\hline 19. I think negatively about other LGBTQ people who act "too gay". & & \\
\hline$\rightarrow$ IF YES: was It within the past 30 days? & & \\
\hline 20. I am uncomfortable with being LGBTQ. & & \\
\hline$\longrightarrow$ IF YES: was It within the past 30 days? & & \\
\hline $\begin{array}{l}21 . \text { I have heard a famlly member make negative comments about LGBTQ } \\
\text { people. }\end{array}$ & & \\
\hline$\longrightarrow$ IF YES: was It within the past 30 days? & & \\
\hline 22. My famlly does not want to talk to me about being LGBTQ. & & \\
\hline$\longrightarrow$ IF YES: was It within the past 30 days? & & \\
\hline $\begin{array}{l}\text { 23. Someone who lives with me has told me they dlsapprove of me being } \\
\text { LGBTQ. }\end{array}$ & & \\
\hline$\longrightarrow$ IF YES: was It within the past 30 days? & & \\
\hline $\begin{array}{l}24 \text {. I feel as though I am a dsappointment to my family because I am } \\
\text { LGBTQ. }\end{array}$ & & \\
\hline$\longrightarrow$ IF YES: was It within the past 30 days? & & \\
\hline 25. My famlly has told me that being LGBTQ is just a phase. & & \\
\hline$\rightarrow$ IF YES: was It within the past 30 days? & & \\
\hline 26. My parents are uncomfortable with LGBTQ people. & & \\
\hline$\longrightarrow$ IF YES: was It within the past 30 days? & & \\
\hline 27. My mother (or female caregiver) does not accept me as LGBTQ. & & \\
\hline$\longrightarrow$ IF YES: was It within the past 30 days? & & \\
\hline 28. My father (or male careglver) does not accept me as LGBTQ. & & \\
\hline$\longrightarrow$ IF YES: was It within the past 30 days? & & \\
\hline 29. My parents are sad that I am LGBTQ. & & \\
\hline$\longrightarrow \rightarrow$ IF YES: was It within the past 30 days? & & \\
\hline 30. My famlly tries to make me straight. & & \\
\hline$\longrightarrow$ IF YES: was It within the past 30 days? & & \\
\hline 31. I felt unsafe or threatened in school because I am LGBTQ. & & \\
\hline$\longrightarrow$ IF YES: was It within the past 30 days? & & \\
\hline 32. Other youth refuse to do school activities with me because I am LGBTQ. & & \\
\hline$\longrightarrow$ IF YES: was It within the past 30 days? & & \\
\hline 33. I have seen other LGBTQ youth treated badly at my school. & & \\
\hline$\longrightarrow$ IF YES: was It within the past 30 days? & & \\
\hline 34. It's hard to be an LGBTQ person at my school. & & \\
\hline$\longrightarrow$ IF YES: was It within the past 30 days? & & \\
\hline 35. Other students make fun of me for being LGBTQ. & & \\
\hline$\longrightarrow$ IF YES: was it within the past 30 days? & & \\
\hline $\begin{array}{l}\text { 36. I have seen other LGBTQ youth treated badly in the nelghborhood } \\
\text { where I Ive. }\end{array}$ & & \\
\hline$\longrightarrow$ IF YES: was It within the past 30 days? & 0 & \\
\hline
\end{tabular}




\begin{tabular}{|c|c|c|}
\hline & Yes & No \\
\hline $\begin{array}{l}\text { 37. I have felt unsate or threatened in the nelghborhood where I live } \\
\text { because I am LGBTQ. }\end{array}$ & O & 0 \\
\hline$\longrightarrow$ IF YES: was It within the past 30 days? & 0 & 0 \\
\hline 38. I have had to move or change where I llve because I am LGBTQ. & 0 & 0 \\
\hline$\rightarrow$ IF YES: was It within the past 30 days? & 0 & 0 \\
\hline $\begin{array}{l}\text { 39. I have felt Isolated or alone in the nelghborhood where I Ilve because I } \\
\text { am LGBTQ. }\end{array}$ & 0 & 0 \\
\hline$\longrightarrow$ IF YES: was it within the past 30 days? & 0 & 0 \\
\hline $\begin{array}{l}\text { 40. Other people in the neighborhood where I live make fun of me for being } \\
\text { LGBTQ. }\end{array}$ & 0 & O \\
\hline$\longrightarrow$ IF YES: was it within the past 30 days? & 0 & 0 \\
\hline $\begin{array}{l}41 . \text { I have been physically assaulted in the neighborhood where I llve } \\
\text { because I am LGBTQ. }\end{array}$ & 0 & 0 \\
\hline$\longrightarrow$ IF YES: was it within the past 30 days? & 0 & 0 \\
\hline 42. My frlends make jokes about LGBTQ people. & 0 & 0 \\
\hline$\longrightarrow$ IF YES: was it within the past 30 days? & 0 & 0 \\
\hline $\begin{array}{l}\text { 43. Other youth refuse to hang out with me because I am LGBTQ. } \\
\rightarrow \rightarrow \text { IF YES: was It within the past } 30 \text { days? }\end{array}$ & 0 & $\stackrel{0}{0}$ \\
\hline $\begin{array}{l}\text { 44. Other people who are in my raclaliethnic community judge me for being } \\
\text { LGBTQ. }\end{array}$ & 0 & 0 \\
\hline$\longrightarrow$ IF YES: was It within the past 30 days? & 0 & 0 \\
\hline $\begin{array}{l}\text { 45. I have heard negative comments from others in my racialiethnic } \\
\text { community about belng LGBTQ. }\end{array}$ & 0 & O \\
\hline$\longrightarrow \rightarrow$ IF YES: was It within the past 30 days? & 0 & 0 \\
\hline $\begin{array}{l}\text { 46. I feel as though I dont fit in my raclal/ethnic community because I am } \\
\text { LGBTQ. }\end{array}$ & 0 & 0 \\
\hline$\rightarrow$ IF YES: was it within the past 30 days? & 0 & 0 \\
\hline $\begin{array}{l}\text { 47. As an LGBTQ person in my racial/ethnic community. I feel like I am a } \\
\text { minority within a minority. }\end{array}$ & 0 & O \\
\hline$\rightarrow$ IF YES: was it within the past 30 days? & 0 & 0 \\
\hline $\begin{array}{l}\text { 48. I hear other LGBTQ people use words llke "fag" or "dyke." } \\
\text { - IF YES: was it within the past } 30 \text { days? }\end{array}$ & 0 & 0 \\
\hline 49. My famlly is part of a rellgion that has homophobic bellefs. & 0 & 0 \\
\hline$\rightarrow$ IF YES: was it within the past 30 days? & 0 & 0 \\
\hline $\begin{array}{l}\text { 50. I have heard negative messages about being LGBTQ from rellglous } \\
\text { people. }\end{array}$ & 0 & $\mathrm{O}$ \\
\hline$\longrightarrow$ IF YES: was It within the past 30 days? & 0 & 0 \\
\hline 51. I would not be accepted as an LGBTQ person in my famly's rellgion. & 0 & 0 \\
\hline$\rightarrow$ IF YES: was It within the past 30 days? & 0 & 0 \\
\hline 52. I belleve it is wrong for me to be LGBTQ because of my religion. & 0 & 0 \\
\hline$\longrightarrow$ IF YES: was It within the past 30 days? & 0 & 0 \\
\hline $\begin{array}{l}\text { 53. A rellglous leader has encouraged me to reconsider my sexual } \\
\text { orlentation. }\end{array}$ & 0 & O \\
\hline$\longrightarrow$ IF YES: was It within the past 30 days? & 0 & 0 \\
\hline 54. A religlous leader tried to change my sexual orlentation. & 0 & 0 \\
\hline$\rightarrow$ IF YES: was It within the past 30 days? & 0 & 0 \\
\hline
\end{tabular}


Please also answer the following If you are currently, or have previously been, employed.

\begin{tabular}{|c|c|c|}
\hline & Ye8 & No \\
\hline $\begin{array}{l}\text { 55. I have seen other LGBTQ youth treated badly at work. } \\
\qquad \rightarrow \text { IF YES: was it within the past } 30 \text { days? }\end{array}$ & 0 & 8 \\
\hline $\begin{array}{l}\text { 56. I have felt unsafe or threatened at work because I am LGBTQ. } \\
\qquad \rightarrow \text { IF YES: was it within the past } 30 \text { days? }\end{array}$ & 0 & 0 \\
\hline 57. I have had to leave or change jobs because I am LGBTQ. & 0 & 0 \\
\hline$\longrightarrow$ IF YES: was It within the past 30 days? & 0 & 0 \\
\hline $\begin{array}{c}\text { 58. I have felt Isolated or alone at work because I am LGBTQ. } \\
\qquad \rightarrow \text { IF YES: was it within the past } 30 \text { days? }\end{array}$ & $\curvearrowright$ & 0 \\
\hline $\begin{array}{l}\text { 59. I have lost friendships since coming out as LGBTQ at work. } \\
\qquad \rightarrow \text { IF YES: was it within the past } 30 \text { days? }\end{array}$ & 0 & 0 \\
\hline $\begin{array}{l}\text { 60. It's hard to be LGBTQ at my workplace. } \\
\text { - } \rightarrow \text { IF YES: was it within the past } 30 \text { days? }\end{array}$ & ค & 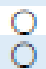 \\
\hline $\begin{array}{l}61 . \text { I have been physically assaulted by people at work because I am } \\
\text { LGBTQ. }\end{array}$ & 0 & D \\
\hline$\longrightarrow$ IF YES: was It within the past 30 days? & 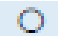 & 0 \\
\hline $\begin{array}{l}\text { 62. My workplace does not protect LGBTQ employees. } \\
\rightarrow \rightarrow \text { IF YES: was it within the past } 30 \text { days? }\end{array}$ & 0 & 0 \\
\hline $\begin{array}{l}\text { 63. People at work talk about me being LGBTQ behind my back. } \\
\text { L IF YES: was it within the past } 30 \text { days? }\end{array}$ & 0 & 0 \\
\hline 64. My boss is unsupportive of me because I am LGBTQ. & $\checkmark$ & 0 \\
\hline$\rightarrow$ IF YES: was It within the past 30 days? & 0 & 0 \\
\hline
\end{tabular}


Scoring Instructions for the SMASI

Four types of scores can be created based on a complete SMASI Instrument: overall Ifetime score (Items 1 54 only), overall 30-day score (ttems $1-54$ only). subscale lifetime scores, and subscale 30 -day scores.

Overall

Responses to lifetime (L.e., numbered) Items are scored in a blnary fashion: "Yes" responses are coded as 1, "No" responses are coded as 0 . The coded responses to ltems $1-54$ are summed to create the overall lifetime score (theoretical range: 0 to 54). A simllar procedure is used for the supplemental 30-day (1.e., "IF YES") items to create the overall 30-day score (theoretical range: 0 to 54 ). Idlopathic mean substitution is recommended for participants who skipped or decilned to answer indlvidual items

subscales

Lifetime and 30-day subscale scores are created as percentages of endorsed statements within the glven subscale. Correspondence between subscales and item numbers is as follows:

Identity management items 1, 2, 3

Negative expectancles: Items $4,8,9$

Negative disclosure experiences: Items 5, 6, 11, 12, 13

Family rejection: Items $7,10,22,23,24,25,26,27,28,29,30$

Internallzed homonegativity: Items $14,15,16,17,18,19,20$

Homonegative communication: Items $21,42,45,48,50$

Homonegative cllmate: Items $31,33,34,35$

Soclal marginalzation: ltems $32,36,37,38,39,40,41,43$

Intersectionallty: Items $44,46,47$

Relgion: Items 49, 51, 52, 53, 54

Work: Items 55, 56, 57, 58, 59, 60, 61, 62, 63, 64

Note: Scores on the work subscale should only be calculated for particlpants who Indlcated current or previous employment. Participants who have never been employed should not be glven a score on the work subscale, even If they respond to the items.

Suggested Cltations

Schrager, S. M., Goldbach, J. T., Mamey, M. R. (2018). Development of the Sexual Minority Adolescent Stress Inventory. Frontlers in psychology, Q, 319.

Goldbach, J. T., Schrager, S. M., Mamey, M. R. (2017). Criterion and divergent valldity of the Sexual Minority Adolescent Stress Inventory. Frontlers in psychology, 8, 2057. 
APPENDIX D

\section{Acceptance and Fusion Questionnaire - Youth}

\section{AFQ-Y8}

\begin{tabular}{|l|l|l|}
\hline Name: & Age: & Gender: \\
\hline Date: & Grade: & Racelethenicity: \\
\hline
\end{tabular}

We want to know noee about what you think, how you feel, and what you do.

Read each sentence. Then, circk a number between $1-5$ that iells how truc each semenee is for you.

\begin{tabular}{|c|c|c|c|c|c|}
\hline & $\begin{array}{l}\text { Nol at } \\
\text { all true }\end{array}$ & $\begin{array}{l}\text { A litile } \\
\text { in } x \text { e }\end{array}$ & $\begin{array}{c}\text { Prelly } \\
\text { iruc }\end{array}$ & True & $\begin{array}{l}\text { Very } \\
\text { Irue }\end{array}$ \\
\hline 1. My life won't be good uril 1 feel happy. & 1 & 2 & 3 & 4 & 5 \\
\hline 2. My thoughts and feclings mess up my life. & 1 & 2 & 3 & 4 & 5 \\
\hline 3. The bad things I think about myself must be true. & 1 & 2 & 3 & 4 & 5 \\
\hline $\begin{array}{l}\text { 4. If my heart beats fast, there must be sousething } \\
\text { wrong with uxe. }\end{array}$ & 1 & 2 & 3 & 4 & 5 \\
\hline $\begin{array}{l}\text { 5. I stop doing things, that are impoctant to nse } \\
\text { whenever I feel bad. }\end{array}$ & 1 & 2 & 3 & 4 & 5 \\
\hline $\begin{array}{l}\text { 6. I do worse in school when I have thoughts that } \\
\text { make me fecl sad. }\end{array}$ & 1 & 2 & 3 & 4 & 5 \\
\hline 7. I am aftaid of uxy foelings. & 1 & 2 & 3 & 4 & 5 \\
\hline 8. I can't be a good friend when I foel upset. & 1 & 2 & 3 & 4 & 5 \\
\hline
\end{tabular}




\section{Avoidance and Fusion Questionnaire for Youth (AFQ-Y8) Scoring and Literpretation Guide}

- Create the Prychological Inflexibility Scale score by summing all 8 isena.

- No reverse-sconing necessary.

- Higher scale scores represent greaier levels of prychological inflexibility.

- A cutotf score of 15 identifies youth at-risk for clinical-level imtemalizing problens.

- No large-scale nonmative data available.

- The AFQ-YS was originally developed by Greco, Lambert, \& Baer (2008)

- For more infonmation visit: www.tylerrenshaw-combafq-y 


\section{APPENDIX E}

\section{Brief Experiential Avoidance Questionnaire (BEAQ)}

BEAQ
\begin{tabular}{|l|l|l|}
\hline Name: & Age: & Gender: \\
\hline Date: & Grade: & Racelethricity: \\
\hline
\end{tabular}

\begin{tabular}{|c|c|c|c|c|c|c|}
\hline 1. The key to a good life is never feeling any pain. & 1 & 2 & 3 & 4 & 5 & 6 \\
\hline $\begin{array}{l}\text { 2. I'M quick to leave any situation that makes } \\
\text { me feel uneasy }\end{array}$ & 1 & 2 & 3 & 4 & 5 & 6 \\
\hline $\begin{array}{l}\text { 3. Whes unpleasant memories come to me, I try to part } \\
\text { then out of my mind. }\end{array}$ & 1 & 2 & 3 & 4 & 5 & 6 \\
\hline 4. I feel disconnected frous my ensotions. & 1 & 2 & 3 & 4 & 5 & 6 \\
\hline 5. I wga'y do something untill I absolusely have so. & 1 & 2 & 3 & 4 & 5 & 6 \\
\hline $\begin{array}{l}\text { 6. Fear ar anxiety wop's stop me from doing scenething } \\
\text { important. }\end{array}$ & 1 & 2 & 3 & 4 & 5 & 6 \\
\hline 7. I would give up a lot not to feel bad. & 1 & 2 & 3 & 4 & 5 & 6 \\
\hline $\begin{array}{l}\text { 8. } \text { recly do something if there is a chance that it will } \\
\text { upoet me. }\end{array}$ & 1 & 2 & 3 & 4 & 5 & 6 \\
\hline 9. It's hand for me to know what l'us feeling. & 1 & 2 & 3 & 4 & 5 & 6 \\
\hline 10. I try to put off unpleasant tasks for as loug as possible. & 1 & 2 & 3 & 4 & 5 & 6 \\
\hline 11. I go out of my way to avoid mocounfortable situations. & 1 & 2 & 3 & 4 & 5 & 6 \\
\hline $\begin{array}{l}\text { 12. One of my big goals is to be free from painful } \\
\text { emotions. }\end{array}$ & 1 & 2 & 3 & 4 & 5 & 6 \\
\hline 13. I work hard to keep out upsetting feelings. & 1 & 2 & 3 & 4 & 5 & 6 \\
\hline 14. If I Gave any doubts about doing sonething, 1 just & 1 & 2 & 3 & 4 & 5 & 6 \\
\hline
\end{tabular}


Please indicase the extent to which you agree or disagree with each of the following statements.

\begin{tabular}{|c|c|c|c|c|c|}
\hline $\begin{array}{c}1= \\
\text { Strougly }\end{array}$ & $\begin{array}{c}2= \\
\text { Modenately }\end{array}$ & $\begin{array}{c}3= \\
\text { Slightly }\end{array}$ & $\begin{array}{c}4= \\
\text { Slightly }\end{array}$ & $\begin{array}{c}5= \\
\text { Moderately }\end{array}$ & $\begin{array}{c}6= \\
\text { Strougly }\end{array}$ \\
\hline Disagree & Disagree & Disagree & Aspee & Arrec & Aspoe \\
\hline
\end{tabular}




\section{Brief Experiential Aroidance Questionnaire (BEAQ)}

\section{Scoring and Literpretation Guide}

- Create the Fxperiential Avoidance Scale by summing all 15 items

- Reverse-scoec item $\$ 6$ (subtract the value froen 7) prior to summing all items.

- Higher scale scores represent greater levels of experiential avoidasce.

- No large-scale nonnative data available.

- The BFAQ was ociginally developed by Geverz et al. (2014) 


\section{APPENDIX F}

\section{Cognitive Fusion Questionnaire (CFQ)}

\section{PFQ}

\begin{tabular}{|l|l|l|}
\hline Name: & Age: & Gender: \\
\hline Date: & Grade: & Racelethericity: \\
\hline
\end{tabular}

Below you will find a list of statements.

Please nate how true each statement is for you by circling a number aext to it.

Use the scale below to make your choice.
$1=$
$2=$
$3=$
Selidoen
$4=$
Never
Very
Sousetimes
True
Frequextly
$6=$
Almost
$7=$
Seldoun True
Always True
Always
True

The

Troe

\begin{tabular}{|c|c|c|c|c|c|c|c|c|}
\hline & $\begin{array}{l}\text { My thoughts cause me distress or } \\
\text { emotional pain. }\end{array}$ & 1 & 2 & 3 & 4 & 5 & 6 & 7 \\
\hline 2. & $\begin{array}{l}\text { I get so caught up in my thoughts that I an } \\
\text { wable to do the things that I most want to do. }\end{array}$ & 1 & 2 & 3 & 4 & 5 & 6 & 7 \\
\hline 3. & $\begin{array}{l}\text { I over-amalyze situations to the point where } \\
\text { it's unhelpful so me. }\end{array}$ & 1 & 2 & 3 & 4 & 5 & 6 & 7 \\
\hline 4. & I struggle with uny thoughts. & 1 & 2 & 3 & 4 & 5 & 6 & 7 \\
\hline 5. & $\begin{array}{l}1 \text { get upses with myself for having } \\
\text { cestain thoughts. }\end{array}$ & 1 & 2 & 3 & 4 & 5 & 6 & 7 \\
\hline 6. & I tend to get very entangled iv my thoughts & 1 & 2 & 3 & 4 & 5 & 6 & 7 \\
\hline 7. & $\begin{array}{l}\text { It's such a struggle to ket go of upsetting } \\
\text { thoughts even when I know that letting go } \\
\text { would be helpful. }\end{array}$ & 1 & 2 & 3 & 4 & 5 & 6 & 7 \\
\hline
\end{tabular}




\section{Cognitive Fusion Questionnaire (CFQ) Scoring and Interpretation Guide}

- Create the Cogneitive Fusioe Scale scoee by summing all 7 items.

- No reverse-sconing secessary.

- Highter scale scores represent greater levels of cognitive fusion.

- No large-scale nonmative data available.

- The CFQ was originally developed by Gilloodern et al. (2014) 
APPENDIX G

Valuing Questionnaire (VQ)

Appendix 1. Valuing Questionnaire (VQ)

Name:

Date:

Please read each statement carefully and then circle the number which best describes how much the statement was for YOu DURING THE PAST WEEK, INCLUDING TODAY

\begin{tabular}{lllllll}
\hline 0 & 1 & 2 & 3 & 4 & 5 & 6 \\
Not at all true & & & & & & Completely true \\
\hline
\end{tabular}

Q1) I spent a lot of time thinking about the 0123456 - past or future, rather than being engaged

in activities that mattered to me

Q2) I was basically on "auto-pilot" most of 0123456 the time

Q3) I worked toward my goals even if I $\quad 0123456$ didn't feel motivated to

Q4) I was proud about how I lived my life 0123456 -

Q5) I made progress in the areas of my life I 0123456 care most about

Q6) Difficult thoughts, feelings or memories 0123456 got in the way of what I really wanted to do

Q7) I continued to get better at being the 0123456 kind of person I want to be

Q8) When things didn't go according to 0123456 plan, I gave up easily

Q9) I felt like I had a purpose in life

Q10) It seemed like I was just "going

$0123456-$ through the motions" rather than focusing on what was important to me 
APPENDIX H

\title{
Mindful Attentive Awareness Scale-Adolescent
}

(MAAS-A)

\section{Day-to-Day Experiences}

\begin{abstract}
Instructions: Below is a collection of statements about your everyday experience. Using the 1-6 scale below, please indicate how frequently or infrequently you currently have each experience. Please answer according to what really reflects your experience rather than what you think your experience should be. Please treat each item separately from every other item.
\end{abstract}

$\begin{array}{cccccc}1 & 2 & 3 & 4 & 5 & 6 \\ \text { Almost } & \text { Very } & \text { Somembut } & \begin{array}{c}\text { Somewhit } \\ \text { Anfrequenty }\end{array} & \begin{array}{c}\text { Very } \\ \text { Infrequeatly }\end{array} & \begin{array}{c}\text { Alnout } \\ \text { Never }\end{array}\end{array}$

I could be experiencing rome emotion and not be convcious of it vatil some time later

$\begin{array}{llllll}1 & 2 & 3 & 4 & 5 & 6 \\ 1 & 2 & 3 & 4 & 5 & 6 \\ 1 & 2 & 3 & 4 & 5 & 6 \\ 1 & 2 & 3 & 4 & 5 & 6 \\ 1 & 2 & 3 & 4 & 5 & 6 \\ 1 & 2 & 3 & 4 & 5 & 6 \\ 1 & 2 & 3 & 4 & 5 & 6 \\ 1 & 2 & 3 & 4 & 5 & 6 \\ 1 & 2 & 3 & 4 & 5 & 6 \\ 1 & 2 & 3 & 4 & 5 & 6 \\ 1 & 2 & 3 & 4 & 5 & 6\end{array}$

I breal or upill things becrase of carelessaess, not parying artention, or thinking of vomething elve.

I find it difficult to stry focused on whrt's happening in the present.

I tead to mall quiskly to get where $\mathrm{T} m$ going without paying attention to what I expecience along the way.

I tead not to notice feelings of phryical tension or dircomfort nutil they really grab my artention

I forget a person's nume almost as voon as Tre been told it for the first time.

It veems I am "muning on zutomatic," without much awracesss of what $\mathrm{Im}$ doing.

I rush throngh actirities without being reslly atteative to them.

I get so focused on the gosl I want to achieve thrt I lose touch with whut $\mathrm{Im}$ doing night now to get there.

I do jobs or task antomatienlly, without being aware of what Tre doing.

I find myself listening to someone with one enr, doing

vomething eles at the same time.

$\begin{array}{llllll}1 & 2 & 3 & 4 & 5\end{array}$ 


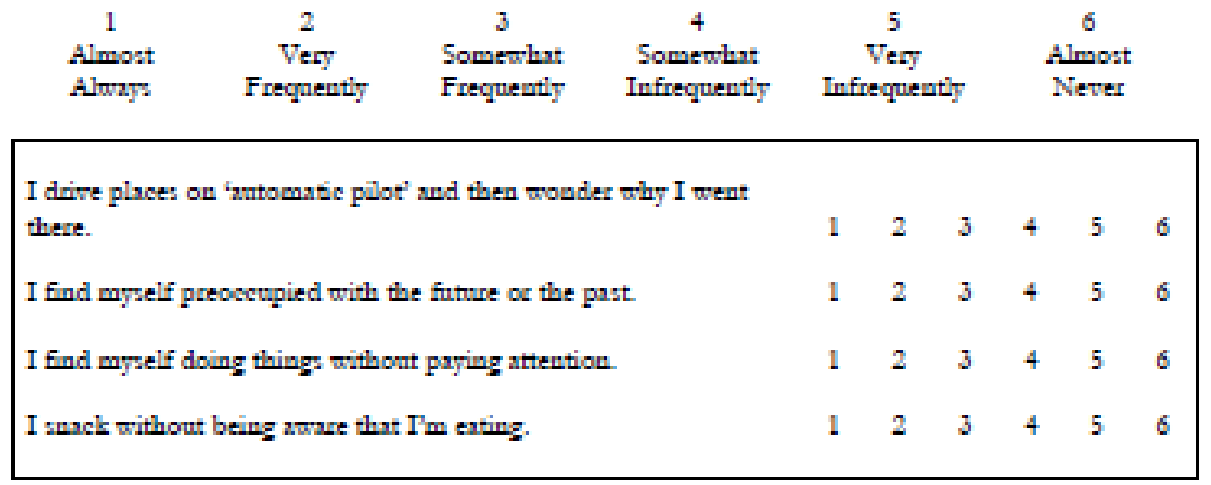




\section{MAAS Scoring}

To score the scale, simply compute 2 menn of the 15 items. Higher scores reflect higher levela of dispositionsl mindfulness. 


\section{APPENDIX I}

\section{Suicidal Behaviors Questionnaire-Revised (SBQ-R)}

The Suicide Behaviors Questionnaire-Revised (SBQ-R) - Overview

The SBQ-R has 4 items, each tapping a different dimension of suldidality:

- Item 1 taps into lifetime suicide ideation and/or sulcide attempt.

v Item 2 asserses the frequency of suicidal ideation over the past tweive months.

I Itern 3 asserses the threat of sulcide attempt.

- Item 4 evaluates self-reported lkel hood of suididal behavior in the future.

Cinical utility

Due to the wording of the four SBQ-R ttems, a broad range of information is obtained in a very brief administration. Responses can be used to identify at-risk individuals and specific risk behaviors.

Scoring

See scoring guideline on following page

Psychometric Propertles'

Adult General Population Cutoff score

Adult Psychlatric inpatients

27

28

Sensitivity
$93 \%$
$80 \%$

Specificity

95\%

$91 \%$ 


\section{SBQ-R - Scoring}

Item 1: taps into Iifetimo suicido ideation and/or suicido attempts

Selected response $1 \quad$ Non-Suicidal subgroup 1 point

Selected response 2 Suicide Fisk ldestion subgroup 2 paints

Selected response 3 a or $3 b$ Suicide Plan subgroup 3 points

$\begin{array}{llll}\text { Selected response } 4 \mathrm{~s} \text { or } 4 \mathrm{~b} & \text { Suicide Attempt subgroup } & 4 \text { points } & \text { Total Points }\end{array}$

\begin{tabular}{|c|c|c|c|}
\hline \multirow[t]{5}{*}{ Selected Response: } & Never & 1 point & \multirow[b]{5}{*}{ Total Points } \\
\hline & Rarely (1 time) & 2 points & \\
\hline & Sornetimes (2 times) & 3 points & \\
\hline & Often (3-4 times) & 4 points & \\
\hline & Very Often ( 5 or more times) & 5 points & \\
\hline \multirow{3}{*}{\multicolumn{2}{|c|}{$\begin{array}{l}\text { Selected response } 1 \\
\text { Selected response } 2 \mathrm{a} \text { or } 2 \mathrm{~b} \\
\text { Selected response } 3 \mathrm{a} \text { or } 3 \mathrm{~b}\end{array}$}} & 1 point & \\
\hline & & 2 points & \\
\hline & & 3 points & Total Points \\
\hline \multicolumn{4}{|c|}{ Item 4: evolustes solf-reported Fizelihood of suicidal behavior in the future } \\
\hline \multirow[t]{7}{*}{ Selected Response: } & Never & 0 points & \\
\hline & No chance at al & 1 paint & \\
\hline & Rasther unlikely & 2 points & \\
\hline & Unlikely & 3 points & \\
\hline & Likely & 4 points & \\
\hline & Rasther Likely & 5 points & \\
\hline & Very Likely & 6 points & Total Points \\
\hline
\end{tabular}

Sum all the scores circled/checked by the respondents.

The total score should range from 3-18.

Total Score

AUC - Area Under the Receiver Oporating Characteristic Curvo; the aros measures

discrimination, that is, the ability of the test to correctly dassify those with and

without the rist. [.90-1.0 - Excellent, $.80-.90$ - Good, .70-.80 - Fair, .60-.70 - Poor]

\begin{tabular}{|c|c|c|c|c|}
\hline & \multicolumn{2}{|c|}{ Sensitivity Specificity } & PPV & AUC \\
\hline $\begin{array}{l}\text { Item 1: a cutoff score of } \geq 2 \\
\text { - Validation Reference: Adult Inpatient } \\
\text { - Validation Reference: Undergraduate Colege }\end{array}$ & $\begin{array}{l}0.80 \\
1.00\end{array}$ & $\begin{array}{l}0.97 \\
1.00\end{array}$ & $\frac{.95}{1.00}$ & $\begin{array}{l}0.92 \\
1.00\end{array}$ \\
\hline $\begin{array}{l}\text { Total SBQ-R : a cutoff score of } \geq 7 \\
\text { - Validation Reference: Undergraduste Colege }\end{array}$ & 0.93 & 0.95 & 0.70 & 0.96 \\
\hline $\begin{array}{l}\text { Total SBQ-R: a cutoff score of } 28 \\
\text { - Validation Reference: Adult Inpatient }\end{array}$ & 0.80 & 0.91 & 0.87 & 0.89 \\
\hline
\end{tabular}

ecoman ot al (1908) 


\section{SBQ-R Suicide Behaviors Questionnaire-Revised}

Patient Name Date of Vist

Instructions: Please check the number beside the statement or phrase that best applies to you.

1. Have you ever thought about or attempted to kill yourself? (chock one anly!

$\square$ 1. Never

$\square$ 2. It was just a brief passing thought

$\square$ 3a. I have had a plan at least once to kill myself but did not try to do It

$\square$ 3b. I have had a plan at least once to kill myself and realy wanted to die

$\square$ 4a. I have attempted to kill myself, but did not want to die

$\square$ 4b. I have attempted to kill myself, and really hoped to die

2. How often have you thought about killing yourself in the past year? (chock one mily)

$\square$ 1. Never

$\square$ 2. Rarely (1 time)

$\square$ 3. Sometimes (2 times)

$\square$ 4. Often (3-4 times)

5. Very often (5 or more times)

3. Have you ever told someone that you were going to commit suldide, or that you might do it? (chock one anly!

$\square$ 1. No

$\square$ 2a. Yes, at one time, but did not really want to die

$\square$ 2b. Yes, at one time, and really wanted to die

$\square$ 3a. Yes, more than once, but did not want to do it

$\square$ 3b. Yes, more than once, and really wanted to do it

4. How likely is it that you will attempt sulcide someday? (chodk mo only

$\square$ 0. Never

$\square$ 1. No chance at all

$\square$ 4. Likely

2. Pather unlkely

$\square$ 5. Rather lkely

$\square$ 3. Unllkely 
APPENDIX J

\section{Suicidal Ideation Questionnaire (SIQ)}

INSTRUCTONS: Lsted below are a number of sentences about thoughts that people sometimes have. Please indlcate Which of these thoughts you have had in the past month. Fil in the circle below the answer that best describes your own thoughts. Be sure to nl in one response for each sentence. Remember, there are no right or wrong answers.

\begin{tabular}{|c|c|c|c|c|c|c|c|}
\hline THIS THOUGHT WAS IN MY MIND: & $\begin{array}{c}\text { Almost } \\
\text { every } \\
\text { dayy }\end{array}$ & $\begin{array}{l}\text { Couple } \\
\text { of tines } \\
\text { a woek. }\end{array}$ & $\begin{array}{l}\text { About } \\
\text { conce a } \\
\text { moek }\end{array}$ & $\begin{array}{c}\text { Couple of } \\
\text { times a } \\
\text { month }\end{array}$ & $\begin{array}{l}\text { About } \\
\text { once a } \\
\text { month }\end{array}$ & $\begin{array}{c}\text { I had twis } \\
\text { thought } \\
\text { before but } \\
\text { not in the } \\
\text { past } \\
\text { month }\end{array}$ & $\begin{array}{l}\text { I never } \\
\text { had this } \\
\text { thought }\end{array}$ \\
\hline 1. I thought it would be better if I was not alve. & 0 & O & O & $\mathrm{O}$ & $\mathrm{O}$ & 0 & 0 \\
\hline 2. I thought about killing myseif. & 0 & 0 & O & $\mathrm{O}$ & $\mathrm{O}$ & 0 & 0 \\
\hline 3. I thought about how I would kll mysel. & 0 & 0 & O & 0 & 0 & 0 & 0 \\
\hline 4. I thought about when I would kill myseit. & 0 & 0 & O & $\mathrm{O}$ & $\mathrm{O}$ & 0 & 0 \\
\hline 5. I thought about pecple dying. & 0 & 0 & 0 & 0 & 0 & 0 & 0 \\
\hline 6. I thought about death. & 0 & 0 & O & $\mathrm{O}$ & 0 & 0 & 0 \\
\hline 7. I thought about what to write in a sulcide note. & O & O & O & $\mathrm{O}$ & O & 0 & 0 \\
\hline 8. I thought about writung a wl. & 0 & 0 & 0 & O & 0 & 0 & 0 \\
\hline 9. I thought about teling people I plan to kll myself. & 0 & ○ & O & $\mathrm{O}$ & O & O & 0 \\
\hline 10. I thought about how pecple would feel if I killed myself. & 0 & 0 & O & O & 0 & 0 & 0 \\
\hline 11. I wished I were dead. & O & 0 & O & ○ & O & 0 & 0 \\
\hline 12. I thought that killing myseif would solve my problems. & 0 & 0 & 0 & 0 & 0 & 0 & 0 \\
\hline 13. I thought that others would be happler If I was dead. & O & O & $\mathrm{O}$ & $\mathrm{O}$ & $\mathrm{O}$ & $\mathrm{O}$ & 0 \\
\hline 14. I wished that I had never been born. & 0 & 0 & 0 & 0 & 0 & 0 & 0 \\
\hline 15. I thought that no one cared if I Iived or ded. & 0 & 0 & O & $\mathrm{O}$ & $\mathrm{O}$ & 0 & 0 \\
\hline
\end{tabular}

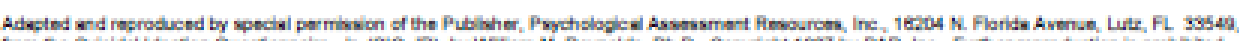

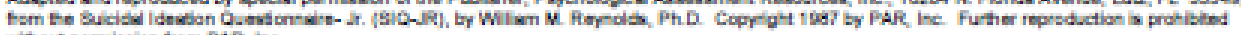
whout parmisoion from PAR, inc.

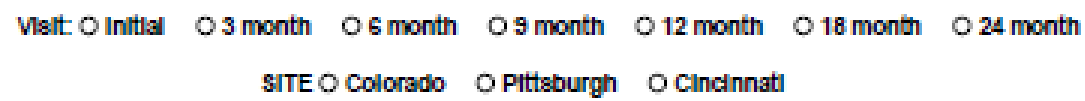
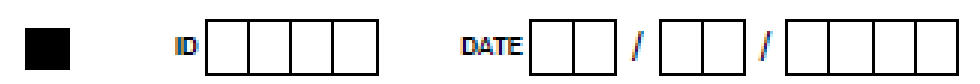

52933 
APPENDIX K

Alcohol Use Disorders Identification Test (AUDIT)

AUDIT

Introduction

The Alcohol Use Disorders Identification Test (AUDIT) is a 10-item screening tool developed by the World Health Organization (WHO) to assess alcohol consumption, drinking behaviors, and alcohol-related problems. Both a clinician-administered version (page 1) and a self-report version of the AUDIT (page 2) are provided. Patients should be encouraged to answer the AUDIT questions in terms of standard drinks. A chart illustrating the approximate number of standard drinks in different alcohol beverages is included for reference. A score of 8 or more is considered to indicate hazardous or harmful alcohol use. The AUDIT has been validated across genders and in a wide range of racial/ethnic groups and is wellsuited for use in primary care settings. Detailed guidelines about use of the AUDIT have been published by the WHO and are available online: http:/whqlibdoc.whoint/hq/2001/who_msd_msb_01.6a.pdf 


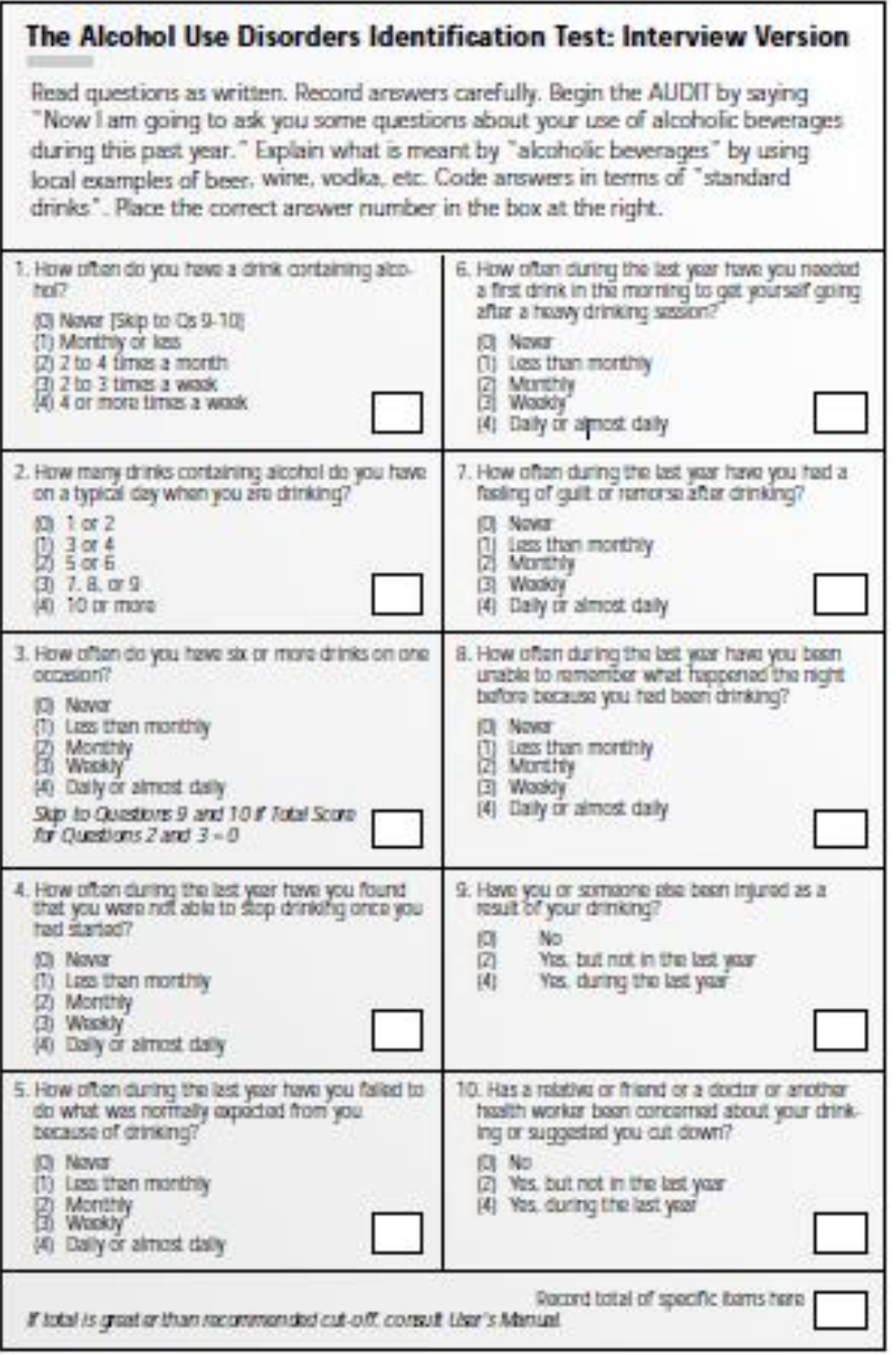


The Alcohol Use Disorders Identification Test: Self-Report Version

PATIENT: Because alcohol use can affect your heath and can interfere with cretain medicatiors and treatments, it is importart that we ask some questiors about your use of alcohol. Your arswers will remain confidential so please be honest. Placr an $\mathrm{X}$ in one bou that best describes your arswer to each question.

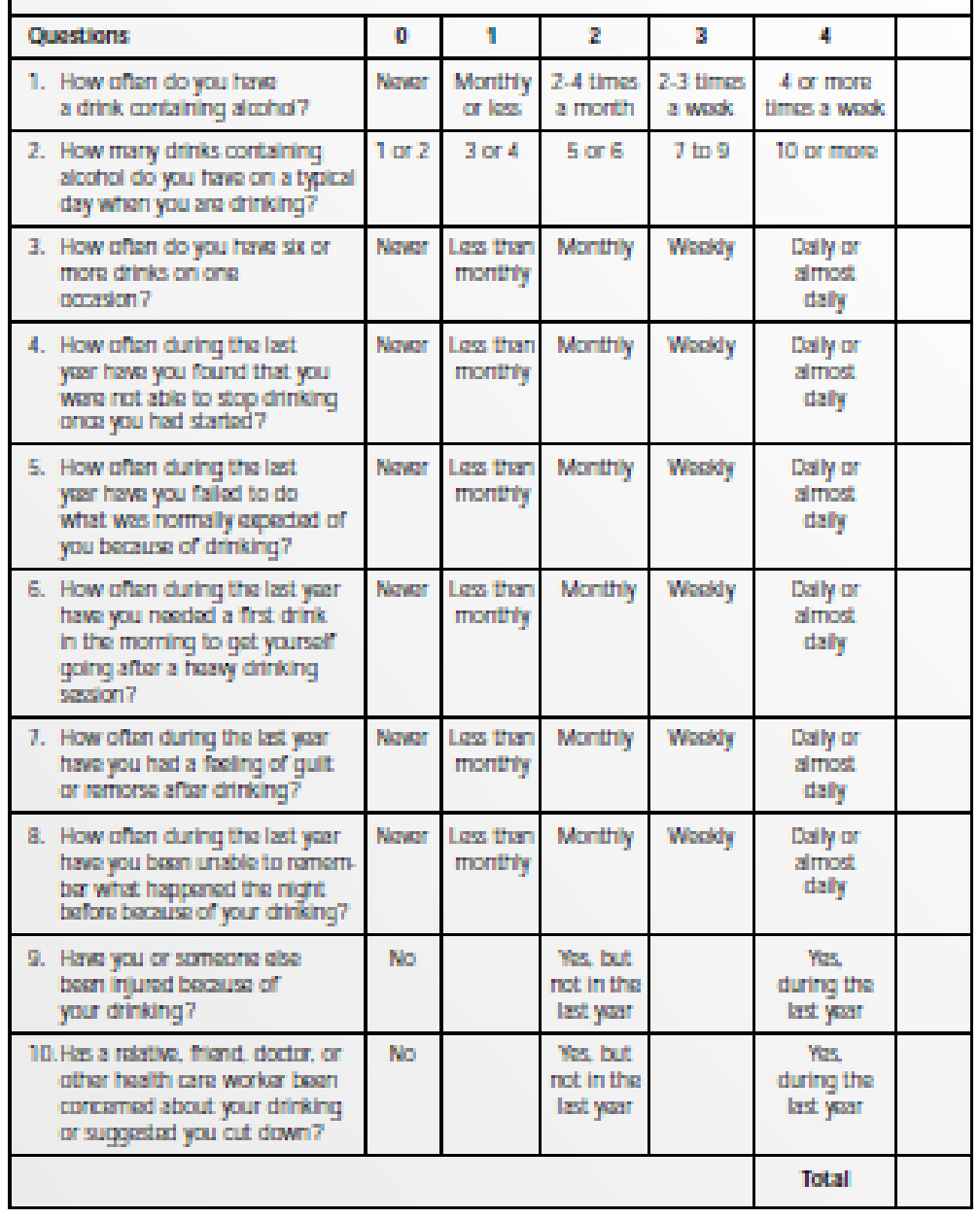




\section{APPENDIX L}

\section{Sean Weeks Curriculum Vitae}

\section{Sean Weeks}

$694 \mathrm{~S} 600 \mathrm{E}$

River Heights, Utah

(859) 230-7857

seannweeks@gmail.com

\section{EDUCATION}

Graduate Coursework ( $\mathrm{Ph}$.D.), School Psychology

Utah State University (NASP Accredited), Logan, Utah

Bachelor of Arts (B.A.), Psychology

University of Kentucky, Lexington, Rentucky

Graduated Cum Laude with Departmental Honors
2017 - Present

$2008-2012$

\section{PROFESSIONAL LICENSES}

Student Teacher/Intern License, Utah (\#712612)

Early Intervention Specialist, Utah Department of Health (\#1239)

\section{CLINICAL EXPERIENCE}

Graduate Student Clinician

Integrated Assessment Clinic, Logan, Utah

August 2019 - Present

Supenvisor: Maryelien McClain Verdoes, Ph.D., LP

- Conducted diagnostic interviews, psychological evaluations, and diagnostic feedback for individuals across the lifespan

- Scored and interpreted results from autism specific and other neurodevelopmental assessments

- Wrote comprehensive reports and recommendations for families

- Presented and staffed client cases with interdisciplinary teams

Behavior Specialist

May 2019 - Present

Up to 3 Early Intervention, Logan, Utah

Supenvisor: Gretchen Peacock, Ph.D., LP

- Provided home-based parent training and behavior support to families with children under 3 across northem Utah

- Consulted and teamed with multidisciplinary groups

School Psychology Practicum Student

Granite School District, West Valley Ciry, Utah

Supenvisors: Paul McClatchy, Ed.S., NCSP \& Megan Hoybarne, Ph. D. LP

- Provided school-based cognitive assessments (verbal \& non-verbal), interventions (class wide \& individual), and consultation (parents \& teachers)

- Conducted psychotherapy (individual), crisis intervention, and family intervention 
Weeks Curriculum Vitae 2

- Reported stadent updates and progress at Multi-Tiered Systems of Support meetings with school staff and administrators

Mental Health Counselor

Bridges Day Treatment Program, Canyons School District, Midvale, Utah

August 2018 - June 2019

Supenvisors: Aaron Fischer, Ph.D., LP \& Mogan Høyborne, Ph.D., LP

- Bridges Program is a restrictive tier three environment for children with severe behavioral problems. An intensive, individualized, multidisciplinary approach is used to address school and home problem behaviors.

- Aided in the development, launch and continual restructuring of the Bridges Program.

- Established program infrastracture inchuding program procectures, forms, and templates

- Provided psychotherapy (individual) for an assigned child presenting with severe emotional and behavioral disorders

- Collected weekly and pre - post data for progress monitoring using empirically validated measures

- Artended multidisciplinary team meetings (mental health providers, special education teachers, behavior analysts, social workers, administrators, private therapists, and parents) to discuss treatment progress, skills development, and goals

- Worked closely with family to update, train, and progress monitor coping skills and positive behaviors through frequent phone conversations, meetings, and home visits

Social/Emotional Slills Group Co-Facilitator

January - May 2018

Bear River Charter School, Logan, Utah

Supenvisor: Donna Gilbertson, Ph.D., LP, NCSP

- Co-facilitated evidence-based social-emotional and mindfulness-based group therapy for elementary and secondary students, targeting skills such as positive peer relationships, productive communication styles, emotion regulation, and bullying

- Developed and implemented behavior management plans in groups of up to forty

Academic Intervention Practicum Student

Jamuary - May 2018

Edith Bowen Laboratory Elementary School, Utah State University, Logan, Utah

Supenvisor: Donna Gilbertson, Ph.D., LP, NCSP

- Assessed reading, writing, and math skills in elementary children referred by teachers

- Provided evidence-based reading and writing interventions weekly (individual \& group)

- Collected data for progress monitoring and intervention adaptation

Adolescent Counselor/Group Leader

Jume - Aug. 2015

Northwest Behavioral Healthcare Services, Portland, Oregon

- Assisted in the substance use and behavioral treatment and rehabilitation of adolescent

- Managed adolescent behavior in group therapeutic classes

- Developed and led recreational activities for patients

Intern

Eastem State Psychiatric Hospital, Lexington, Kentucky

Supenvisor: Sung Hee Kim, Ph. D.

- Assisted and led inpatient rehabilitation courses

- Observed diagnostic assessments and treatment planning

Jan. - May 2012 
Weeks Curriculum Vitae 3

\section{RESEARCH EXPERIENCE}

Graduate Student Researcher

Utah State University, Logan, Utah

August 2017 - Present

Supenvisor: Tyler L. Renshaw, Ph.D., NCSP

- Conducted systematic reviews of current Acceptance and Commitment Therapy literature

- Presented preliminary finding at national conferences

Principal Investigator, Master's Thesis

August 2017 - Present

Utah State University, Logan Utah

Supervisor: Tyier L. Renshaw, Ph.D., NCSP

- Thesis: The moderating role of psychological flexibility in the relationship between minority stress, substance misuse, and suicidality in LGB+ adolescents.

Undergraduate Research Assistant

Jan. 2011 - May 2012

Universiry of Kentucky, Lexington, Kentucky

Supenisor: Nathan DeWail, Ph.D.

- Assisted with design, execution, and evaluation of research projects

- Obtained participant data through observation in lab settings

- Managed subject participation and experimental methods

\section{PUBLICATIONS}

\section{Book Chapter}

Renshaw, T. L. Barr. J., Farley, C.. Franzmann, T. K. Vinal, S., \& Weels, S. N. (in press). Mindfulness-based curricula for classrooms and schools. In Renshaw, T. L., \& Jimerson, S. R. (Eds.), Mindfulness for improving mental health in schools. Oxford University Press.

\section{$\underline{\text { Technical Manuals }}$}

Weeks, S.N., Ficklin. E., Forsyth Lefevre, J., Curtright, T. Gabrielsen, T. (in review). Rainbow spectrum: A practitioner's guide for inclusive clinical care for LGBTQIA+ individuals with autism. Utah Regions. Leadership Education in Neurodevelopmental Disabilities.

Fischer, A.J., Hidalgo, R. Feldman, E.D... Weels, S.N. (2019). Bridges program manual: Consultant version. Practical and Tutorial Manual. Department of Educational Psychology, University of Utah Salt Lalke City, UT.

Fischer, A.J., Hidalgo, R, Feldman, E.D ... Weels, S.N. (2019). Bridges program manual: Teacher version. Practical and Tutorial Manual. Department of Educational Psychology, University of Utah Salt Lake City, UT. 
Weeks Curriculum Vitae 4

\section{PRESENTATIONS}

\section{Conference Poster Presentations}

Weeks, S. N., Renshaw, T. L., Sedgwick, S. (2020, February) Toward a Systematic Review of Acceptance and Commitment Therapy with Youth: Upshot of the Evidence and Implications for Practice. Poster presented at the National Association of School Psychology Conference, Baltimore, MD.

Renshaw, T. L. Sedgwick, S., Weels, S. N. (2020, February) Toward a Systematic Review of Dialectical Behavior Therapy with Youth: Upshot of the Evidence and Implications for Practice. Poster presented at the National Association of School Psychology Conference, Baltimore, MD.

Renshaw, T. L. Weels, S. N.. Sedgwick, S. (2019, November) Systematic Review of Acceptance and Commitment Therapy with Youth: Upshot of the Evidence and Implications for Practice. Poster presented at the Annual Conference on Advancing School Mental Health, Austin, TX.

Renshaw, T. L. Sedgwick, S., Weelss, S. N. (2019, November) Systematic Review of Dialectical Behavior Therapy with Youth: Upshot of the Evidence and Implications for Practice. Poster presented at the Annual Conference on Advancing School Mental Health, Austin, TX

Weeks, S. N., Renshaw, T. L. (2018, November). The mediating roles of psychological flexibility and persons]identity in the relationship between sexual orientation, substance misuse and suicidality in adolescents. Poster presented at the meeting of the Uthh Association of School Psychologists, Salt Lake City, UT.

\section{Professional Development Presentations \& Workshops}

Weels, S. N., Ortiz, E. (2019, October). Activities and Resources for After School. Topic presented in Spanish to community members at South Main Clinic in Salt Lake City, UT.

Weeks, S. N. (2019, February). Risk Assessment in Schoois. Topic presented to teachers and paraprofessionals of Canyons School District in Midvale, UT.

Weeks, S. N., Fischer, A. J., Siberman, M., Perez, L. Totsky, J. (2018, November). Behavior Management in Groups. Topic presented to teachers and paraprofessionals of Canyons School District in Midvale, UT.

Weeks, S. N., Domenech Rodriguez, M M. (2018, October). Diversity and Inciusion, Sqfe Passages for $U$. Topic presented to teachers and administrators of Canyons School District in Salt Lake City, UT.

\section{TEACHING EXPERIENCE}

Graduate Teaching Assistant, Utah State University, Department of Psychology Aug 2017 - May 2019

Courses: Introduction to Psychology \& Research Methods

- Provided support to over 500 undergraduate students by grading assigrments and tests, providing meaningful feedback, meeting with students, and guest lecturing classes 
Weeks Curriculum Vitae 5

Guest Lecturer (6), Utah State University, Department of Psychology

December 2019

Course: Introduction to Psychology (undergraduate coursework)

Course: Introduction to School Psychology (graduate coursework)

February \& March 2019

December 2018

English Teacher, Sumitomo Electric English Center, Amata City, Thailand

- Taught English as a second language to Thai professional level employees

Nov. 2013 - Apr. 2014

- Developed the initial English Center and the course structure implemented in the classrooms

- Designed lesson plans, activities, and tests for individual and peer-based learning

English Teacher, Huayprab Public School, Rayong, Thailand

Now. 2013 - Apr. 2014

- Taught English as a second language to middle school aged children

- Created lesson plans, activities, and events designed to improve English ability

- Collaborated with Thai faculty and administration to implement coursework

\section{HONORS, FELLOWSHIPS, AND AWARDS}

Utah Regional Leadership Education in Neurodevelopmental Disabilities, 2019

Anthony La Pray Scholarship, Utah State University, 2019

\section{SERVICE TO PROGRAM/PROFESSION}

Stadent Representative, USU School Psychology

Chair, Community Service, USU Student Affiliates of School Psychology

Diversity Event Coordinator, USU College of Education and Human Services

Guest Speaker, USU Graduate Student Panel, PSY 2010

Student Member, USU Deparment of Psychology Faculty Search Conmittee

Chair, Awareness, USU Student Affiliates of School Psychology

September 2017- May 2019

August 2018 - May 2019

January 2018 - May 2019

Feb. 2018 \& Feb. 2019

May - July 2018

Jamuary - May 2018

\section{CERTIFIED TRAININGS}

American Instirute for Avalanche Research and Education (AIARE) 1

January 2020

American Heart Association First Aid CPR.

Department of Health. Baby Watch Early Intervention

H.i. A.A. certified

Question, Persuade, and Refer (QPR) Training for suicide prevention

Cognitive Behavioral Intervention for Trauma in Schools (CBTS) training

Safe Passages for U, diversity and inclusion training

LGBTQ Ally training

FERPA training for confidentiality in schools

Collaborative Institutional Training Initiative (CITI) training for ethical research

September 2019

April 2019

October 2018

September 2018

April 2018

March 2018

March 2018

August 2017

August 2017 
Weeks Curriculum Vitae 6

Teaching English as a Foreign Language (TEFL) certification

October 2013

\section{COMAUNITY DEVELOPMENT}

Volunteer, Logan Pride Foundation, Logan UT

- Facilitated allies trainings for Utah State University and the community

March 2019 - Present

Volunteer, Common Ground Outdoor Adventures, Logon, UT

January 2018- Present

- Instructed individuals with physical and mental disabilities to sli

- Organized group volunteer activities

Volunteer, Legal Aid of the Bluegrass, Lexington, KY

May - December 2014

- Assisted the immigration attorney with any necessary duties

- Translated letters and court documents

Volunteer, Kloinomadelifia Orphanage, Santiago, Chile

January - April 2013

- Tutored children with emotional disabilities in their native Spanish language

- Organized recreational activities, games, art projects, and workshops

\section{ORGANIZATIONS \& PROFESSIONAL AFFILIATIONS}

Utah Regional Leadership Education in Neurodevelopmental and related Disabilities Association of Psychological Science

National Association of School Psychology

Utah Association of School Psychology

Student Affliates of School Psychology, APA 